Aus der Klinik für Nephrologie und Rheumatologie

(Prof. Dr. G. A. Müller)

der Medizinischen Fakultät der Universität Göttingen

\title{
Vaskuläres Regenerationspotential im Muskel und endotheliale Vorläuferzellen im Blut bei Patienten mit Myositis
}

\author{
INAUGURAL-DISSERTATION \\ zur Erlangung des Doktorgrades \\ der Medizinischen Fakultät der \\ Georg-August-Universität zu Göttingen
}

vorgelegt von

Dana Lemmer (geb. Burghardt)

aus

Dresden

Göttingen 2017 
Dekan:

\section{Betreuungsausschuss}

Betreuerin

Ko-Betreuer:

\section{Prüfungskommission}

Referentin

Ko-Referent:

Drittreferentin:

Datum der mündlichen Prüfung: 06.06.2018
PD Dr. Susann Patschan

Prof. Dr. rer. nat. H. K. Kroemer

PD Dr. S. Patschan

Prof. Dr. J. Schmidt

Prof. Dr. Jens Schmidt

Prof. Dr. Margarete Schön 
Hiermit erkläre ich, die Dissertation mit dem Titel "Vaskuläres Regenerationspotential im Muskel und endotheliale Vorläuferzellen im Blut bei Patienten mit Myositis" eigenständig angefertigt und keine anderen als die von mir angegebenen Quellen und Hilfsmittel verwendet zu haben.

Göttingen, den

(Unterschrift) 
„So eine Arbeit wird eigentlich nie fertig,

man muß sie für fertig erklären,

wenn man nach Zeit und Umständen

das möglichste getan hat.“

$$
\text { J. W. von Goethe }
$$

(Italienische Reise, Teil 2. Hrsg. v. Michel C., Dewitz. H.-G., Deutscher Klassiker Verlag, Berlin 2011) 


\section{Inhaltsverzeichnis}

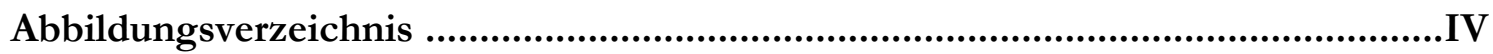

Tabellenverzeichnis ............................................................................................... VII

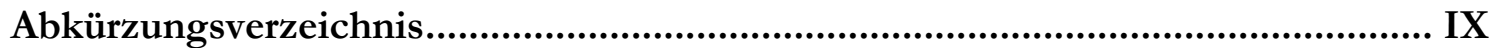

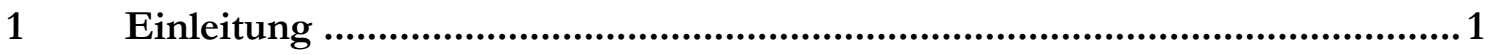

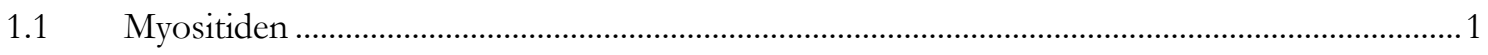

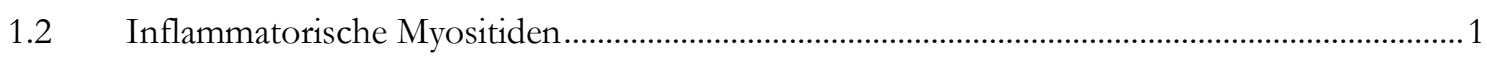

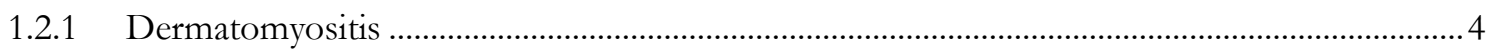

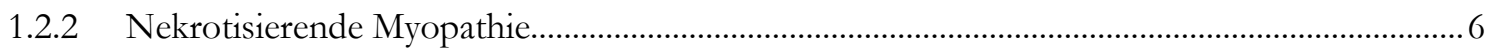

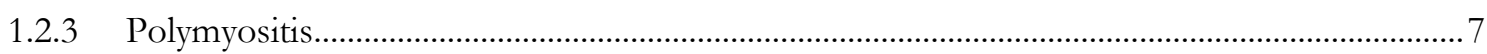

1.2.4 Therapie der inflammatorischen Myositiden ……………....................................................

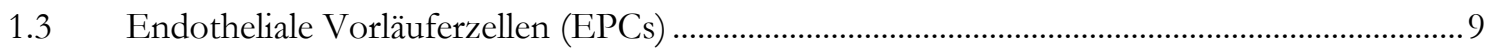

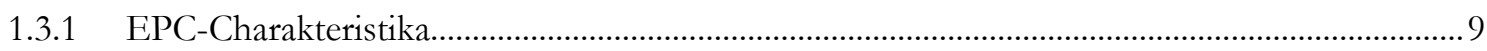

1.3.2 Hämato- und angiopoetische Stammzellmarker ...............................................................

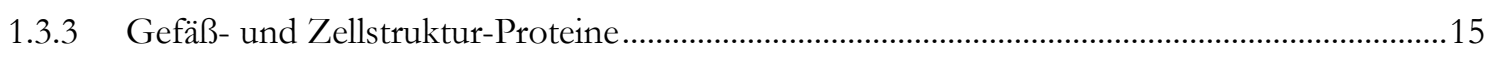

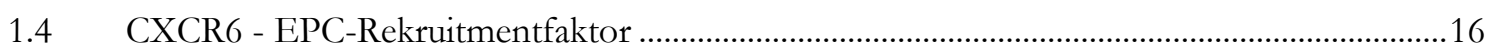

$1.5 \quad$ Nestin - endothelialer und muskulärer Regenerationsmarker ....................................................18

1.6 MHC-I - Standardmarker für muskuläre Entzündung..................................................................18

$1.7 \quad$ Kapillarmikroskopie bei Myositiden........................................................................................19

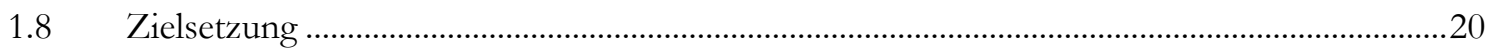

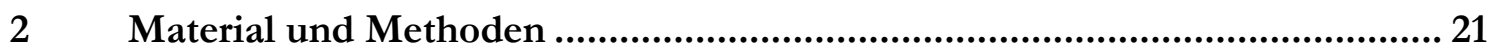

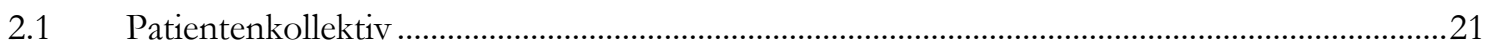

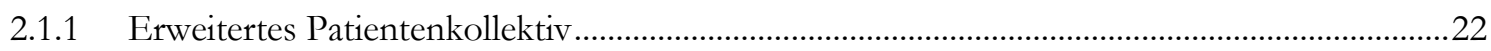

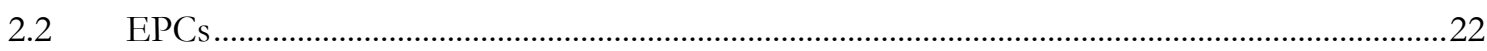

2.2.1 Geräte und Chemikalien für EPC-Bestimmung.....................................................................22

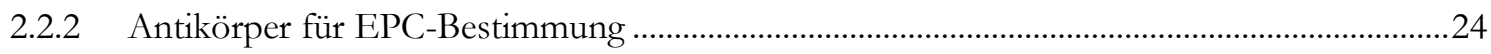

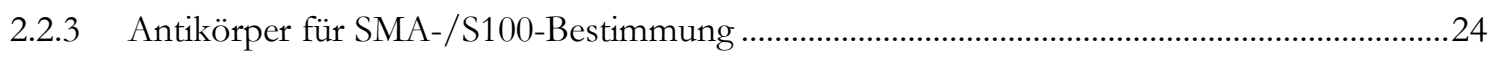

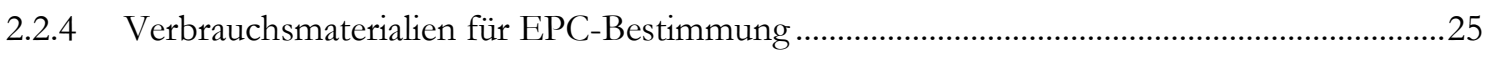

2.3 Methodik: Bestimmung endothelialer Vorläuferzellen.............................................................25

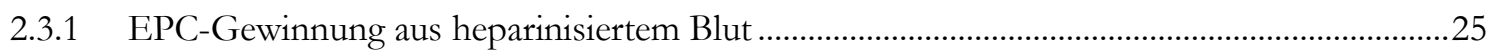

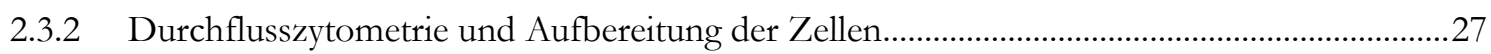

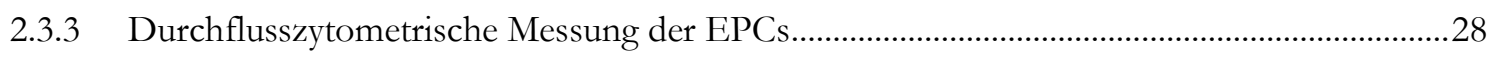

2.3.4 EPC-Proliferationsmessung durch Kolonie-Zählung ................................................................

2.3.5 Laser-Scanning Mikroskopie auf Gefäß- und EPC-Strukturproteine.......................................33

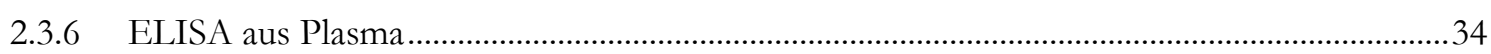

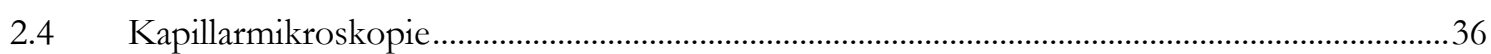

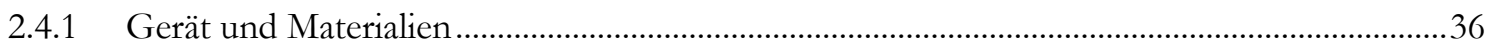

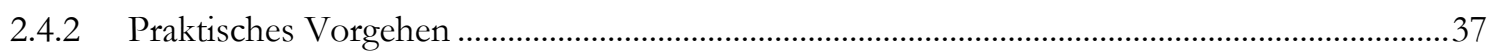

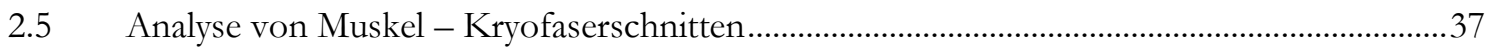


2.5.1 Geräte und Chemikalien für Muskelschnitt-Verarbeitung...................................................37

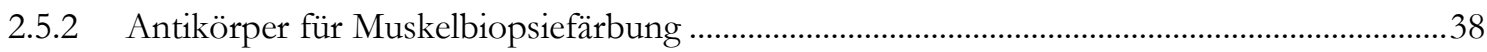

2.5.3 Methodik: Muskelschnitt-Färbung, Fluoreszenzmikroskopie und Auszählung......................38

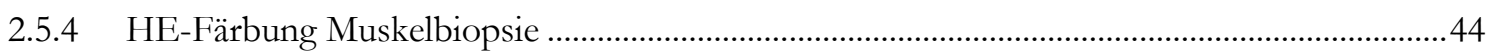

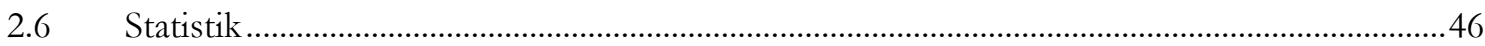

$3 \quad$ Ergebnisse................................................................................. 47

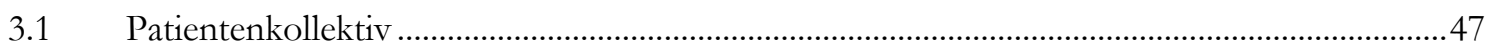

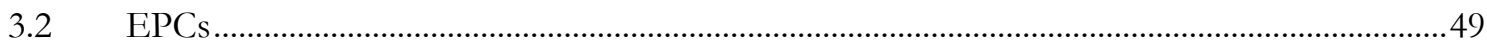

3.2.1 Peripher zirkulierende endotheliale Vorläuferzellen...........................................................49

3.2.2 EPC-Kolonien als Regenerationsparameter........................................................................50

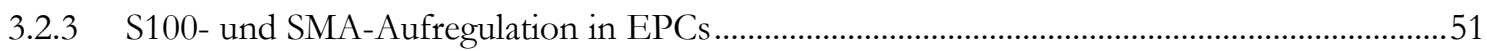

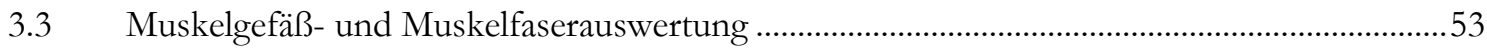

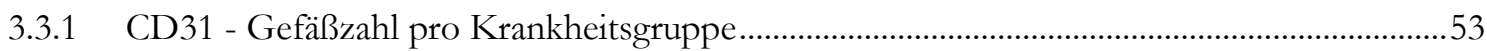

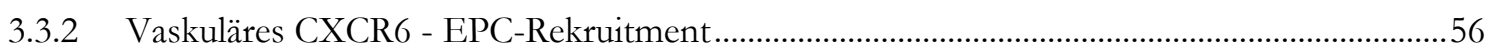

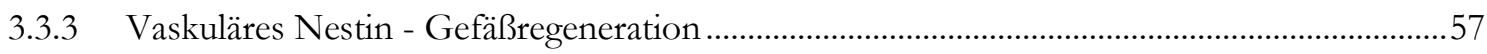

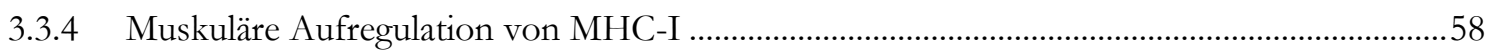

3.3.5 Muskuläre Aufregulation von Nestin - muskuläre Regeneration .............................................59

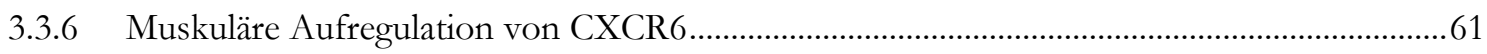

3.3.7 Muskuläres CXCR6 im Vergleich zu CD4 und CD8 .........................................................62

3.4 Angiogene Mediatoren bei Patienten mit inflammatorischen Myositiden .............................63

3.5 Korrelationsanalysen innerhalb der Ergebnisgruppen ......................................................67

3.5.1 Vergleiche der Koloniezahl zu Patientendaten....................................................................67

3.5.2 Zellkernhäufung und Gefäßabnahme an MHC-I- und Nestin-positiven Muskelfasern ........70

3.5.3 Kapillarmikroskopie bei inflammatorischen Myositiden ........................................................ 70

$4 \quad$ Diskussion............................................................................. 74

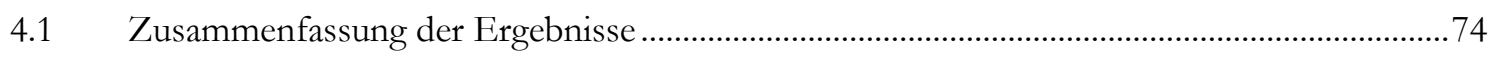

4.2 Endotheliale Vorläuferzellen bei inflammatorischen Myositiden.............................................75

4.3 Angiogene Mediatoren von frühen EPCs im Plasma...........................................................76

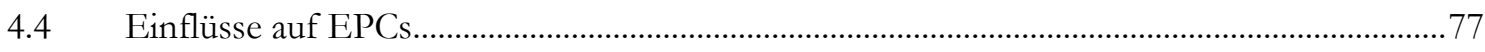

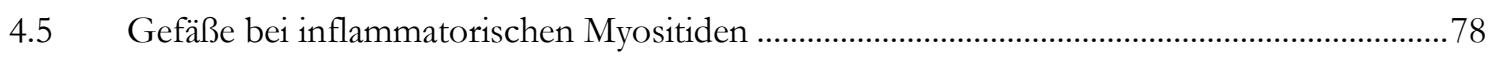

4.6 Nestin- und CXCR6-Fluoreszenz in Gefäßen inflammatorischer Myositiden .......................80

4.7 Nestin- und CXCR6-Fluoreszenz in Muskelfasern inflammatorischer Myositiden ...............81

$4.8 \quad$ Hinweise für endothelial-mesenchymale Transition..........................................................82

4.9 Kapillarmikroskopie bei inflammatorischen Myopathien....................................................83

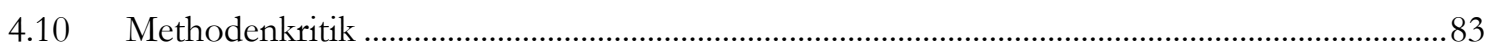

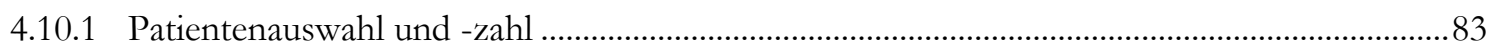

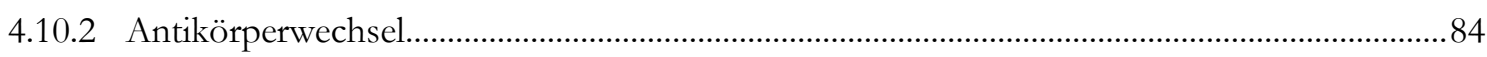

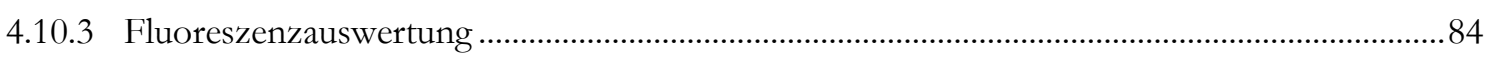

4.11 Assoziation der EPC-Abweichung zu vaskulärer Pathologie und veränderter

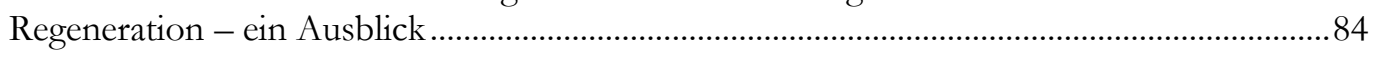




\section{Abbildungsverzeichnis}

Abbildung 1: Mobilisation und Reifung von EPCs und hypothetische Darstellung zum Vorkommen von CXCR6 auf humanen mesenchymalen Stammzellen (MSCs) des Knochenmarks. Modifiziert nach Hristov et al. 2003 und Isozaki et al. 2013.....

Abbildung 2: Kapillarmikroskopie-Normalbefund, haarnadelförmige Kapillaren, normale Kapillardichte, nur vereinzelte Torquierungen

Abbildung 3: Dichtegradientenzentrifugation, die Blutbestandteile trennen sich in Erythrozyten (unten), Biocoll, monozytäre Zellen (Mitte) und Plasma (oben)

Abbildung 4: Dotplot-Analysefenster auf monozytäre Zellpopulation - "Gating" - durch Auftragung der jeweiligen Intensitäten auf der x-Achse (FSC) und y-Achse (SSC). Die umkreiste Region beinhaltet die gesuchte Zellpopulation.

Abbildung 5: Isotyp-Kontrolle zur Berechnung VEGFR-2-positiver Zellen......................................30

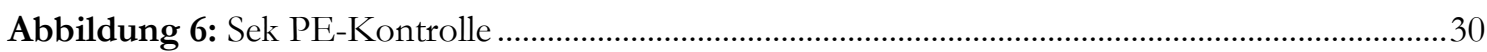

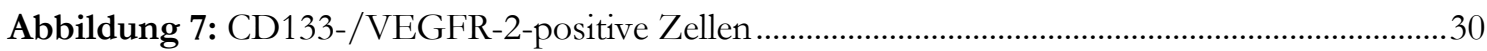

Abbildung 8: Darstellung des Übertrags nicht adhärenter Zellen der 6-Well-Platte in die 24Well-Platte.

Abbildung 9: Darstellung der Kolonien in Abb 9 a-c (Kreise) Tag 5 mit lanzettförmigen Zellen in der Peripherie (Pfeile) und kugelförmigen Zellen im Zentrum; d: Kapillarisierung Tag 9

Abbildung 10: Verdünnungsreihe aus Tierserum mit Konservierungsstoff der Dichte 0 pg/ml mit humaner VEGF-Standard-Lösung der Dichte 2000 pg/ml nach dem Protokoll „Quantikine ELISA Human VEGF Immunoassay“

Abbildung 11: Vorgehen Kapillarmikroskopie..

Abbildung 12: CD31-Fluoreszenz bei nekrotisierender Myopathie, Auszählung von Muskelfasern und -gefäßen anhand einer Nummerierung der Muskelfasern und Markierung der Gefäße durch Pfeile

Abbildung 13: Doppelfärbung bei nekrotisierender Myopathie: links - Marker eins (rotCD31), Mitte - Marker zwei (grün-CXCR6), rechts - Doppelfärbung, Darstellung der Auswertung von doppelt positiven Fasern und Gefäßen, die sich orange-gelb darstellen

Abbildung 14: Biopsie-Fluoreszenz mit CD31 (oben links) und Nestin (Mitte links) sowie CD31 (oben rechts) und CXCR6 (Mitte rechts) bei einem Patienten mit nekrotisierender Myopathie, Gefäßdarstellung in der Muskelbiopsie (gelbe Pfeile), doppelt positive Gefäßfärbung (unten links und rechts) in orange-Darstellung.....

Abbildung 15: Darstellung von Muskelfasern durch Fluoreszenzmarker .......................................43

Abbildung 16: Messungenauigkeit bei Berechnung der Gefäßzahl $/ \mathrm{mm}^{2}$

Abbildung 17: Auswahl eines perivaskulären Areals bei einem Patienten mit Dermatomyositis zur Veranschaulichung der Ergebnisinterpretation zwischen der Hämatoxylin-EosinFärbung (HE) und den Fluoreszenzfärbungen..

Abbildung 18: Anzahl der CD133+-/VEGFR-2+-Zellen in den Vergleichsgruppen DM, PM, NM sowie Kontrollgruppe.

Abbildung 19: Anzahl der CD133+-/c-KIT ${ }^{+}-$Zellen in den Vergleichsgruppen DM, PM, NM sowie Kontrollgruppe. [Signifikante Unterschiede der Verteilungen mittels WilcoxonRangsummentest: * $\mathrm{p}<0,05]$

Abbildung 20: Anzahl der Kolonien in den Vergleichsgruppen DM, PM, NM sowie Kontrollgruppe. [Signifikante Unterschiede der Verteilungen mittels WilcoxonRangsummentest: * $\mathrm{p}<0,05 ; * * \mathrm{p}<0,01]$. 
Abbildung 21: Anzahl der S100+-Zellen als Anteil der CD31+- und UEA-Lektin ${ }^{+}$ZZellen in den Vergleichsgruppen DM, PM, NM sowie Kontrollgruppe. Die rote Linie stellt den Median dar.

Abbildung 22: Anzahl der SMA+-Zellen als Anteil der CD31+- und UEA-Lektin+- Zellen in den Vergleichsgruppen DM, PM, NM sowie Kontrollgruppe. Die rote Linie stellt den Median dar.

Abbildung 23: Anzahl der CD31+_Gefäße pro Muskelfasergesamtzahl in den Vergleichsgruppen DM, PM, NM sowie Kontrollgruppe. Die rote Linie stellt den Median dar. [Signifikante Unterschiede der Verteilungen mittels WilcoxonRangsummentest: * $\mathrm{p}<0,05 ; * * \mathrm{p}<0,01]$

Abbildung 24: Anzahl der CD31+_Gefäße pro $\mathrm{mm}^{2}$ Biopsiequerschnitt in den Vergleichsgruppen DM, PM, NM sowie Kontrollgruppe. Die rote Linie stellt den Median dar. [Signifikante Unterschiede der Verteilungen mittels WilcoxonRangsummentest: * $\mathrm{p}<0,05]$

Abbildung 25: Anzahl der Muskelfasermenge pro $\mathrm{mm}^{2}$ Biopsiequerschnitt in den Vergleichsgruppen DM, PM, NM sowie Kontrollgruppe. Die rote Linie stellt den Median dar.

Abbildung 26: Anzahl der CD31+_/CXCR6+-Muskelgefäße in den Vergleichsgruppen DM, PM, NM sowie Kontrollgruppe. Die rote Linie stellt den Median dar. [Signifikante Unterschiede der Verteilungen mittels Wilcoxon-Rangsummentest: * $\mathrm{p}<0,05 ;{ }^{* *} \mathrm{p}<$ $0,01]$

Abbildung 27: Anzahl der CD31+-/Nestin+-Muskelgefäße in den Vergleichsgruppen DM, PM, NM sowie Kontrollgruppe. Die rote Linie stellt den Median dar.

Abbildung 28: Anzahl der MHC-I+-Muskelfasern pro Muskelfaserzahl in den Vergleichsgruppen DM, PM, NM sowie Kontrollgruppe. Die rote Linie stellt den Median dar. [Signifikante Unterschiede der Verteilungen mittels WilcoxonRangsummentest: * $\mathrm{p}<0,05 ; * * \mathrm{p}<0,01]$

Abbildung 29: Anzahl der Nestin ${ }^{+}$-Muskelfasern pro Muskelfaserzahl in den Vergleichsgruppen DM, PM, NM sowie Kontrollgruppe. Die rote Linie stellt den Median dar. [Signifikante Unterschiede der Verteilungen mittels WilcoxonRangsummentest: ** $\mathrm{p}<0,01]$

Abbildung 30: Anzahl der Nestin+-/MHC-I+-Muskelfasern pro Muskelfaserzahl in den Vergleichsgruppen DM, PM, NM sowie Kontrollgruppe. Die rote Linie stellt den Median dar. [Signifikante Unterschiede der Verteilungen mittels WilcoxonRangsummentest: * $\mathrm{p}<0,05 ; * * \mathrm{p}<0,01]$

Abbildung 31: Anzahl der CXCR6+-Muskelfasern pro Muskelfaserzahl in den Vergleichsgruppen DM, PM, NM sowie Kontrollgruppe. Die rote Linie stellt den Median dar. [Signifikante Unterschiede der Verteilungen mittels WilcoxonRangsummentest: * $\mathrm{p}<0,05 ; * * \mathrm{p}<0,01]$

Abbildung 32: Anzahl der CXCR6+-/CD4+- (links) und CXCR6+-/CD8+- (rechts) Muskelfasern pro Muskelfaserzahl in den Vergleichsgruppen DM, PM, NM sowie Kontrollgruppe. Die rote Linie stellt den Median dar.

Abbildung 33: Vorkommen von CXCL16 in den Vergleichsgruppen DM, PM, NM sowie Kontrollgruppe. Die rote Linie stellt den Median dar. [Signifikante Unterschiede der Verteilungen mittels Wilcoxon-Rangsummentest: $\left.{ }^{*} \mathrm{p}<0,05 ;{ }^{* *} \mathrm{p}<0,01\right]$

Abbildung 34: VEGF im Plasma in den Vergleichsgruppen DM, PM, NM sowie Kontrollgruppe. Die rote Linie stellt den Median dar.

Abbildung 35: Angiopoetin 1 im Plasma in den Vergleichsgruppen DM, PM, NM sowie Kontrollgruppe. Die rote Linie stellt den Median dar. [Signifikante Unterschiede der Verteilungen mittels Wilcoxon-Rangsummentest: * $\mathrm{p}<0,05]$

Abbildung 36: Korrelationsanalyse - Koloniezahl versus CXCL16 im Plasma.

Abbildung 37: Darstellung der Koloniezahlen bei Rauchern (R) und Nichtrauchern (NR) Die rote Linie stellt den Median dar.... 
Abbildung 38: Koloniezahl versus CK zum Abnahmezeitpunkt der EPC-Bestimmung..... .68

Abbildung 39: Darstellung der Koloniezahlen bei Prednisolontherapie $>$ 7,5 $\mathrm{mg}$ und $<$ 7,5 mg. Die rote Linie stellt den Median dar.

Abbildung 40: Darstellung der Korrelation zwischen Koloniezahl und Krankheitsdauer

Abbildung 41:Kapillarmikroskopie bei Dermatomyositis

Abbildung 42: Darstellung der Koloniezahl bei Patienten mit Einblutungen in der Kapillarmikroskopie (Ja) bzw. ohne Einblutungen (Nein). Die rote Linie stellt den Median dar.

Abbildung 43: Darstellung der Koloniezahl bei Patienten mit Ektasie des afferenten und efferenten Kapillarschenkels in der Kapillarmikroskopie (Ja) bzw. ohne Ektasie (Nein). Die rote Linie stellt den Median dar.

Abbildung 44: Darstellung der Koloniezahl bei Patienten mit Megakapillaren in der Kapillarmikroskopie (Ja) bzw. ohne Megakapillaren (Nein). Die rote Linie stellt den Median dar.

Abbildung 45: Hypothesenaufstellung zur Dermatomyositis (DM) anhand der vorliegenden Ergebnisse.

Abbildung 46: Hypothesenaufstellung zur nekrotisiernden Myopathie (NM) anhand der vorliegenden Ergebnisse.

Abbildung 47: Hypothesenaufstellung zur Polymyositis (PM) anhand der vorliegenden Ergebnisse 


\section{Tabellenverzeichnis}

Tabelle 1: Eigenschaften inflammatorischer Myositiden: Dermatomyositis (DM), nekrotisierende Myopathie (NM) und Polymyositis (PM) im Überblick nach (Dalakas und Hohlfeld 2003; Dalakas 2015; Herbert et al. 2016; Luo und Mastaglia 2015; Malik et al. 2016; Pappu et al. 2015)

Tabelle 2: Therapiestrategien der Dermatomyositis (DM), nekrotisierenden Myopathie (NM) und Polymyositis (PM) nach (Dalakas 2015; Schmidt und Vorgerd 2011)

Tabelle 3: Eigenschaften von in vitro gezüchteten frühen und späten endothelialen Vorläuferzellen (EPCs) nach (Cheng et al. 2013; Goligorsky 2014; He et al. 2004; Hur et al. 2004; D Patschan et al. 2016; Sieveking et al. 2008; Yoon et al. 2005)...........................11

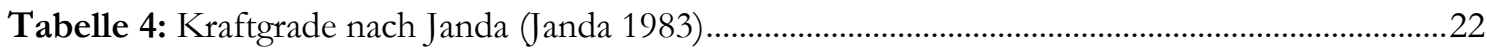

Tabelle 5: Symptome und Diagnosen der Biopsie-Kontrollgruppe ....................................................22

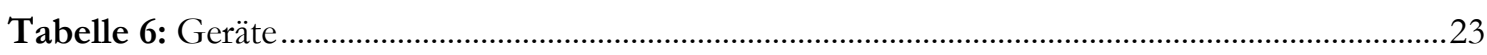

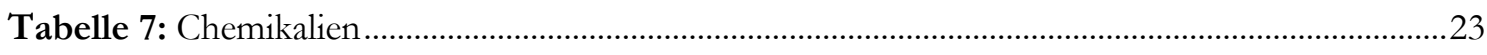

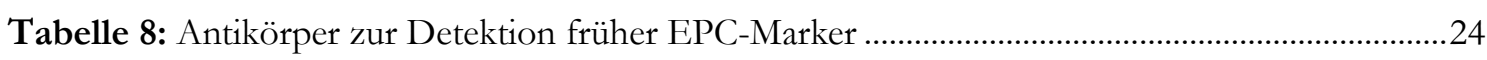

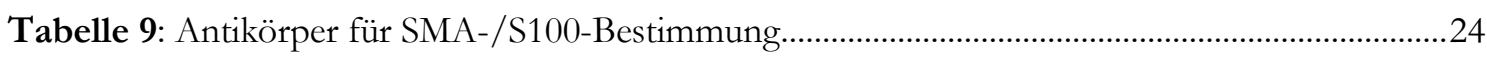

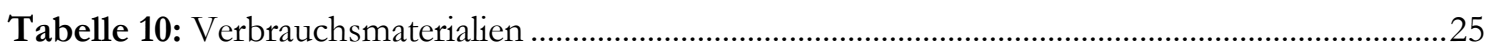

Tabelle 11: Immunoassays zur Bestimmung von Stimulations- und Wachstumsfaktoren ..................35

Tabelle 12: Materialien, Chemikalien und Geräte zur Detektion von Stimulations- und

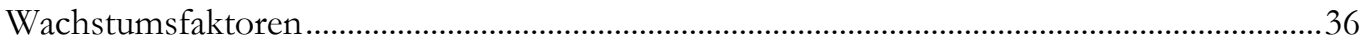

Tabelle 13: Zur Muskelfärbung genutzte Antikörper, $\mathrm{mk}=$ monoklonal, $\mathrm{pk}=$ polyklonal................38

Tabelle 14: Chemikalien für HE-Färbung, EtOH = Ethanol ............................................................. 44

Tabelle 15: Übersicht Patientenkollektiv, *Methotrexat, Azathiprin, Cyclophosphamid, Mycophenolat-Mofetil; ** Adeno-Karzinom, CUP-Syndrom, Mamma-Karzinom

Tabelle 16: Vergleich der CD133+-/VEGFR-2+-Zellen. Dargestellt sind der p-Wert des Kruskal-Wallis-Tests für den Gesamtvergleich aller Untergruppen sowie die p-Werte des Wilcoxon-Rangsummentests für die Einzelvergleiche der Gruppen.

Tabelle 17:Vergleich der CD133+-/c-KIT'-Zellen. Dargestellt sind der p-Wert des KruskalWallis-Tests für den Gesamtvergleich aller Untergruppen sowie die p-Werte des Wilcoxon-Rangsummentests für die Einzelvergleiche der Gruppen.

Tabelle 18: Vergleich der Kolonien. Dargestellt sind der p-Wert des Kruskal-Wallis-Tests für den Gesamtvergleich aller Untergruppen sowie die p-Werte des Wilcoxon-

Rangsummentests für die Einzelvergleiche der Gruppen.

Tabelle 19: Vergleich der S100A4+-Zellen. Dargestellt sind der p-Wert des Kruskal-WallisTests für den Gesamtvergleich aller Untergruppen sowie die p-Werte des WilcoxonRangsummentests für die Einzelvergleiche der Gruppen.

Tabelle 20: Vergleich der SMA+-Zellen. Dargestellt sind der p-Wert des Kruskal-Wallis-Tests für den Gesamtvergleich aller Untergruppen sowie die p-Werte des WilcoxonRangsummentests für die Einzelvergleiche der Gruppen.

Tabelle 21: Vergleich der Gefäßzahl pro Muskelfasergesamtzahl. Dargestellt sind der p-Wert des Kruskal-Wallis-Tests für den Gesamtvergleich aller Untergruppen sowie die pWerte des Wilcoxon-Rangsummentests für die Einzelvergleiche der Gruppen.

Tabelle 22: Vergleich der Gefäßzahl pro $\mathrm{mm}^{2}$ Biopsiequerschnitt. Dargestellt sind der p-Wert des Kruskal-Wallis-Tests für den Gesamtvergleich aller Untergruppen sowie die pWerte des Wilcoxon-Rangsummentests für die Einzelvergleiche der Gruppen.

Tabelle 23: Vergleich der Muskelfaserzahl pro $\mathrm{mm}^{2}$ Biopsiequerschnitt. Dargestellt sind der p-Wert des Kruskal-Wallis-Tests für den Gesamtvergleich aller Untergruppen sowie die p-Werte des Wilcoxon-Rangsummentests für die Einzelvergleiche der Gruppen...........56

Tabelle 24: Vergleich der CD31+-/CXCR6+-Gefäße. Dargestellt sind der p-Wert des KruskalWallis-Tests für den Gesamtvergleich aller Untergruppen sowie die p-Werte des Wilcoxon-Rangsummentests für die Einzelvergleiche der Gruppen. 
Tabelle 25: Vergleich der CD31+-/Nestin+-Gefäße. Dargestellt sind der p-Wert des KruskalWallis-Tests für den Gesamtvergleich aller Untergruppen sowie die p-Werte des Wilcoxon-Rangsummentests für die Einzelvergleiche der Gruppen.

Tabelle 26: Vergleich der MHC-I ${ }^{+}-$Muskelfasern pro Muskelfaserzahl. Dargestellt sind der pWert des Kruskal-Wallis-Tests für den Gesamtvergleich aller Untergruppen sowie die p-Werte des Wilcoxon-Rangsummentests für die Einzelvergleiche der Gruppen.

Tabelle 27: Vergleich der Nestin ${ }^{-}$-Muskelfasern pro Muskelfaserzahl. Dargestellt sind der pWert des Kruskal-Wallis-Tests für den Gesamtvergleich aller Untergruppen sowie die p-Werte des Wilcoxon-Rangsummentests für die Einzelvergleiche der Gruppen.

Tabelle 28: Vergleich der Nestin ${ }^{+}$-/MHC-I+-Muskelfasern pro Muskelfaserzahl. Dargestellt sind der p-Wert des Kruskal-Wallis-Tests für den Gesamtvergleich aller Untergruppen sowie die p-Werte des Wilcoxon-Rangsummentests für die Einzelvergleiche der Gruppen.

Tabelle 29: Vergleich der CXCR6 ${ }^{+}$-Muskelfasern pro Muskelfaserzahl. Dargestellt sind der pWert des Kruskal-Wallis-Tests für den Gesamtvergleich aller Untergruppen sowie die p-Werte des Wilcoxon-Rangsummentests für die Einzelvergleiche der Gruppen.

Tabelle 30: Vergleich doppelt positiver $\mathrm{CXCR}^{+-} / \mathrm{CD} 4^{+}$- und $\mathrm{CXCR} 6^{+-} / \mathrm{CD} 8^{+-}$

Muskelfasern. Dargestellt sind der p-Wert des Kruskal-Wallis-Tests für den Gesamtvergleich aller Untergruppen sowie die p-Werte des Wilcoxon-

Rangsummentests für die Einzelvergleiche der Gruppen.

Tabelle 31: Vergleich von CXCL16 im Plasma von Patienten mit DM, PM, NM. Dargestellt sind der p-Wert des Kruskal-Wallis-Tests für den Gesamtvergleich aller Untergruppen sowie die p-Werte des Wilcoxon-Rangsummentests für die Einzelvergleiche der Gruppen.

Tabelle 32: Vergleich von VEGF im Plasma. Dargestellt sind der p-Wert des Kruskal-WallisTests für den Gesamtvergleich aller Untergruppen sowie die p-Werte des WilcoxonRangsummentests für die Einzelvergleiche der Gruppen.

Tabelle 33: Vergleich von Angiopoetin 1 im Plasma. Dargestellt sind der p-Wert des KruskalWallis-Tests für den Gesamtvergleich aller Untergruppen sowie die p-Werte des Wilcoxon-Rangsummentests für die Einzelvergleiche der Gruppen.

Tabelle 34: Korrelationsanalyse zwischen Koloniezahl und CXCL16 im Plasma. Dargestellt sind der Korrelationskoeffizient berechnet nach Pearson sowie der p-Wert für die Signifikanz der Abweichung von der Nullhypothese (keine Korrelation).

Tabelle 35: Darstellung von Zellkernanhäufungen mittels DAPI Fluoreszenz sowie Gefäßverminderung an Nestin- und MHC-I-positiven Muskelfasern, Angabe in Prozent $(\%)$......

Tabelle 36: Kapillarmikroskopie - Ergebnisse, Pat. = Patient 


\section{Abkürzungsverzeichnis}

\begin{tabular}{|c|c|}
\hline Abb. & Abbildung \\
\hline acLDL & Acetyliertes Lipoprotein niedriger Dichte \\
\hline AK & Antikörper \\
\hline BSA & Bovines Serum - Albumin \\
\hline CD31 & Cluster of differentiation 31 \\
\hline $\mathrm{CK}$ & Kreatininkinase \\
\hline EMG & Elektromyogramm \\
\hline EndoMT & Entohtelial- mesenchymale Transition \\
\hline ENMC & European Neuromuscular Center \\
\hline evtl. & eventuell \\
\hline EPC & Endothelial progenitor cells (endotheliale Vorläuferzellen) \\
\hline $\mathrm{EtOH}$ & Ethanol \\
\hline fem. & feminin \\
\hline FACS & Fluorescence-activated cell sorting \\
\hline FLK-1 & Fetal liver kinase 1 \\
\hline HE-Färbung & Hämatoxylin-Eosin-Färbung \\
\hline $\mathrm{HIV}$ & Humanes Immundefizienz Virus \\
\hline HMVEC & Human dermal microvascular endothelial cells \\
\hline IL & Interleukin \\
\hline KDR & Kinase insert domain receptor \\
\hline $\mathrm{Lj}$. & Lebensjahr \\
\hline M & maskulin \\
\hline MAA & Myositis-assoziierte Antikörper \\
\hline MAC & Membrane attack comlex \\
\hline MHC-I & Major histocompatibility complex I \\
\hline MMP-9 & Matrix-Metallprotease 9 \\
\hline MNC & Mononuclear cells (Monozyten) \\
\hline MSA & Myositis-spezifische Antikörper \\
\hline Nestin & Neuroepithelial stem cell protein \\
\hline NKT & Natürliche Killer-T-Zellen \\
\hline NM & Nekrotisierende Myopathie \\
\hline $\mathrm{NO}$ & Stickstoffmonoxid \\
\hline Pat. & Patient/-en \\
\hline PBS & Phosphate-buffered saline (Phosphatgepufferte Salzlösung) \\
\hline PECAM-1 & Platelet/ endothelial cell adhesions molecule 1 \\
\hline PM & Polymyositis \\
\hline Tab. & Tabelle \\
\hline S100 & Calcium-bindende Proteine, in verschiedenen Zelltypen exprimiert \\
\hline SMA & Smooth muscle actin \\
\hline VEGFR-2 & $V$ ascular endothelial growth factor receptor 2 \\
\hline $\mathrm{vWF}$ & von Willebrand-Faktor \\
\hline
\end{tabular}




\section{$1 \quad$ Einleitung}

\subsection{Myositiden}

Muskeln bilden mit 31,6 \% des Körpergewichtes das massenmäßig größte Organ des menschlichen Organismus (Flindt 1995). Zusammen übernehmen sie neben Stütz-, Halteund Bewegungsfunktionen den Herzschlag, die Darmpersitaltik oder die Bewegung der Extremitäten. Kommt es zu plötzlichen Funktionseinschränkungen, sind Aktivität, Lebensqualität oder gar das Leben selbst gefährdet.

Entzündliche Veränderungen der Muskulatur sind, wie sie die griechisch/lateinischen Silben mys (Muskel) und -itis (Entzündung) beschreiben, ursächlich sehr heterogen bedingt. Ihre Genese wird in die Gruppen der infektiösen, der autoimmunen und der toxisch bedingten Entzündungen eingeteilt. Als infektiöse Erreger kommen Viren, Bakterien, Parasiten oder auch Pilzinfektionen in Betracht (Crum-Cianflone 2008). Weiterhin können ursächlich idiopathisch-autoimmune (Papadakis et al. 2014), traumatische, chirurgisch-idiopathische oder toxisch-medikamentöse Gründe vorliegen (Tiwari et al. 2006). Die klinische Symptomatik einer myopathischen Veränderung reicht im Allgemeinen von Schwellungen über Schmerzen bis hin zu Schwäche (Crum-Cianflone 2008). Die inflammatorischen oder auch autoimmunen Myositiden werden in die Gruppen der Dermatomyositis (DM), der Polymyositis (PM), der nekrotisierenden Myopathie (NM), der nicht spezifischen Myositis und der Einschlusskörpermyositis (IBM) eingeteilt (Dalakas 2015). Diese in Bezug auf Ätiologie, Immunpathologie und klinische Ausprägung heterogene Gruppe geht, mit Ausnahme der Einschlusskörpermyositis, in der Regel mit einer Schwäche der proximalen Extremitätenmuskulatur einher (Dalakas 2011, 2015). In dieser Arbeit wurden ausschließlich die ersten drei inflammatorischen Myositiden evaluiert. Als Sonderformen der Myositiden im Allgemeinen sind die eosinophile Myositis sowie die granulomatöse Myositis zu nennen.

\subsection{Inflammatorische Myositiden}

Idiopathische inflammatorische Myositiden (IIM) sind eine heterogene Gruppe von Muskelerkrankungen unklarer Genese, die typischerweise mit symmetrischer Muskelschwäche einhergehen und auf Grundlage von definierten klinischen Symptomen, Serum-CK-Konzentrationen, typischen Muskelbiopsie-Befunden, Myositis-spezifischen oder -assoziierten Antikörpern, EMG-Mustern und bildgebenden Befunden einhergehen . Die Inzidenz des Auftretens der IIM liegt bei fünf bis zehn Fällen pro einer Million Einwohner pro Jahr, bei Kindern bei einem bis fünf Fällen pro einer Million pro Jahr (Rider und Miller 2011). 
Neben den geläufigen Formen der Poly- und Dermatomyositis, die 1975 von Bohan und Peter erstmals klassifiziert wurden (Bohan und Peter 1975), haben sich in den letzten Jahren Subgruppen mit spezifischen Eigenschaften herauskristallisiert, so dass auf diesem Gebiet derzeit viel Weiterentwicklung stattfindet. Neben der Einschlusskörpermyositis (IBM) und nekrotisierenden Myopathie (NM) sind dabei die overlap-Myositiden zu nennen (Fernandez et al. 2013; Hoogendijk et al. 2004; Ioannou et al. 1999). Die aktuellen Klassifikationskriterien richten sich nach den ENMC-Kriterien, die 2004 auf dem 119. internationalen ENMC Workshop definiert wurden (Hoogendijk et al. 2004). Diese Kriterien umfassen klinische Kriterien wie Muskelschwäche, die proximal stärker als distal ausgeprägt ist, Hauteffloreszenzen wie ein heliotropes Exanthem, Gottronsche Papeln oder ein periorbitales Exanthem, weiterhin Laborwerte wie eine Erhöhung der Kreatininkinase (CK) und EMG-Kriterien sowie solche der histopathologischen Biopsie (Benveniste und Rider 2016; Hoogendijk et al. 2004). Fibrillationen und eine spontane Aktivität der Muskelfasern sprechen dabei für einen pathologischen Befund im EMG. Bioptisch charakterisiert sich die DM-Gruppe durch eine perifaszikuläre Atrophie sowie perivaskuläre $\mathrm{CD}^{+}{ }^{+}$-T-Zell-Infiltrate. Die PM-Gruppe geht hingegen mit endomysialen CD8 ${ }^{+}$-T-Zell-Infiltraten einher und zeigt eine ubiquitäre MHC-I-Aufregulation. Die NMGruppe charakterisiert sich mit vielen nekrotischen Fasern und wenig Inflammation (Hoogendijk et al. 2004).

Die Genese der IIM bleibt weiterhin ungeklärt. Möglicherweise kommt es, durch genetische Risikofaktoren bedingt, $\mathrm{zu}$ einer Immunreaktion gegen unbekannte Umweltantigene (Rider und Miller 2011). Als mögliche auslösende Agenzien werden u. a. Viren wie Influenza-, Paramyxo-, Coxsackie-, Cytomegalie- und Epstein-Barr-Viren vermutet (Dalakas 2015). In der Folge werden Autoantikörper gegen muskuläre oder je nach IIM vaskuläre Proteine ausgebildet (Altmeyer und Paech 2011). Die Autoimmunität richtet sich dabei gegen nukleäre und zytoplasmatische Komponenten (Tansley und Gunawardena 2014). Bei den IIM werden Myositis-assoziierte (MAA) und Myositisspezifische Antikörper (MSA) unterschieden. Die MSA kommen dabei vorwiegend bei inflammatorischen Myositiden vor, die MAA insbesondere als Überlappungssyndrom in Kombination mit Autoimmunerkrankungen wie z. B. der systemischen Sklerose (Betteridge und McHugh 2016; Meisel und González 2015). Die Unterteilung der MSA und auch gesonderte Aufführung unter den jeweiligen Krankheitsbildern erfolgt vor dem Hintergrund der für sie typischen Krankheitsausprägungen, Phänotypen, zugrunde liegenden Pathomechanismen und Therapieansprechen (Fujimoto 2013; Ghirardello et al. 2013). In Tabelle 1 sind typische Eigenschaften der drei inflammatorischen Myositiden aufgeführt, die in dieser Arbeit betrachtet wurden. 
Tabelle 1: Eigenschaften inflammatorischer Myositiden: Dermatomyositis (DM), nekrotisierende Myopathie (NM) und Polymyositis (PM) im Überblick nach (Dalakas und Hohlfeld 2003; Dalakas 2015; Herbert et al. 2016; Luo und Mastaglia 2015; Malik et al. 2016; Pappu et al. 2015)

\begin{tabular}{|c|c|c|c|}
\hline & $\mathbf{D M}$ & $\mathbf{N M}$ & $\mathbf{P M}$ \\
\hline Alter & Jedes Alter & $\begin{array}{l}\text { Jedes Alter } \\
\text { Häufiger Adulte }\end{array}$ & $>18 . \mathrm{Lj}$. \\
\hline Familiäre Assoziation & - & - & - \\
\hline Myalgie/Parese & $\begin{array}{c}\text { akut } \\
\text { proximal } \\
\text { symmetrisch }\end{array}$ & $\begin{array}{l}\text { subakut } \\
\text { proximal } \\
\text { symmetrisch }\end{array}$ & $\begin{array}{l}\text { subakut } \\
\text { proximal } \\
\text { symmetrisch }\end{array}$ \\
\hline Myalgie & fast immer & fast immer & häufig \\
\hline Kreatinin (CK) & $\begin{array}{l}\text { bis fünfzigfach } \\
\text { erhöht }\end{array}$ & $\begin{array}{l}>\text { als fünfzigfach } \\
\text { erhöht }\end{array}$ & $\begin{array}{l}\text { bis fünfzigfach } \\
\text { erhöht }\end{array}$ \\
\hline Muskelbiopsie & $\begin{array}{c}\text { perifaszikuläre, } \\
\text { perimysiale oder } \\
\text { perivaskuläre } \\
\text { CD4 + Infiltrate, } \\
\text { B-Zellen, } \\
\text { perifaszikuläre } \\
\text { Atrophie }\end{array}$ & $\begin{array}{c}\text { Myozyten-Nekrose } \\
\text { ohne signifikante } \\
\text { Entzündung / } \\
\text { Infiltrate, } \\
\text { Makrophagen } \\
\text { CD68+/CD163+ }\end{array}$ & $\begin{array}{l}\text { CD8/MHC-I- } \\
\text { Komplex }\end{array}$ \\
\hline Hauteffloreszenz & + & - & - \\
\hline Typische Antikörper (Ak) & $\begin{array}{l}\text { Mi-2, MDA5, } \\
\text { TIF-1, NXP-2 }\end{array}$ & SRP, HMGCR & - \\
\hline Paraneoplasie & + & + & + \\
\hline $\begin{array}{l}\text { Extramuskuläre } \\
\text { Manifestation }\end{array}$ & + & + & + \\
\hline $\begin{array}{l}\text { Assoziation HIV, HTLV-1, } \\
\text { Hepatitis C }\end{array}$ & + & + & + \\
\hline MAC (C5b-9) & ++ & $+/-$ & - \\
\hline MHC- I/II & ++ & $\begin{array}{c}+ \text { in vor allem } \\
\text { nekrotischen Fasern }\end{array}$ & ++ \\
\hline Kapillarreduktion & ++ & - & $+/-$ \\
\hline $\begin{array}{l}\text { Geschlechtsverhältnis } \\
\text { F : M }\end{array}$ & $2: 1$ & $1: 1$ & $2: 1$ \\
\hline
\end{tabular}




\subsubsection{Dermatomyositis}

Diese heterogene Gruppe der Myositiden tritt mit einer Inzidenz von 0,6 bis 1,0/100.000 Einwohner pro Jahr auf, wobei Frauen bis zu zweimal häufiger als Männer betroffen sind. Die juvenile Form zeigt sich mit einer Inzidenz von 0,2/100.000 Einwohner pro Jahr in einem Verhältnis von Frauen zu Männern von 6:1 (Altmeyer und Paech 2011). Die Dermatomyositis machte in einer retrospektiven Studie $36 \%$ der IIM aus (van der Meulen et al. 2003). Sie wurde erstmals genauer von E. L. Wagner 1863 und P. Potain 1875 beschrieben (Dourmishev et al. 2009). Der Form ihres Auftretens nach wird sie weiter in die amyopathische, die adermatopathische und dem Alter des Auftretens nach in eine juvenile und eine adulte Dermatomyositis untergliedert (Hoogendijk et al. 2004; Malik et al. 2016). Während die amyopathische Form ohne Muskelbeteiligung auftritt, ist die adermatopathische Gruppe gekennzeichnet durch eine isolierte Myositis, die jedoch typische Muskelbiopsiebefunde einer Dermatomyositis aufweist (Hoogendijk et al. 2004; Malik et al. 2016). Dabei kann eine amyopathische Form einer Muskelsymptomatik bzw. eine adermatopathische Form einer Hautbeteiligung vorausgehen (Rosler und Scheidegger 2015).

Als typischer histopathologischer Befund der Muskelbiopsie tritt im Bereich der kleinsten Muskelgefäße schon frühzeitig der C5b-9 MAC (membrane attack complex) auf. Dieser Vorgang führt in der Folge zu einem Gefäßschaden, dem Ischämie und Muskelfibrillenatrophie folgen (Malik et al. 2016). Es kommt zur Kapillarreduktion, hypoxiebedingter perifaszikulärer Atrophie und Nekrose. Elektronenmikroskopisch können zudem tubuloretikuläre Einschlüsse in kleinen Muskelgefäßen nachgewiesen werden (Schoser 2009). Weiterhin treten perivaskuläre und inter-/perifaszikuläre Infiltrate aus $\mathrm{CD}^{+}$-T-Zellen auf (Rider und Miller 2011). MHC-I wird hier typischerweise auf beschädigten, nicht jedoch auf nekrotischen Muskelfasern nachgewiesen. Aber auch Muskelfasern ohne Inflammation können MHC-I-positiv sein (Dalakas 2011; Rider und Miller 2011).

Eine Hautbiopsie bei Patienten mit Dermatomyositis ist typischerweise charakterisiert durch eine vakuoläre Degeneration der epidermalen Basalzellen mit Atrophie dieser sowie Vorhandensein nekrotischer Keratinozyten (Carstens und Schmidt 2014; Malik et al. 2016). Dermale Infiltrate bestehen dabei vorrangig aus HLA-DR-positiven T-Lymphozyten und Makrophagen (Hausmann et al. 1991). In kutanen Gefäßen wurde ebenfalls der MACKomplex C5b-9 identifiziert (Hausmann et al. 1991; Magro et al. 2008). Insgesamt spricht man von einer lichenoiden Gewebsreaktion bzw. einer interface Dermatitis (Greenberg 2010).

Die Genese der humoralen Mikroangiopathie wird anhand zweier Theorien diskutiert: Zum einen der humoral bedingten Theorie, wobei sich Antikörper gegen das vaskuläre Endothel ausbilden und in der Folge Komplementfaktoren aktivieren. Diese Form führt, wie beschrieben, zur Vaskulitis im Muskelparenchym mit Kapillardestruktion, Ischämie, 
Muskelfaseratrophie, Hypoperfusion und Infiltraten aus CD4 ${ }^{+}-\mathrm{T}-$ Zellen (u. a.) (Luo und Mastaglia 2015). Zum anderen wird die Überexpression von Interferon Typ 1 durch dendritische Zellen diskutiert. Diese Typ 1-Interferon-Ausschüttung wird dabei als Immunantwort auf virale RNA und DNA hin veranlasst (Greenberg 2010). Durch Aktivierung von Toll-like-Rezeptoren werden Zytokine und Chemokine aktiviert, die wiederum zur Zellmigration und Infiltration von mononukleären Zellen wie CD4 ${ }^{+}-\mathrm{T}$ - und B-Zellen in die Muskelfasern mit den oben genannten Konsequenzen führen (Malik et al. 2016).

Symptomatisch geht die adulte Form der Dermatomyositis häufig mit einer rasch auftretenden Muskelschwäche einher und wird von spezifischen Hautmanifestationen begleitet. Dazu gehören ein fliederfarbenes Erythem um die Augenlider mit Ödem, auch heliotroper rash genannt, weiterhin Erytheme an Knien, Ellenbogen, im Nacken oder im Dekolleté Bereich (V-Zeichen) sowie Gottronsche Papeln, auch erythematöse Plaques, an Gelenken der Fingerstreckseiten (Dalakas 2015). Insgesamt besteht eine Photosensitivität. Neben dem Hautbefall mit einem im Verlauf poikilodermatischen Hautbild und möglichen Kalzifikationen der Muskulatur kann es auch zur Lungenerkrankung durch eine primär interstitielle Pneumonitis, einer kardialen oder gastrointestinalen Beteiligung mit Dysphagie (bis 50 \%) kommen (Altmeyer und Paech 2011; Zierz et al. 2014). Schluck-, Kau- sowie Sprechstörungen werden bei einem Drittel der Patienten beobachtet (Rosler und Scheidegger 2015). Atrioventrikuläre Leitungsstörungen, dilatative Kardiomyopathien oder Tachyarrythmien sind in bis zu $70 \%$ bei Patienten mit Dermato- und Polymyositis beschrieben (Zierz et al. 2014).

Je nach Antikörper-Beteiligung können der klinische Befund und seine Ausprägung variieren. Im Folgenden sind daher die häufigsten Dermatomyositis-assoziierten Antikörper mit ihrem Verlauf und assoziierter Organmanifestation erläutert: Anti-Mi2Antikörper ( $<10 \%$ der adulten IIM) prägen sich klinisch eher mild mit den typischen genannten Hauterscheinungen, geringer Myositis-Ausprägung sowie seltener Krebsrate aus und sprechen gut auf eine immunsuppressive Therapie an (Bodoki et al. 2015; CasciolaRosen und Mammen 2012). Eine Polyarthritis oder Lungenbeteiligung werden nicht beobachtet (González-González et al. 2015). Anti-MDA5-Antikörper (13-35 \% der adulten IIM) sind dementgegen bei ostasiatischen Populationen häufig mit einer amyopathischen Form der DM und eher schwerer Lungenbeteiligung assoziiert (Bodoki et al. 2015). Die kaukasische Population ist durch eine leichte Myositis, inflammatorische Arthritiden und orale Ulzerationen charakterisiert (Casciola-Rosen und Mammen 2012; Fujimoto 2013; Hall et al. 2013). Schließlich gehen anti-TIF-1y-Antikörper (13-21\% der adulten IIM) und anti-NXP2-Antikörper (2-17 \% der adulten IIM) mit einer erhöhten Krebsentstehungsrate einher und zeigen häufig eine schwere Hautbeteiligung (Ceribelli et al. 2012; Ghirardello et al. 2014). 
Die Dermatomyositis kann im Rahmen eines overlap-Syndroms mit z. B. der systemischen Sklerose auftreten. Diese manifestiert sich ohne typischen rash, jedoch deutlich ausgeprägten histopathologischen Befunden in der Muskelbiopsie (Dalakas 2015). Typische Autoantikörper, die im Rahmen eines overlap-Syndroms auftreten können sind anti-Ku-, anti-PM/Scl-, anti-Ro- sowie anti-snU1-RNP-Antikörper. Insgesamt besteht bei Patienten mit Dermatomyositis in den ersten drei bis fünf Jahren eine erhöhte Krebsentstehungsrate zwischen $9 \%$ bis $32 \%$. Assoziierte Karzinomarten sind u. a.: das Pankreas-Karzinom, das Kolon-Karzinom, das Melanom, das Mamma-Karzinom, das Nasopharyngeal-Karzinom bei Asiaten oder das Ovarial-Karzinom (Hill et al. 2001).

Typische Befunde der Kapillarmikroskopie bei juveniler und adulter Dermatomyositis werden unter Abschnitt 1.7 beschrieben.

\subsubsection{Nekrotisierende Myopathie}

Diese Form der inflammatorischen Myopathien stellt eine erst kürzlich, im Jahre 2004 definierte Untergruppe dar (Hoogendijk et al. 2004). Sie macht ca. $19 \%$ aller inflammatorischen Myositiden aus (Dalakas 2015) und kennzeichnet sich histopathologisch durch Nekrose von Myozyten, ohne dass eine signifikante Aktivierung inflammatorischer Prozesse nachweisbar wäre (Liang und Needham 2011; Mammen 2014). Dennoch zählt sie zu den autoimmunen Myopathien, da sowohl MHC-I als auch der Komplementkomplex C5b-9, welcher für einen humoralen Prozess spricht, an Kapillaren und nekrotischen Muskelfasern nachgewiesen werden kann (Luo und Mastaglia 2015; Malik et al. 2016). Folgende Trigger der nekrotisierenden Myopathie werden derzeit differenziert: maligne Prozesse, Autoantikörper wie anti-SRP, anti- in Assoziation mit einer Statin-Therapie und Antisynthetase-Antikörper, virale Infektionen wie HIV oder Hepatitis C sowie Kollagenosen (Luo und Mastaglia 2015; Mammen 2014).

Auf vaskulärer Ebene sind Fälle mit sogenannten bleistiftförmigen bzw. pipestem-Kapillaren beschrieben (Schroder et al. 2013). Diese Formen sind eher mit subakuter Schwäche sowie Apoplex durch vaskulitische Veränderungen assoziiert oder treten im Zusammenhang mit Kollagenosen auf (Malik et al. 2016). Eine Mikroangiopathie kann zumindest in diesen Fällen vermutet werden (Schroder et al. 2013). Klinisch tritt die Muskelschwäche bei Patienten mit nekrotisierender Myopathie hoch akut auf und maximiert sich im Einzelfall in einer Gehunfähigkeit (Rosler und Scheidegger 2015).

Klinische Verläufe mit anti-SRP-Antikörpern, die erstmals 1986 noch unter dem Terminus der Polymyositis beschrieben wurden, sind teils rasch progressiv, teils chronisch mit typisch proximaler Muskelschwäche einhergehend (Mammen 2014). Diese Form tritt eher bei jüngeren Patienten auf (Malik et al. 2016). Häufig werden sehr hohe CK-Werte mit wenigen extramuskulären Manifestationen beobachtet. $\mathrm{Zu}$ diesen zählt eine schwere Herzbeteiligung (Bodoki et al. 2015). Therapien gestalten sich oft als resistent gegenüber konventionellen immunsuppressiven Therapien, wobei eine Plasmapherese-Behandlung 
durch Abfall der Antikörper zur klinischen Verbesserung führt (Benveniste et al. 2011). Eine vermehrte MHC-I-Expression und Inflammation sind bei dieser Unterform eher unterrepräsentiert. Neben den anti-SRP-Antikörpern werden häufig auch C5b-9 Komplementablagerungen an der Oberfläche von betroffenen Muskelfasern beschrieben (Rojana-Udomsart et al. 2013), so dass hier ein Komplement-assoziierter Prozess vermutet wird. Es ist letztlich unklar, inwiefern das Auftreten der anti-SRP-Antikörper eine Muskelfasernekrose verursacht (Luo und Mastaglia 2015).

Anti-HMGCR-Antikörper richten sich gegen das Schlüsselenzym 3-Hydroxy-3methylglutaryl-Coenzym A der Cholesterinbiosynthese (Mohassel und Mammen 2013). Assoziierte Verläufe der nekrotisierenden Myopathie wurden zunächst mit einer vorangehenden Statin-Therapie in Zusammenhang gebracht. Prädisponierende Faktoren einer Muskelschwäche im Allgemeinen sind zum Beispiel von Alter, Geschlecht und auch genetischen Ursachen abhängig. Zahlreiche Gene wurden diesbezüglich identifiziert (Luo und Mastaglia 2015). Hält eine Myopathie vier bis sechs Wochen nach Abbruch einer Statin-Therapie an oder verschlechtert sich diese, sollte nach einer nekrotisierenden Myopathie gefahndet werden (Dalakas 2012). Der Antikörper-Titer korreliert dabei mit der Serum-CK-Erhöhung sowie der Muskelschwäche, so dass dieser Antikörper als Verlaufsparameter herangezogen werden kann (Werner et al. 2012). MHC-I wurde bei dieser Unterform diffus verteilt und sogar auf nicht nekrotischen Muskelfasern beschrieben, wobei Statine alleine keine MHC-I-Aufregulation verursachen (Needham et al. 2007). Auch müssen anti-HMGCR-Antikörper nicht mit einer vorhergehenden Statintherapie einhergehen (Mammen 2014). Klinisch besteht, wie bei der Dermatomyositis, ein Zusammenhang mit dem gehäuften Auftreten von Tumorerkrankungen (Kadoya et al. 2016).

Assoziationen zu Antisynthetase-Antikörpern, wie anti-Jo-1, wurden ebenfalls beschrieben. Klinisch gehen diese mit hohen CK-Werten und ggf. Antisynthetase-assoziierten Symptomen wie der interstitiellen Lungenerkrankung, nicht erosiven Arthropathien oder Fieber einher (Mammen 2014; Stenzel et al. 2012).

\subsubsection{Polymyositis}

Die Polymyositis machte laut Rider et al. 2011 einen Anteil von 30-45 \% der inflammatorischen Myositiden aus (Rider und Miller 2011). Im Verlauf der Unterklassifizierungen von Myositis-Gruppen hat sich jedoch herausgestellt, dass die Polymyositis häufig falsch diagnostiziert wurde, die Patienten stattdessen an einer Einschlusskörpermyositis, einer nekrotisierenden Myopathie oder inflammatorischen Dystrophie erkrankt waren (Dalakas 2015; Luo und Mastaglia 2015; van der Meulen et al. 2003). Sie wird daher mittlerweile als Ausschluss-Diagnose angesehen. Die selten isoliert auftretende Polymyositis tritt daher eher mit 2-9 \% auf (Zierz et al. 2014). Die Zahlen zum Anteil der Polymyositis an den inflammatorischen Myopathien schwanken in der Literatur 
jedoch stark. In den USA tritt sie unter Afroamerikanern häufiger auf als in der weißen Bevölkerungsgruppe. Bei Japanern wird sie insgesamt seltener diagnostiziert (Pappu et al. 2015).

Die Polymyositis wird als T-Zell-mediierte Autoimmunmyopathie - im Sinne einer zellulär vermittelten Immunreaktion - beschrieben. Hierbei werden histopathologisch nicht nekrotische Muskelfasern, welche MHC-I exprimieren von CD8 ${ }^{+}$-T-Zellen umschlossen und als teils infiltriert beschrieben. Warum diese Muskelfasern pathologischer weise MHCI aufregulieren, wird derzeit nur vermutet (Dalakas 2015). In der Muskelbiopsie können weiterhin Nekrosen vorkommen, endomysiale Infiltrate bestehen v.a. aus zytotoxischen CD8 ${ }^{+}$-T-Zellen und weniger aus Makrophagen (Breithaupt und Schmidt 2014). Auf vaskulärer Ebene wurde durch Carter et al. zumindest in Anfangsstadien sowie bei einem chronischen Verlauf der Erkrankung eine verminderte Kapillardichte beschrieben, wie sie bereits bei der Dermatomyositis benannt wurde. Dementgegen war die VEGF-Expression an Muskelfasern nur im Anfangsstadium aufreguliert, was darauf hindeuten könnte, dass auch bei der Polymyositis Hypoxie in der Pathogenese eine Rolle spielt (Grundtman et al. 2008). VEGF wirkt sich fördernd auf die Angiogenese aus (Carter et al. 2015).

Klinisch geht diese Muskelerkrankung mit einer moderaten bis schweren symmetrischen Muskelschwäche einher und ist oft mit Begleiterkrankungen assoziiert. Darunter sind u. a. zu nennen: interstitielle Lungenerkrankungen, Herz-Arrhythmien, Myokarditiden sowie in bis zu $50 \%$ ventrikuläre Dysfunktionen. Bei einem Drittel der Patienten werden Schluckstörungen beobachtet (Rosler und Scheidegger 2015). Diese Komplikationen wirken sich lebenslimitierend aus (Lundberg und Forbess 2008). Die Polymyositis geht häufig mit Myositis-assoziierten Antikörpern einer (Altmeyer und Paech 2011). Vor diesem Hintergrund tritt sie mit anderen Autoimmunerkrankungen in Form eines overlapSyndroms auf. Beschrieben sind u. a. die Skleroderma-Myositis und in Zusammenhang mit der systemischen Sklerose oder dem systemischen Lupus erythematodes unter der Connective Tissue Disease zusammengefasste Erkrankungen (Luo und Mastaglia 2015). Die wichtigsten assoziierten Antisynthetase-Antikörper sind anti-Jo1-, anti-PL7- und anti-PL12-Antikörper (Fujimoto 2013). Das damit einhergehende Antisynthetase-Syndrom charakterisiert sich durch typische Symptome wie die Myositis, die symmetrische nicht erosive Arthritis und die interstitielle Lungenbeteiligung, die in Abhängigkeit des vorliegenden Antikörpers unterschiedlich schwer ausfallen und die Prognose beeinflussen (Bodoki et al. 2015; Marie et al. 2012). Weiterhin können Fieber, Mechanikerhände oder ein Raynaud-Phänomen auftreten (Bodoki et al. 2015).

\subsubsection{Therapie der inflammatorischen Myositiden}

Die Therapiestrategien der nekrotisierenden Myopathie beruhen aktuell weitestgehend auf Fallstudien (Kassardjian et al. 2015). Eine Übersicht zu möglichen Therapieempfehlungen bei DM, NM und PM bietet Tabelle 2 . 
Tabelle 2: Therapiestrategien der Dermatomyositis (DM), nekrotisierenden Myopathie (NM) und Polymyositis (PM) nach (Dalakas 2015; Schmidt und Vorgerd 2011)

\begin{tabular}{|c|c|}
\hline & Therapie DM, PM, NM \\
\hline Initial & $\begin{array}{l}\text { Prednisolon } 1 \mathrm{mg} / \mathrm{kg} \text { bis } 100 \mathrm{mg} / \mathrm{Tag}, 4-6 \text { Wochen, } \\
\text { langsames Ausschleichen um } 10 \mathrm{mg} \text { alle } 2-4 \text { Wochen, ab } \\
20 \mathrm{mg} \text { um 2,5-5 mg Reduktion bis Erhaltungsdosis 5-10 mg }\end{array}$ \\
\hline Alternative Immunsuppression & $\begin{array}{l}\text { Azathioprin, Methotrexat, Ciclosporin, Mycophenolat- } \\
\text { mofetil }\end{array}$ \\
\hline $\begin{array}{l}\text { insuffizientes Ansprechen } \\
\text { Glukokortikoide }\end{array}$ & $\begin{array}{l}\text { Immunglobuline intravenös (initial } 2 \mathrm{~g} / \mathrm{kg} \text {, verteilt über } 2-5 \\
\text { Tage, dann } 1 \mathrm{~g} / \mathrm{kg} \text { alle } 6-8 \text { Wochen) }\end{array}$ \\
\hline $\begin{array}{l}\text { insuffizientes Ansprechen } \\
\text { Glukokortikoide, } \\
\text { Immunglobuline }\end{array}$ & Re-Evaluation, Rituximab-Versuch, Cyclophosphamid \\
\hline
\end{tabular}

Die Prognose der inflammatorischen Myopathien hängt von Begleitfaktoren ab. So hatten Patienten mit einer Krebs-assoziierten inflammatorischen Myopathie das schlechteste outcome, während overlap-Myositiden die günstigste Prognose aufwiesen. Prognostische Faktoren wie eine kardiale oder respiratorische Beteiligung führten v.a. bei Patienten mit primärer Dermato- oder Polymyositis zum Tod. Die fünf Jahres Überlebensrate lag insgesamt bei 94,2 \%, die zehn Jahres Überlebensrate bei 89,4 \% (Dankó et al. 2004). Trotz Therapie behalten ein Drittel der Patienten milde bis schwere Paresen (Dalakas und Hohlfeld 2003).

\subsection{Endotheliale Vorläuferzellen (EPCs)}

\subsubsection{EPC-Charakteristika}

Im 19. Jahrhundert beschrieb Friedrich D. von Recklinghausen erstmals Zellen, die Blutgefäße auskleideten. Noch 1896 wurde das vaskuläre Endothel von Ernest Starling als statische Barriere betrachtet. Untersuchungen am Elektronenmikroskop enthüllten jedoch in den fünfziger Jahren des 20. Jahrhunderts, dass Endothel ein heterogenes dynamisches Organ darstellt und u. a. immunologische, hämostatische und sekretorische Funktionen übernimmt (Cines et al. 1998; Fishman 1982; Y Lin et al. 2000).

In den siebziger Jahren des 20. Jahrhunderts konnten Endothelzellen erstmals kultiviert werden (Jaffe et al. 1973). Im Zusammenhang mit Blutgefäßen und Endothelzellen beschäftigte man sich auch mit den Prozessen der Angiogenese, wie z. B. bei Gefäßschäden 
und der Vaskulogenese. In ersterem Fall kommt es zur Gefäßbildung durch Vermehrung lokaler reifer Endothelzellen. Dieser Vorgang wurde lange Zeit als einziger Mechanismus im adulten Organismus angenommen. Die Vaskulogenese hingegen ist durch die Einwanderung zirkulierender unreifer mesodermaler Zellen der endothelialen Linie und deren lokaler Differenzierung charakterisiert (Drake 2003). Dieser Mechanismus wurde bis Ende der neunziger Jahre des letzten Jahrhunderts nur im embryonalen Organismus vermutet. 1997 erhielt die Arbeitsgruppe um Asahara et al. erstmals Hinweise auf eine adulte Vaskulogenese (Asahara et al. 1997). Dabei wurden CD34-positive (CD34 ${ }^{+}$) Zellen aus humanem peripheren Blut isoliert und unter pro-endothelialen Bedingungen auf Fibronektin kultiviert. CD34 wird auf hämato- und angiopoetischen Vorläuferzellen exprimiert, so dass eine Differenzierung in endotheliale Zellen angenommen wurde. Die kultivierten Zellen wiesen nach ihrer Inkubation gereifte Zellen mit endothelialen Eigenschaften nach (Hristov et al. 2003). Sie exprimierten zudem Oberflächenmarker, die auf Endothelzellen beschränkt sind (Asahara et al. 1997). Im Verlauf der Forschung wurden weitere Marker für frühe endotheliale Vorläuferzellen charakterisiert (Hristov et al. 2003), die im Abschnitt 1.3.2 genauer beschrieben werden.

Asahara konnte zudem in vivo nachweisen, dass die Gabe dieser $\mathrm{CD}^{2} 4^{+}$endothelialen Vorläuferzellen in iatrogen herbeigeführtes ischämisches Gewebe von Ratten zum Einbau dieser injizierten Zellen in das mikrovaskuläre Endothelium der ischämischen Region führte. Weiterhin nahm die postischämische Reperfusion zu (Asahara et al. 1997).

Seit 1997 wurde in Folge dieser Veröffentlichung viel um das Thema der endothelialen Vorläuferzellen geforscht. Kontroverse Diskussionen fanden um mögliche weitere und andere Sub-Populationen von Vorläuferzellen statt oder wurden in Frage gestellt (Hur et al. 2004; Richardson und Yoder 2011; Urbich und Dimmeler 2004). Möglicherweise sind diese auf geringfügig unterschiedliche Kultivierungsprotokolle zurückzuführen (Urbich und Dimmeler 2004) oder der „Sammel“-Begriff EPC ist veraltet (Richardson und Yoder 2011). Abgesehen von letzterer These werden seit 2004 folgende Populationen dieser heterogenen Zellen unterschieden:

Frühe endotheliale Vorläuferzellen: In der Literatur werden sie auch unter folgenden Namen geführt: „Colony-Forming Unit-Endothelial Cells“ (CFU-ECs) sowie „Early Endothelial Progenitor / Outgrowth Cells“ (eEPCs / eEOCs) (Fadini et al. 2012). Sie werden aus den mononukleären Zellen des peripheren Blutes gewonnen und zunächst über 24 bis 48 Stunden auf Fibronektin unter proendothelialen Bedingungen inkubiert. Nicht adhärente Zellen werden anschließend erneut auf Fibronektin kultiviert. Nach insgesamt sieben Tagen können schließlich Zellen mit endothelialen Charakteristika nachgewiesen werden (Fadini et al. 2012). Diese Zellen entsprechen den initial von Asahara beschriebenen Zellen. Sie wirken durch parakrine Effekte proangiogen (Hur et al. 2004).

Späte endotheliale Vorläuferzellen: Sie werden auch „Endothelial Colony-Forming Cells“ (ECFCs) bzw. „Late Endothelial Progenitor / Outgrowth Cells“ (IEPCs/IEOCs) 
genannt und können ebenfalls aus mononukleären Zellen des peripheren Blutes gewonnen werden. Nach einer kurzen Phase des Plattierens und Inkubierens werden adhärente Zellen für weitere 14 bis 21 Tage kultiviert (D Patschan et al. 2016). Diese Zellen formen vaskulär-tubuläre Strukturen (Mukai et al. 2008).

Weitere Eigenschaften und Unterschiede zwischen beiden Zellreihen sind in Tabelle 3 dargestellt.

Tabelle 3: Eigenschaften von in vitro gezüchteten frühen und späten endothelialen Vorläuferzellen (EPCs) nach (Cheng et al. 2013; Goligorsky 2014; He et al. 2004; Hur et al. 2004; D Patschan et al. 2016; Sieveking et al. 2008; Yoon et al. 2005)

\begin{tabular}{|c|c|c|}
\hline EPCs & Früh & spät \\
\hline In vitro Entstehung & Nach 3 - 5 Tagen & 2 - 4 Wochen \\
\hline Lebensspanne & 3-4 Wochen & 12 Wochen \\
\hline Erscheinung & lanzetten- und kugelförmig & pflastersteinartig \\
\hline Gefäße & $\begin{array}{c}\text { Fördern Tubulogenese, } \\
\text { Angiogenese durch parakrine } \\
\text { Mechanismen }\end{array}$ & $\begin{array}{l}\text { Formen vaskuläre, tubuläre } \\
\text { Netzwerke }\end{array}$ \\
\hline $\begin{array}{l}\text { Sekretion angiogener } \\
\text { Faktoren }\end{array}$ & $\begin{array}{c}\text { HGF, VEGF, IL2. IL8, G-CSF } \\
\text { (u. a.) }\end{array}$ & MMP-9 \\
\hline Proliferationsrate & niedrig & hoch \\
\hline Oberflächenantigene & $\begin{array}{l}\text { hämato- und angiopoetische } \\
\text { (CD34, CD31, VEGFR-2, Tie- } \\
\text { 2, Ve-Cadherin, CD14, CD105, } \\
\text { (u. a.)) }\end{array}$ & $\begin{array}{l}\text { Angiopoetische (VEGFR-2, vWF, } \\
\text { CD36, Ve-Cadherin, Tie-2) }\end{array}$ \\
\hline Beschichtung & Fibronektin & Kollagen-Typ I oder Fibronektin \\
\hline NO-Produktion & gering & hoch \\
\hline Lektinbindung & positiv & positiv \\
\hline Aufnahme acLDL & positiv & positiv \\
\hline
\end{tabular}

Unter dem von Richardson und Yoder eingeführten Terminus der „ProAngiogenicCells“ (PACs) werden die heterogenen endothelialen Vorläuferzellen nun ebenfalls in der Literatur gefunden (Florczyk et al. 2014; He et al. 2004).

Eine Erhöhung der endothelialen Vorläuferzellen wurde im Rahmen von physiologischen und nicht physiologischen Bedingungen beschrieben (Hunting et al. 2005). Wie ursprünglich durch Asahara gezeigt, fördern sie die endotheliale Regeneration durch ReEndothelialisierung und Neovaskularisation (Urbich und Dimmeler 2004). Als mögliche stimulierende Einflussfaktoren auf die EPCs wurden Statine und Bewegung beschrieben. Dementgegen wirken Risikofaktoren der koronaren Herzkrankheit hemmend auf die 
Spiegel der EPCs. Somit haben die Faktoren modulierende Wirkung und in der Konsequenz einen Effekt auf die Reparaturkapazität der Gefäße (Urbich und Dimmeler 2004). Dabei hängt die Regulation der Angiogenese nicht nur von der Zahl der EPCs, sondern auch von deren Proliferationsaktivität ab. Weiterhin ging die Anzahl der EPCs umgekehrt proportional mit der Anzahl der Krankheitsprognosefaktoren z. B. bei Diabetes mellitus oder kardiovaskulären Erkrankungen einher (Cheng et al. 2013). Schließlich konnten die regenerierenden Effekte der EPCs auch in pathologischen Situationen am Menschen genutzt werden. Bei Patienten mit Myokardinfarkt führte z. B. die koronare Infusion von autologen endothelialen Vorläuferzellen zu einer verbesserten koronaren Flussreserve und förderte die linksventrikuläre Funktion (Assmus et al. 2002). EPCs werden weiterhin auch mit der Neovaskularisation bei Tumorprozessen in Zusammenhang gebracht (Patenaude et al. 2010).

Zudem fanden Untersuchungen zu antiischämischen Effekten und einer veränderten EPCRegeneration unter verschiedensten experimentellen Bedingungen statt, wie z. B. bei septischen Zuständen, dem akuten und chronischen Nierenversagen (D Patschan et al. 2006), der koronaren Herzkrankheit (Schuleri et al. 2008), der pulmonalen Hypertonie (Diller et al. 2010) sowie rheumatischen Erkrankungen wie der systemischen Sklerose (S Patschan et al. 2016), dem systemischen Lupus erythematodes (S Patschan et al. 2013) oder der Granulomatose mit Polyangiitis (S Patschan et al. 2012). Erst kürzlich wurde eine endotheliale Dysfunktion bei Patienten mit Dermato- und Polymyositis beschrieben. Dabei waren sowohl die Anzahl der zirkulierenden EPCs als auch deren Reifungskapazität zu ausdifferenzierten Endothelzellen vermindert. Weiterhin wurde eine erhöhte Typ IInterferon-Aktivität im Serum dieser Patienten gefunden. Der Effekt auf EPCs konnte durch Antikörper gegen Interferon Typ-I und IL-18 neutralisiert werden (Ekholm et al. 2016; S Patschan et al. 2012).

Von der Tatsache ausgehend, dass bei der Dermatomyositis histopathologisch ein reduziertes, destruiertes Kapillarbett mit Komplementablagerungen beschrieben wird, sollte in dieser Arbeit untersucht werden, ob es Veränderungen von der Anzahl zirkulierender EPCs oder von deren Regenerationsfähigkeit gibt. Im Vergleich standen dazu die Erkrankungsgruppen der nekrotisierenden Myopathie, welche ebenfalls mit vaskulären Komplentablagerungen einhergeht und die Polymyositis, bei der $\mathrm{CD} 8^{+}$-T-Zellen im Gefäßsystem nachgewiesen wurden.

\subsubsection{Hämato- und angiopoetische Stammzellmarker}

1997 isolierte Asahara CD34+-positive Zellen aus menschlichem Blut und konnte nach deren Züchtung auf Fibronektin endotheliale Charakteristika nachweisen (Asahara et al. 1997). Im anschließenden Verlauf der Forschung charakterisierte man weitere Marker früher endothelialer Vorläuferzellen. Dazu gehören neben CD34 auch CD133 und VEGFR-2, ebenfalls unter KDR oder FLK-1 bekannt (Hristov et al. 2003). Im Verlauf des 
Reifungsprozesses endothelialer Vorläuferzellen werden Marker wie CD133 wieder herunterreguliert, während neue reifere Marker wie CD31 oder von-Willebrand-Faktor (vWF) aufreguliert werden. Dieser komplexe Prozess wird durch verschiedene Enzyme, Rezeptoren und Wachstumsfaktoren reguliert. Eine erhöhte EPC-Ausschüttung aus dem Knochenmark konnte in pathologischen Situationen wie einer Extremitätenischämie, wie durch Asahara ursprünglich 1997 gezeigt, nach einer Koronarthrombose oder koronaren Bypass-Operation und nach Verbrennungen nachgewiesen werden (Hristov et al. 2003). Eine Darstellung und Aufschlüsselung des Reifungsprozesses und der in dieser Arbeit verwendeten Marker ist in Abbildung 1 schematisch dargestellt. Weiterhin wurden der Vollständigkeit wegen das durch Asahara zum Nachweis von Vorläuferzellen verwendete CD34 und der vWF eingefügt:

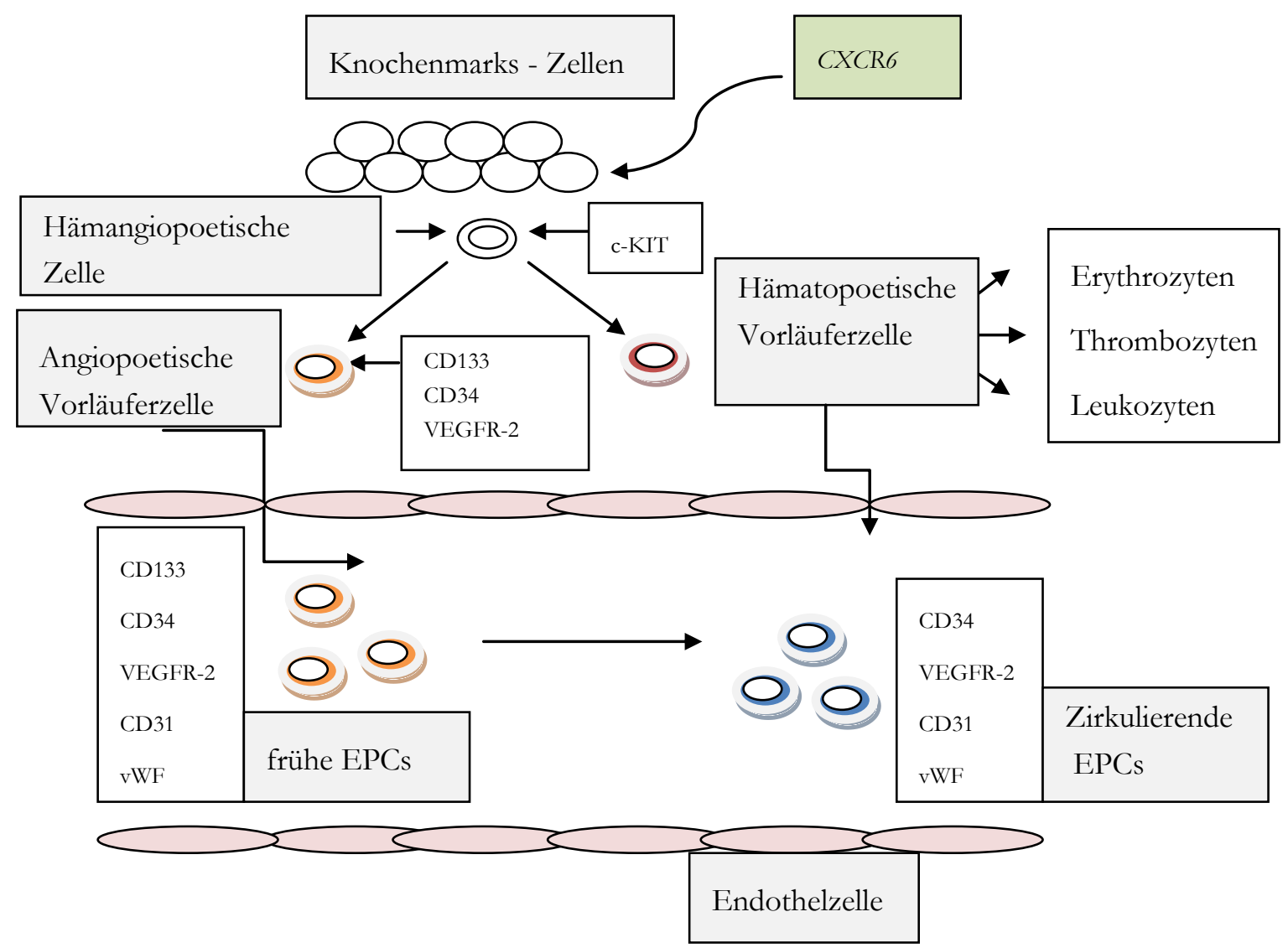

Abbildung 1: Mobilisation und Reifung von EPCs und hypothetische Darstellung zum Vorkommen von CXCR6 auf humanen mesenchymalen Stammzellen (MSCs) des Knochenmarks. Modifiziert nach Hristov et al. 2003 und Isozaki et al. 2013

\section{CD34:}

Dieses Transmembranglykoprotein wird an der Oberfläche von hämatopoetischen Stammund Vorläuferzellen aufreguliert. Weiterhin kann es auf der Zellmembran von ruhenden endothelialen Zellen kleiner Blut- und Lymphgefäße nachgewiesen werden (Siemerink et al. 2012). Es wird die Ausübung einer Funktion als Adhäsionmolekül bei der frühen BlutzellMigration und -differenzierung vermutet (G Lin et al. 1995). 


\section{CD31:}

CD31 stellt als $130 \mathrm{kDa}$ großes Protein der Immunglobulin-Superfamilie ein Adhäsionsmolekül für Endothelzellen, Thrombozyten und wie im Verlauf der Literatur beschrieben auch der Leukozyten dar (L Liu und Shi 2012). Es spielt eine wichtige Rolle bei der ZellZell-Transmigration durch interzelluläre Junktionen der endothelialen Zellen (Kim et al. 2014). In Untersuchungen wirkte CD31 stimulierend auf das endotheliale Zellwachstum. Die Injektion des Immunglobulins in ischämische Extremitäten führte weiterhin zur Aufregulation von angiogenen Faktoren und unterstützte die Vaskulogenese (Kim et al. 2010). Weiterhin nimmt CD31 an der Regulation von T-Zell-Aktivierung, Angiogenese, Thrombozyten-Aktivierung sowie Leukozytenfreisetzung teil (L Liu und Shi 2012). Es wird auch unter den Namen PECAM-1, endoCam oder GPIIA geführt. In dieser Arbeit diente es als Marker für Endothelzellen in humanen Muskelbiopsieschnitten.

\section{CD133:}

Dieses glycosylierte Polypeptid mit 120 kDa, auch Prominin-1 genannt, ist typischerweise auf frühen endothelialen Vorläufern nachweisbar, nicht jedoch auf reifen Endothelzellen (Hilbe et al. 2004). Aufgrund dieser Eigenschaft bietet es dem CD34 gegenüber, das auch auf reiferen Endothelzellen exprimiert wird, einen Vorteil in der Detektion endothelialer Vorläuferzellen. Das CD133/VEGFR-2 Paar weist damit sicherer unreife EPCs nach als CD34/VEGFR-2, das auch reifere abgeschilferte Endothelzellen der Gefäße beinhalten kann (Urbich und Dimmeler 2004). Die genaue Funktion des Polypeptids ist bisher unklar. Im Rahmen der EPCs scheint es den Übergang von zirkulierenden EPCs in eher reifere endothelartige Zellen zu markieren (Hristov et al. 2003). Erhöhte CD133-Spiegel wurden bei Patienten mit kleinzelligem Bronchial-Karzinom und Mamma-Karzinom nachgewiesen, so dass hier der Verdacht der Tumorvaskulogenese durch EPCs unterstützt wurde (Bock et al. 2014; Hilbe et al. 2004)

\section{c-KIT:}

Dieses Protein gehört zu den Tyrosinrezeptorkinasen und wird von hämatopoetischen, kardial-epithelialen und endothelialen Stammzellen exprimiert (Dentelli et al. 2007). Es spielt eine Rolle bei der Hämatopoese, Pigmentation, Fertilität (Lennartsson und Ronnstrand 2012) und wurde zudem auf Mastzellen und Melanozyten nachgewiesen. In letzteren sind die Aufgaben assoziiert mit Proliferation und Differenzierung, in Mastzellen weiterhin mit Chemotaxis und Degranulation (Webster et al. 2006). Eine veränderte c-KIT Expression kann in einer Neoplasieentstehung wie der AML oder in Prostatatumoren enden (Webster et al. 2006).

In der Literatur wird c-KIT auch unter Stammzellfaktor-Rezeptor, CD117 oder Tyrosinkinase-KIT geführt. Sein Ligand KitL, auch als „Mastcell Growth Factor“ beschrieben, tritt in zwei Varianten auf: einem größeren Abschnitt, der sich an seiner extrazellulären Seite von der Zelloberfläche lösen kann und einem kleineren Membran- gebundenen 
Abschnitt an der Zelloberfläche. In Bedarfssituationen kann durch die Matrix Metallproteinase-9 der größere Abschnitt von z. B. hämatopoetischen Zellen losgelöst werden. Dieser Prozess leitet den Beginn der endothelialen und hämatopoetischen Proliferation ein (Dentelli et al. 2007). Es wurde ein weiterer Zusammenhang von c-KIT zu endothelialen Vorläuferzellen beschrieben. Dabei wurde nachgewiesen, dass die Adhäsion von EPCs an endotheliale Zellen, z. B. vor dem Hintergrund des homings bei Ischämien oder Verletzungen, zytokinstimuliert verläuft und wesentlich durch das Zusammenspiel zwischen dem Ligand mbKitl und seinem Rezeptor c-KIT beeinflusst wird. Eine Herunterregulation einer der beiden führte zu einer 70\%igen Reduktion der Adhäsionsrate von EPCs an endothelialen Zellen (Dentelli et al. 2007).

In dieser Arbeit diente c-KIT zur Unterscheidung zwischen hämatopoetischen Vorläuferzellen und angiopoetischen Vorläuferzellen in der Durchflusszytometrie.

\section{VEGFR-2:}

Der Wachstumsfaktor-Rezeptor gehört zu einer Subfamilie der Rezeptor-Tyrosin-Kinasen. Er wird in der Literatur auch unter FLK-1 oder KDR geführt. Gemeinsam mit VEGFR-1 sind sie am Prozess der Angiogenese durch spezifische intrazelluläre Signalkaskaden beteiligt (Rahimi 2006). VEGFR-2 gilt als Marker der frühen endothelialen Vorläuferzellen (Hristov et al. 2003). Dieser wird von frühster Entwicklung an exprimiert. Eine erhöhte Expression lässt sich in malignen Tumorepithelien nachweisen (Miettinen et al. 2012). In dieser Arbeit diente VEGFR-2 zum Nachweis der frühen endothelialen Vorläuferzellen in der Durchflusszytometrie. Weiterhin wurde VEGF im Serum von Patienten bestimmt. Er gilt als Mediator für die Vaskulo- und Angiogenese bei der Embryogenese sowie im adulten Organismus (Byrne et al. 2005).

Weitere gebräuchliche Zellmarker sind CD14, auf Makrophagen exprimiert, und CD45, auf hämatopoetischen Stammzellen mit Ausnahme der Erythrozyten aufreguliert. Sie werden herangezogen, um hämatopoetische Stammzellen während der EPC-Detektion auszuschließen (Toshner und Morrell 2010). Marker für reife EPCs sind weiterhin vWF, VE-Cadherin (Hristov et al. 2003) sowie Tie-2 (Davis et al. 1996) und eNOS (Hristov et al. 2003).

\subsubsection{Gefäß- und Zellstruktur-Proteine}

aSMA: „Alpha smooth muscle actin“, auch ACTA2 genannt, wird typischerweise in glatten Gefäßmuskelzellen exprimiert. Es trägt zur vaskulären Stabilität, Kontraktilität und Beweglichkeit bei. Mutationen im ACTA2-Gen können verschiedene Vaskulopathien, wie Aortopathien - inklusive Aneurysmata und Gefäßdissektionen - sowie vaskuläre Verschlusskrankheiten fördern (Gabbiani et al. 1981; Yuan 2015). Im Rahmen der endothelial mesenchymalen Transition (EndoMT), die verschiedenen Krankheitsprozessen unterliegt, verlieren endotheliale Zellen typische endotheliale Faktoren und regulieren mesenchymale auf. Dieser Prozess findet z. B. bei der kardialen oder nephrogenen Fibrose, 
vermutlich bei der systemischen Sklerose und bei Tumorprozessen statt (Jimenez 2013; Le Bleu et al. 2013; S Patschan et al. 2016; Zeisberg et al. 2007a; Zeisberg et al. 2007b). Bei Tumor-spezifischen endothelialen Zellen konnte in vitro unter TGFB-Stimulation eine Aufregulation von $\alpha \mathrm{SMA}^{+}$-endothelialen Zellen beobachtet werden (Xiao et al. 2015). Auch $\mathrm{CD}^{+} 4^{+}$-Zellen aus humanem Umbilicalvenenblut exprimierten im Vergleich zu CD $133^{+}$-Zellen $\alpha \mathrm{SMA}$, so dass man annahm, dass die Population sowohl in einen endothelialen als auch glatten Muskelzelltyp differenzieren kann (Lu et al. 2004).

S100: Diese ca. 10-14 kDa großen Proteine zeichnen sich durch ihr Calcium bindendes EFHand-Motiv, eine Helix-Loop-Helix Struktur, aus. Die Gruppe der S100-Proteine wurde bisher nur in Wirbeltieren nachgewiesen, sie umfasst über zwanzig Subgruppen sowie eine Reihe intra- und extrazellulärer gewebsspezifischer Funktionen (Hermann et al. 2012; Marenholz et al. 2004). An intrazellulären Aufgaben sind die Zell-Differenzierung, die Regulation des Zell-Zyklus, die Apoptose sowie Membran-Zytoskelett-Interaktionen zu nennen (Hermann et al. 2012). Von Zellen exprimierte extrazelluläre S100-Proteine sind an neuronaler Aktivität sowie an der Beeinflussung von Ionenkanälen beteiligt. Sie aktivieren durch ihre Freisetzung aus destruierten Zellen das Immunsystem oder das vaskuläre Endothel (Hermann et al. 2012). Durch ihre vielfältigen Aufgaben sind sie auch an Tumorgenese und -progress beteiligt (Chen et al. 2014). Auf Ebene der Endothelzellen spielt insbesondere S100A6 im Zellzyklus eine wichtige Rolle. S100P hingegen fördert z. B. die transendotheliale Bewegung von Tumorzellen. Weiterhin sind S100-Proteine an der Angiogenese beteiligt, indem sie pro- und antiangiogene Faktoren wie z. B. VEGF beeinflussen (Chen et al. 2014). Besonders endotheliale Zellen ohne ausreichende Menge an S100A10 zeigen eine verminderte Neovaskularisationskapazität (Surette et al. 2011). In dieser Arbeit detektiertes S100A4, auch FSP1 genannt (Osterreicher et al. 2011), wurde in der Literatur auch als potenter angiogener Mediator beschrieben. Weiterhin ist es am Zellüberleben und der Zellbeweglichkeit beteiligt. Es wurde v.a. im Zusammenhang mit der Tumorangiogenese und Fibrogenese genannt (Boye und Mælandsmo 2010; Osterreicher et al. 2011). Bei letzterer wird es als Marker für eine endothelial mesenchymale Transition (EndoMT) genutzt (Osterreicher et al. 2011).

Die Identifizierung von SMA und S100 an Kolonien endothelialer Vorläuferzellen wurde in dieser Arbeit genutzt, um mesenchymale Eigenschaften von EPCs mit Hinweis auf eine EndoMT oder Abweichungen im Zytoskelett zu detektieren.

\subsection{CXCR6 - EPC-Rekruitmentfaktor}

CXCR6 gehört als Rezeptorprotein zur Familie der Chemokinrezeptoren. Er ist weiterhin bekannt unter Bonzo, STRL33 und TYMSTR (Hattermann et al. 2008). Diese Vielfalt entstand historisch vor der Zuordnung des Moleküls zu den Chemokinenrezeptoren, z. B. bei der Beschreibung des Proteinmoleküls als Co-Rezeptor für das HI-Virus (Wilbanks et al. 2001) und für das simiane Immundefizienz-Virus (Latta et al. 2007). Aktiviert werden 
kann es durch den einzigen bisher bekannten Liganden, das Zytokin CXCL16. CXCR6 selbst stellt ein Transmembranprotein aus der Familie der G-Proteine dar (Heydtmann et al. 2005; Isozaki et al. 2013).

Chemokine im Allgemeinen sind an grundlegenden Prozessen der Entwicklung und Gewebshomöostase vieler Organe sowie an pathologischen Reaktionen wie Entzündung, Angiogenese und Tumorprogress sowie interzellulärer Kommunikation beteiligt. Deren Chemokinrezeptoren können wiederum Zellmigration signalisieren, Zellproliferation und apoptose beeinflussen und die Zytokinproduktion verändern (Hattermann et al. 2008).

Die Aufregulation von CXCR6 und CXCL16 wurde neben der T-Zell-Aktivierung zuletzt immer wieder im Rahmen von Tumorgeweben/-prozessen beschrieben (Singh et al. 2016; Xu et al. 2014), wobei die nachgewiesenen Level mit dem Malignitätsgrad anstiegen (Deng et al. 2010; Heydtmann et al. 2005). Auch im Rahmen von Autoimmunerkrankungen, wie der rheumatoiden Arthritis, spielt das Chemokin/Chemokinrezeptor-Paar als möglicher angiogener Mediator und chemotaktischer Faktor an endothelialen Vorläuferzellen eine Rolle (Isozaki et al. 2013).

CXCR6 selbst wird auf aktivierten T- und Astroglia-Zellen, auf NKT-Zellen, Knochenmarkzellen, auf endothelialen Vorläuferzellen sowie auf den EPCs des Gehirns und an glatten Muskelzellen nachgewiesen (Hattermann et al. 2008; Isozaki et al. 2013). CXCR6 wurde nicht nur auf endothelialen Vorläuferzellen, sondern auch auf den humanen mesenchymalen Stammzellen (MSC) des Knochenmarks gesehen. Es besteht daher der hypothetische Verdacht, dass CXCR6 vor dem Hintergrund der Adhäsions- und Rekrutierungsfunktion von Lymphozyten auch diese MSCs in entzündete Gewebe lockt oder gar mit in den Prozess der Vaskulogenese oder in Gewebsreparaturprozesse involviert ist. Es konnte zudem gezeigt werden, dass „Human Dermal Microvascular Endothelial Cells“ (HMVECs) CXCR6 im Rahmen von entzündlichen Stimuli aufregulieren (Isozaki et al. 2013).

Sein einziger Ligand, CXCL16, ein transmembranöses Multidomain-Molekül, das auch als scavenger-Rezeptor und Adhäsionsmolekül fungiert, wird auf Makrophagen, dendritischen Zellen, endothelialen und glatten Muskellzellen exprimiert (Hattermann et al. 2008). In diesem Zusammenhang konnte eine proangiogene Aktivität von CXCL16 durch Induktion humaner Umbilicalvenen-Endothelzellen (HUVECs) im Rahmen der ArterioskleroseEntstehung nachgewiesen werden (Jovanovic et al. 2015).

Insgesamt ist die vollständige Funktion des CXCR6/CXCL16-Paares noch nicht bekannt. Es kommt ihm vermutlich neben den genannten Funktionen eine wichtige Aufgabe bei der T-Zell-Bewegung und dem Zell-Zell-Kontakt bei Entzündungs- und Immunprozessen zu (Latta et al. 2007).

Vor dem Hintergrund der vielfältig diskutierten Funktionen im Rahmen der Angiogenese und Chemotaxis von EPCs und Immunzellen wurde der Chemokinrezeptor im Rahmen 
dieser Arbeit u. a. mit zur Färbung der Muskelfasern und deren Gefäßen verwendet. CXCL16 wurde zudem im Serum der untersuchten Patienten bestimmt.

\subsection{Nestin - endothelialer und muskulärer Regenerationsmarker}

Das „Tур VI Intermediärfilament Nestin“ verdankt seinen Namen dem ursprünglichen Entdeckungsort in den neuronalen Vorläuferzellen und heißt vollständig: neuroepitheliales Stammzellprotein. In diesen neuronalen Vorläuferzellen des ZNS wird es in der Embryogenese vorübergehend exprimiert, bevor die genannten Zellen in Gliazellen oder Neuronen differenzieren (Sejersen und Lendahl 1993; Xie et al. 2015). Es wird während der Entwicklung ebenfalls in der Muskulatur nachgewiesen, im adulten Muskel jedoch nicht mehr exprimiert (Sejersen und Lendahl 1993). Lediglich nach Muskelzellverletzung konnte es sechs Stunden nach dem Trauma neben dem Intermediärfilament Vimentin in Myoblasten oder nach Myokardinfarkt in den Astrozyten der Myokardnarbe nachgewiesen werden. Im Verlauf der Muskelzellregeneration oder Muskelzellentwicklung wird Nestin wie in anderen Geweben durch Gewebs-spezifische Intermediärfilamente ersetzt (Michalczyk und Ziman 2005; Vaittinen et al. 2001). Es wird als Bestandteil des Zytoskeletts vor allem in sich schnell teilenden Progenitorzellen exprimiert (Michalczyk und Ziman 2005). Nestin konnte dabei u. a. in endothelialen Zellen des ZNS sowie nichtZNS-spezifischen Geweben (Mokrý et al. 2004; Suzuki et al. 2010), Tumorzellen (Krupkova et al. 2010), mesenchymalen Stammzellen, der Haut oder kürzlich geformten Blutgefäßen, z. B. bei der Tumorangiogenese, nachgewiesen werden (Xie et al. 2015). Mokrý et al. gehen soweit, dass die Expression von Nestin zwischen differenzierten und undifferenzierten Zellen unterscheiden lässt (Mokrý et al. 2004).

Neben einer mikrovaskulären muskulären Nestin-Aufregulation im Adulten konnten auch Nestin-positive Satellitenzellen gesehen werden (Day et al. 2007). In dieser Arbeit wurde Nestin in Muskelbiopsien von Patienten mit inflammatorischen Myositiden untersucht. Dabei standen die muskuläre und vaskuläre Aufregulation im Zentrum der Betrachtungen. In der Literatur wird jedoch diskutiert, ob die Nestinexpression nun auf endotheliale Zellen oder glatte Muskelzellen des Gefäßes zurückzuführen ist, denn reife Endothelzellen werden eher als Nestin-negativ beschrieben (Mokrý et al. 2004). Weiterhin gibt es Schilderungen, dass Nestin in den glatten Gefäßmuskelzellen von reifenden embryonalen Gefäßen sowie bei vaskulären Umbauprozessen von bereits ausgereiften Gefäßen nachgewiesen werden konnte (Oikawa et al. 2010).

\subsection{MHC-I - Standardmarker für muskuläre Entzündung}

Die Aufregulation dieses Histokompatibilitätskomplexes weist eine Antigen spezifische TZell-mediierte Zytotoxizität nach. Diese gilt als notwendig für die Diagnose einer inflammatorischen Myositis (Appleyard et al. 1985), mit Ausnahme der nekrotisierenden 
Myopathie. An gesunden Muskelfasern kann der Komplex nicht dargestellt werden. Bei der juvenilen Dermatomyositis wurde der Marker als früher und später Marker unabhängig von der Glukokortikoid-Therapie, dem Grad der Inflammation oder der Erkrankungsdauer beschrieben (Sallum et al. 2009). In der adulten Dermatomyositis wird die Expression von MHC-I typischerweise perifaszikulär geschildert (Shinjo et al. 2012). Eine Aufregulation von MHC-I sah man auch an Blutgefäßen (Emslie-Smith et al. 1989; Prabowo et al. 2013). In dieser Arbeit wurde der Marker als Standardmarker für muskuläre Entzündung herangezogen.

\subsection{Kapillarmikroskopie bei Myositiden}

Die Kapillarmikroskopie stellt ein bildgebendes, nicht invasives Verfahren zur Analyse der Mikrozirkulation auf Ebene kapillärer Gefäße dar. Historisch wird Johan Christophorus Kolhaus als derjenige benannt, der erstmals 1663 Blutgefäße mit einem primitiven Mikroskop beschrieb. Noch im 19. Jahrhundert wurden Vergrößerungsgläser genutzt, bevor durch technische Optimierung die heutigen digitalen Geräte mit Auswertungssystematik entwickelt wurden (Cutolo und Smith 2013; Souza und Kayser 2015). Technisch lassen sich Veränderungen der Kapillardichte und -morphologie sowie Blutflussveränderungen mittels assistierter Videotechnik nachweisen (Sander et al. 2010). Dies ist am Übergang von Haut zu Nagel, d. h. von Dermis zu Epidermis, möglich, da hier die Kapillaren parallel zur Haut und nicht wie an den übrigen Stellen der Haut vertikal zur Dermis verlaufen. Dadurch können afferente und efferente Schenkel sowie Scheitel der Kapillaren dargestellt werden (Gerhold 2012). Ein Normalbefund mit haarnadelförmigen Kapillaren ist in Abbildung 2 dargestellt.

Die Kapillarmikroskopie dient neben der Differentialdiagnose von primärem und sekundärem Raynaud-Syndrom bei einer Reihe rheumatischer Erkrankungen zur Diagnoseund Verlaufskontrolle (Cutolo et al. 2006). Sie wird u. a. bei der Klassifikation der Sklerodermie-Muster in den Stadien früh-aktiv-spät angewendet (Gerhold 2012) und dem systemischen Lupus erythematodes, der rheumatoiden Arthritis oder der juvenilen sowie der adulten Dermatomyositis eingesetzt.

Letztere Erkrankung gilt als Komplement-assoziierte Mikroangiopathie und geht in der Kapillarmikroskopie typischerweise mit Kapillarreduktion, Verzweigungen bis hin zur Büschelkapillare, Elongation mit Ektasie des afferenten und efferenten Schenkels bis hin zur Megakapillare und Einblutungen einher (Gerhold 2012; Manfredi et al. 2015; Mercer et al. 2010). Gleiche Kapillarveränderungen wurden in geringerer Ausprägung auch für die TZell-mediierte Polymyositis beschrieben (Ganczarczyk et al. 1988; Mercer et al. 2010; Souza und Kayser 2015). Allerdings wird in erst kürzlich veröffentlichter Literatur eher Abstand von typischen kapillarmikroskopischen Veränderungen bei der Polymyositis genommen (Klein-Weigel et al. 2016; Manfredi et al. 2015). Auch bei der juvenilen Dermatomyositis sind pathologische Kapillarmuster beschrieben. Diese verhalten sich ähnlich den unter der 
adulten Dermatomyositis beschriebenen Veränderungen mit verminderter Kapillardichte, avaskulären Arealen, Ektasien, büschelartigen und Megakapillaren, Torquierungen sowie einem sklerodermieformen Muster (Gerhold 2012). Unter Therapie kann die Kapillardichte wieder zunehmen. Bei der nekrotisierenden Myopathie sind ebenfalls histologisch Komplementablagerungen an Gefäßen beschrieben (Cong et al. 2014), so dass auch hier eine Mikroangiopathie im Pathogeneseprozess vermutet werden kann. Fallberichte oder Studien, in denen diese Patienten gezielt kapillarmikroskopisch untersucht wurden, gibt es bisher nicht.

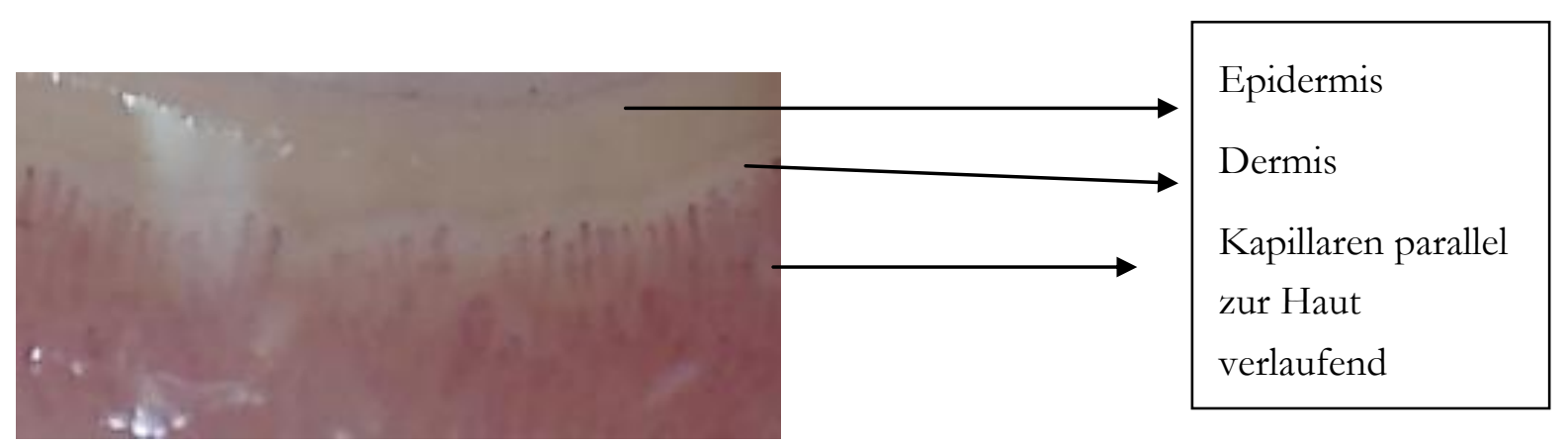

Abbildung 2: Kapillarmikroskopie-Normalbefund, haarnadelförmige Kapillaren, normale Kapillardichte, nur vereinzelte Torquierungen

\section{$1.8 \quad$ Zielsetzung}

Ausgehend von der Annahme, dass Zellen des Autoimmunsystems von kleinsten Gefäßen der Muskulatur in den betroffenen Muskel migrieren, kann eine endotheliale Dysfunktion in den Krankheitsgruppen vermutet werden. Insbesondere bei der Dermatomyositis wird die Vermutung durch beschriebene destruierte Kapillaren mit Gefäßbettreduktion unterstützt (Dalakas 2015). Endotheliale Vorläuferzellen (EPCs) werden für die Neovaskularisation im Rahmen von Ischämien benötigt (Assmus et al. 2002; Cheng et al. 2013).

Ziel der Arbeit ist es, das Vorkommen und die funktionellen Veränderungen der EPCs im Vergleich zu relevanten Markern für Gefäße und Muskelfasern in Muskelbiopsien der einzelnen Krankheitsgruppen im Vergleich zu gesunden Kontrollpersonen zu analysieren. Darüber hinaus soll untersucht werden, ob eventuelle Abweichungen ggf. mit der vaskulären Pathologie bzw. einer veränderten muskulären Regeneration assoziiert sind. Dabei werden Begleitparameter wie Alter, medikamentöse Therapie und Kapillarmikroskopie analysiert. 


\section{Material und Methoden}

\subsection{Patientenkollektiv}

Sämtliche für die Untersuchung eingeschlossene Patienten wurden stationär oder ambulant in den drei Kliniken Nephrologie/Rheumatologie, Neurologie und Dermatologie der Universitätsmedizin Göttingen (UMG) behandelt. Der Einschluss von $\mathrm{n}=35$ Patienten und $n=40$ gesunden Probanden wurde im Zeitraum von 08/2013 bis einschließlich 11/2016 vorgenommen. Die Diagnosestellung der entsprechenden Myositisform erfolgte bei Patienten mit Muskelbiopsie ( $\mathrm{n}=27$ ) nach den ENMC-Kriterien durch die Kollegen der Neuropathologie, die entsprechende Muskelbiopsie-Schnittreihen als Kryoschnitte zur Verfügung stellten. Die übrigen Patienten $(\mathrm{n}=8)$ erhielten bereits externe Muskelbiopsien ( $\mathrm{n}=4$ ), interne Hautbiopsien ( $\mathrm{n}=3$ ) zur Diagnosesicherung oder wurden nach den von Bohan und Peter im Jahr 1975 entwickelten und durch Tanimoto et al. erweiterten Klassifikationskriterien zu den Myositisformen Dermato- oder Polymyositis ( $\mathrm{n}=1$ ) zugeordnet (Tanimoto et al. 1995). Zwei Patienten der Dermatomyositisgruppe mit Muskelbiopsie $(\mathrm{n}=2 / 10)$ hatten die Sonderform der adermatopathischen Dermatomyositis. Nach erfolgter Diagnosestellung und entsprechender mündlicher und schriftlicher Aufklärung sowie Aushändigung eines Patienteninformationsblattes über das geplante Prozedere wurde allen Teilnehmern $(\mathrm{n}=75)$, d. h. Patienten $(\mathrm{n}=35)$ und gesunden Probanden $(n=40)$, Vollblut in Lithium-Heparinröhrchen abgenommen. Weiterhin erhielten alle Patienten $(n=35)$ eine körperliche Untersuchung nach einem vorgefertigten Anamnesebogen und wurden, soweit einverstanden, einer Kapillarmikroskopie ( $\mathrm{n}=17$ ) unterzogen. Anschließend wurden die Personendaten anonymisiert. Die Kontrollgruppe bestand aus vierzig gesunden Probanden, die an keiner Muskelerkrankung litten und umfasste in etwa das gleiche Altersspektrum wie die Erkrankungsgruppen. Detaillierte Informationen und Zahlen zu Patienten, Labor, Paraneoplasien und Antikörperprofil zum Diagnosezeitpunkt lassen sich Tabelle 15 in Abschnitt 3.1 entnehmen. Da in die Datensammlung vor allem auch bereits diagnostizierte Patienten eingeschlossen wurden, beziehen sich die Informationen zur immunsuppressiven Therapie und der Krankheitsausprägung auf den Zeitpunkt der Patientenkonsultation. Die Schwere der Muskelschwäche der Extremitätenmuskulatur (axial, proximal und distal) als $\mathrm{Maß}$ für die Intensität der Erkrankung wurde in die Kraftgrade Null bis Fünf unterteilt. Diese Einteilung des semiquantitativen Messverfahrens nach Janda entspricht den in der Tabelle 4 dargestellten Muskelkraftausprägungen.

Die Studie erfolgte entsprechend den ethischen Vorgaben der Deklaration von Helsinki. Die dafür benötigten Ethikanträge lagen mit den Nummern 17/2/08 und 30/9/05 zur Bearbeitung der genannten Materialien vor. 
Tabelle 4: Kraftgrade nach Janda (Janda 1983)

\begin{tabular}{ccl}
\hline Kraftgrad & Muskelkraft & \multicolumn{1}{c}{ Beschreibung } \\
\hline $5 / 5$ & $100 \%$ & Volle Kraft gegen Widerstand \\
$4 / 5$ & $75 \%$ & Kraft gegen leichten Widerstand \\
$3 / 5$ & $50 \%$ & Bewegung entgegen der Schwerkraft \\
$2 / 5$ & $25 \%$ & Bewegung parallel zur Schwerkraft \\
$1 / 5$ & $10 \%$ & Muskelaktivität fühlbar \\
$0 / 5$ & $0 \%$ & Keine Muskelkraft \\
\hline
\end{tabular}

\subsubsection{Erweitertes Patientenkollektiv}

Die Patienten der Kontrollgruppe mit Muskelbiopsie $(n=5)$ werden in Tabelle 5 nochmals charakterisiert:

Tabelle 5: Symptome und Diagnosen der Biopsie-Kontrollgruppe

\begin{tabular}{|c|c|c|c|}
\hline Patient & Geschlecht & Initiale Symptome vor Muskelbiopsie & $\begin{array}{l}\text { Diagnose im } \\
\text { Verlauf }\end{array}$ \\
\hline 1 & W & $\begin{array}{l}\text { Muskelschmerz, Schwere der Beine nach } \\
\text { Belastung, diffuse Gelenkschmerzen }\end{array}$ & $\begin{array}{l}\text { Rheumatoide } \\
\text { Arthritis }\end{array}$ \\
\hline 2 & M & $\begin{array}{l}\text { Kraftlosigkeit Muskulatur, schnelle } \\
\text { Ermüdbarkeit dieser }\end{array}$ & Myasthenia gravis \\
\hline 3 & W & Tremor unklarer Genese & $\begin{array}{l}\text { Idiopathischer } \\
\text { Tremor }\end{array}$ \\
\hline 4 & M & $\begin{array}{l}\text { Muskelschmerz und Muskelschwäche nach } \\
\text { EBV-Infektion }\end{array}$ & $\begin{array}{l}\text { Ausschluss Myositis, } \\
\text { intraspinales } \\
\text { Neurinom }\end{array}$ \\
\hline 5 & M & $\begin{array}{l}\text { Muskelschmerz, unk. Lymphadenopathie, sIL2- } \\
\text { Erhöhung }\end{array}$ & $\begin{array}{l}\text { Sarkoidose ohne } \\
\text { Muskelbeteiligung }\end{array}$ \\
\hline
\end{tabular}

\subsection{EPCs}

\subsubsection{Geräte und Chemikalien für EPC-Bestimmung}

Die Geräte und Chemikalien für die Bestimmung der EPCs sind in Tabelle 6 und Tabelle 7 dargestellt. 
Tabelle 6: Geräte

\begin{tabular}{cc}
\hline Gerät & Typ, Hersteller \\
\hline Sentrifuge & Biohazard \\
\hline Vortex Genie 2 & Beckmann Coulter, Allegra TM X-RR, Serien- \\
Nr. ALV 06 K32 \\
Mikroskop: Diavert & Bodo Schmidt GmbH \\
Zell-Zähler & Leica Microsystems - Nr. 985923 \\
Neubauer Zählkammer & IVO \\
Brutschrank & Brand \\
FACS-Calibur & Sanyo, W. Kranich GmbH + Co K.G. \\
Fluoreszenzmikroskop IX-71 & Becton Dickinson GmbH \\
iCys Laser Scanning Cytometer & Olympus Deutschland \\
Kühlschrank & Olympus IX71, Software: iCys 3.4.12.92 \\
Gefrierschrank & Liebherr \\
CO2 Incubator (Wärmeschrank) & Sanyo \\
Eppendorf - Pipetten & Sanyo \\
\hline
\end{tabular}

Tabelle 7: Chemikalien

\begin{tabular}{ccc}
\hline Substanz & Hersteller & Katalognummer \\
\hline Biocoll 1,0777 g/ml & Biochrom AG & L6115 \\
Endocult Basal Medium & Stem Cell Technologies Inc & 05901 \\
Endocult Supplement & Stem Cell Technologies Inc & 05902 \\
PBS pH 7,4 & GIBCO & $10010-15$ \\
Fibronektin & Sigma & V0132 50UG \\
Lectin Ulexeuropaeus & Sigma Aldrich & L-9006-1MG \\
BSA pH 7,0 & Lab Clinics SA & K41-001 \\
FcR Blocking Reagent & Miltenyl Biotec & $120-000-442$ \\
Paraformaldehyd 4 \% & Roth & 7398.1 \\
\hline
\end{tabular}




\subsubsection{Antikörper für EPC-Bestimmung}

Die für die EPC-Bestimmung verwendeten Antikörper sind in Tabelle 8 aufgelistet.

Tabelle 8: Antikörper zur Detektion früher EPC-Marker

\begin{tabular}{ccc}
\hline Antikörper & Hersteller & Katalognummer \\
\hline IgG1-FITC/IgG2a PE & Beckman Coulter & PN A10974 \\
c-KIT (Ab81), mit Alexa Fluor & Cell Signaling Best & 3310-S \\
FITC konjugiert & & \\
Sekundär PE-Antikörper goat & Jackson Immuno Research & $111-116-114$ \\
anti rabbit & R\&D Systems & FAB 357F \\
FLK = mouse anti human & & \\
VEGFR-2 / KDR, IgG & & \\
fluoreszenzmarkiert & abcam & Ab16518 \\
Anti CD133 rabbit & EMELCA (Für 10 Kontrollpatienten) & MBS462020
\end{tabular}

Für die zytometrische Bestimmung sind c-KIT und VEGFR-2 direkt FITC markiert. Nur der CD133-Antikörper wird mit dem PE-Antikörper sekundär markiert.

\subsubsection{Antikörper für SMA-/S100-Bestimmung}

Für die SMA- und S100-Bestimmung wurden die in Tabelle 9 genannten Antikörper genutzt.

Tabelle 9: Antikörper für SMA-/S100-Bestimmung

\begin{tabular}{cc}
\hline Antikörper & Hersteller/Katalognummer \\
\hline Lectin von Ulexeuropaeus FITC conjugate & Sigma Aldrich Nr.: L9006-1mg \\
Anti CD31 antibody & (ab28364)-abcam \\
PE goat anti rabbit & Jackson Immuno Research-Code Nr.111-116- \\
& 144 \\
SMA: anti alpha smooth muscle Actin antibody, & abcam-ab32575 \\
rabbit & abcam-ab68124 \\
S100: anti S100A4 antibody, mouse & R\&D-Cat. NL493 \\
Nothern lights anti rabbit & R\&D-Cat. NL637 \\
Nothern lights anti mouse & MoBiTec-Nr. D1306 \\
DAPI &
\end{tabular}




\subsubsection{Verbrauchsmaterialien für EPC-Bestimmung}

Die verwendeten Verbrauchsmaterialen sind in Tabelle 10 aufgeführt.

Tabelle 10: Verbrauchsmaterialien

\begin{tabular}{cc}
\hline Material & Hersteller \\
\hline Pipetten-Spitzen & Eppendorf AG \\
$50 \mathrm{ml}$ Röhren & Sarstedt AG \& Co \\
\hline $5 \mathrm{ml}$ Röhren für Durchflusszytometrie & Sarstedt AG \& Co \\
E-Cups $1,5 \mathrm{ml}$ & Eppendorf AG \\
24-Well Cell Culture Plate & CELLSTAR \\
Multiwell TM 6 well & FALCON \\
\hline Eppendorf-Röhrchen $1,5 \mathrm{ml}$ & Eppendorf AG \\
\hline
\end{tabular}

\subsection{Methodik: Bestimmung endothelialer Vorläuferzellen}

\subsubsection{EPC-Gewinnung aus heparinisiertem Blut}

An der Studie nahmen insgesamt 35 Patienten und 40 gesunde Probanden teil. Von den insgesamt vierzig gesunden Probanden erhielten dabei sechsunddreißig Patienten neben einer Messung der peripher zirkulierenden EPCs auch eine Koloniezell-Züchtung. Alle Probanden und Patienten erhielten vor Blutentnahme eine Patientenaufklärung mit anschließender Punktion einer peripheren Vene. Aus dieser wurde Vollblut in drei LithiumHeparinröhrchen mit je $3 \mathrm{ml}$ Blut entnommen, um eine frühzeitige Gerinnung des Blutes zu vermeiden. Die gesunde Kontrollgruppe bestand aus vierzig freiwilligen Patienten, die übrigen verteilten sich entsprechend des unter 2.1 aufgeführten Patientenkollektivs. Das Blut wurde sofort oder nur wenige Stunden nach Entnahme verarbeitet.

Die Zellisolierung erfolgte unter der Sterilbank bei Raumtemperatur. Im Protokoll wurde wie folgt vorgegangen:

Zunächst wurde Biocoll mit 5-9 ml Blut im Verhältnis 1:2 langsam überschichtet. Das Biocoll dient als Dichtegradient während der Zentrifugation, da dieses für einzelne schwere Blutbestandteile wie Erythrozyten durchlässig ist, für andere leichtere wie die Lymphozyten und Monozyten nicht. In der Population aus monozytären Zellen befinden sich die endothelialen Vorläuferzellen. Anschließend erfolgte die Dichtegradientenzentrifugation bei 1400 Umdrehungen pro Minute ohne Bremse über insgesamt $30 \mathrm{~min}$.

Nach der Zentrifugation des in Absatz zwei mit Blut versetzten Biocolls konnten die monozytären Zellen (MNCs) gewonnen werden. Diese befinden sich in der Interphase auf 
dem Biocoll. Die Auftrennung der Blutbestandteile lässt sich wie in Abbildung 3 gezeigt, darstellen:

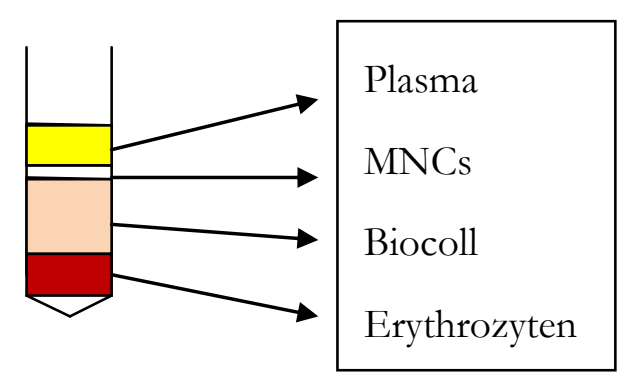

Abbildung 3: Dichtegradientenzentrifugation, die Blutbestandteile trennen sich in Erythrozyten (unten), Biocoll, monozytäre Zellen (Mitte) und Plasma (oben)

Das Plasma wurde nach Zentrifugation zunächst mit einer Pipette abgenommen und durchschnittlich $2 \mathrm{ml}$ in ein E-cup gefüllt und für eine ELISA-Messung bei $-20{ }^{\circ} \mathrm{C}$ tiefgefroren.

Die MNCs wurden anschließend vorsichtig abpipettiert, mit $50 \mathrm{ml}$ PBS als Puffer gewaschen und erneut bei 1400 Umdrehungen pro Minute und bei $4{ }^{\circ} \mathrm{C}$ mit Bremse zentrifugiert. Der Überstand wurde verworfen, die Zellen am Vortex gemischt und daraufhin mit $50 \mathrm{ml}$ PBS erneut in Suspension gebracht. Für die anschließende Zellzählung wurden $10 \mu \mathrm{l}$ entnommen.

Die Zellzählung erfolgte in der Neubauer Zählkammer indem die entnommenen $10 \mu \mathrm{l}$ durch Ansetzen der Pipettenspitze an die Kante zwischen Deckblatt und Zählkammer pipettiert wurden. Dann wurden die Zellen unter dem Mikroskop der Firma Leica in 125facher Vergrößerung pro Quadrant ausgezählt. Die Zellzahl konnte nach folgender schematischer Berechnung ermittelt werden:

- Berechnung des Mittelwertes der Zellzahl pro Quadrat nach Auszählen der Zellen in den 4 Quadranten der Neubauer Zählkammer, z. B. 40 Zellen

- Anhand der Zellgeometrien (Seitenlängen je $1 \mathrm{~mm}$, Höhe 0,1 mm) lässt sich folgende Zelldichte aus dem Beispiel ableiten: 40 Zellen in einem Volumen von $0,1 \mu \mathrm{l}$

- diese entsprechen 400 Zellen pro $1 \mu \mathrm{l}$

- auf die ursprünglich gelösten $50 \mathrm{ml}$ beträgt die Zellmenge dann 2 x $10^{7}$ Zellen

Die $50 \mathrm{ml}$ Zellsuspension in PBS wurde anschließend auf zwei Röhrchen aufgeteilt und diese erneut bei 1400 Umdrehungen pro Minute über insgesamt 5 min mit Bremse zentrifugiert. Der Überstand wurde wiederum verworfen, so dass nun zwei Reagenzgläser mit berechneter Zellzahl von $2 \times 10^{7}$ Zellen vorlagen, die zum einen für die Kolonisierung auf Fibronektin verwendet werden konnten, zum anderen zur quantitativen durchflusszytometrischen Messung genutzt wurden. 


\subsubsection{Durchflusszytometrie und Aufbereitung der Zellen}

Das erste Reagenzglas mit berechneter Zellzahl wurde zur Aufbereitung und Messung der endothelialen Vorläuferzellen via Durchflusszytometrie verwendet. Für diese Messung wurden fünf FACS-Röhrchen mit jeweils 1,5 x $10^{6}$ Zellen/100 $\mu$ l benötigt. Anhand des Beispiels mit $2 \times 10^{7}$ Zellen musste wie folgt mit 1\%ig PBS/BSA aufgefüllt werden:

$$
\begin{aligned}
\frac{x}{2 \times 10^{7}} & =\frac{100 \mu \mathrm{l}}{1,5 \times 10^{6}} \\
x & =1,3 \mathrm{ml}
\end{aligned}
$$

Insgesamt wurden fünf Versuchsansätze vorbereitet, die allesamt parallel weiter verarbeitet wurden:

1. Leerprobe für ungefärbte Zellen

2. Probe für Sekundärantikörper 1 zur Isotyp-Kontrolle (sekundär PE und IgG-FITC)

3. Probe für Sekundärantikörper 2 (sekundär PE)

4. Probe für 1. Primär- mit einem Sekundärantikörper-Antikörper gegen CD 133 und VEGFR-2

5. Probe für 2. Primär- und Sekundärantikörper-Antikörper gegen CD 133 und c-KIT Entsprechend wurden in die fünf 1,5 ml großen Eppendorf Glasröhrchen je $100 \mu \mathrm{l}$ der zuvor hergestellten Suspension, aus unserem Beispiel mit 1,3 ml, abpipettiert. Sämtliche Schritte fanden auf Eis in einer Styroporbox sowie nach Zugabe der Sekundärantikörper im Dunkeln statt.

Es folgte für alle fünf Versuchsansätze zunächst die FcR-Blockung durch Verabreichen von $1 \mu \mathrm{l} \mathrm{FcR} \mathrm{„Blocking} \mathrm{Reagent“} \mathrm{um} \mathrm{unspezifische} \mathrm{Bindungen} \mathrm{abzufangen.} \mathrm{Anschließend}$ erfolgte eine zehn minütige Inkubationszeit bei $4{ }^{\circ} \mathrm{C}$ bevor die Zellsuspension mit $2 \mathrm{ml}$ PBS-BSA $1 \%$ gewaschen wurde. Dafür wurden die Röhrchen bei 1400 Umdrehungen pro Minute für fünf Minuten zentrifugiert, danach der Überstand verworfen. Das Pellet wurde anschließend am Vortex gemischt.

Die Endothelzellen wurden via Primär-Antikörper detektiert. Dafür wurden die Ansätze 4. mit CD133/VEGFR-2- und 5. mit CD133/c-KIT-Primär-Antikörpern versetzt. Das Mischverhältnis lag für $100 \mu \mathrm{l}$ CD133-Antikörper bei 1:100. Dieser Antikörper war nicht sekundär markiert. Weiterhin wurden $3 \mu \mathrm{l}$ VEGFR-2 in Ansatz 4. sowie $2 \mu \mathrm{l} \mathrm{c-KIT} \mathrm{unter}$ Ansatz 5. benötigt. VEGFR-2 ist bei einer Wellenlänge von $488 \mathrm{~nm}$ IgGfluoreszenzmarkiert, c-KIT ist mit Alexa Fluor ebenfalls bei $488 \mathrm{~nm}$ konjugiert.

Es folgten nun eine dreißig minütige Inkubation bei $4{ }^{\circ} \mathrm{C}$, waschen für alle fünf Versuchsansätze mit $2 \mathrm{ml}$ PBS-BSA 1\% sowie eine Zentrifugation für fünf Minuten bei 1400 Umdrehungen pro Minute. Der Überstand wurde entsprechend verworfen. 
Als Sekundär-Antikörper wurde den Ansätzen 3., 4. und 5. jeweils $1 \mu l$ PE-konjugiertesZiege anti Kaninchen-Fab hinzugegeben. Für den 2. Ansatz wurde die Probe mit $1 \mu \mathrm{l}$ unspezifisch bindenden Antikörpern auf IgG-FITC und IgG2a-PE versetzt um unspezifische Bindungen zu detektieren. Es folgte eine Inkubation bei $4{ }^{\circ} \mathrm{C}$ über zehn Minuten im Dunkeln.

Danach erfolgte für alle Ansätze ein zweimaliges Waschen mit $2 \mathrm{ml}$ PBS. Nach erneuter Zentrifugation bei 1400 Umdrehungen für fünf Minuten und Verwerfen des Überstandes wurden alle 5 Eppendorf Röhrchen mit $500 \mu$ l PBS-BSA aufgefüllt. In dieser Form wurden sie im FACS Gerät gemessen.

\subsubsection{Durchflusszytometrische Messung der EPCs}

Die Durchflusszytometrie, häufig auch synonym FACS genannt, ermöglicht es Oberflächenmoleküle von DNA, Peptiden oder Proteinen zu bestimmen. In der folgenden Messung wurden die Oberflächenmoleküle CD133 als frühen Marker für angiopoetische Vorläuferzellen und VEGFR-2, häufig auch durch FLK oder KDR beschrieben, bestimmt. Auch letzteres Oberflächenmolekül ist charakteristisch für frühe Formen endothelialer Vorläuferzellen. Als Unterform wurde zudem c-KIT als Oberflächenmolekül hämatopoetischer Vorläuferzellen nachgewiesen.

Die Messung der in 2.3.2 aufbereiteten Zellen erfolgte im FACS-Calibur Zytometer nach Hersteller-Angaben. Dieses Zytometer besitzt einen Argon Laser für grün bei $488 \mathrm{~nm}$ und einen Dioden Laser für rot bei $635 \mathrm{~nm}$. Anhand von morphologischen Eigenschaften der Zellen, deren quantitativen Nachweis und Fluoreszenzmarkierung konnten die Zellen auf CD133 (rot), VEGFR-2 (grün) und c-KIT (grün) hin untersucht werden. Bei dem Vorgang wird die aufbereitete Lösung durch eine Kapillare in die Durchflussmesszelle gezogen. Über eine Lichtquelle in Form von Lasern kann Fluoreszenzlicht erzeugt werden, das durch Detektoren zum einen auf Vorwärtsstreulicht (FSC) und Seitwärtsstreulich (SSC) hin untersucht wird. Vorwärtsstreulicht gilt hier als Maß für das Volumen bzw. die Größe der Zelle, das Seitwärtsstreulicht als Maß für die Granularität und Zellkomplexität der Zelle. Zum anderen wird Fluoreszenzlicht detektiert. Je nach gewähltem Fluoreszenzantikörper wird Licht einer bestimmten Wellenlänge emittiert und lässt damit Rückschlüsse auf die gesuchte Eigenschaft zu.

Zur Detektion der EPCs musste zunächst, wie in Abbildung 4 dargestellt, ein Gating auf die Population der monozytären Zellen vorgenommen werden, da in diesen die endothelialen Vorläuferzellen erwartet und eine genauere Analyse der dortigen Zellen durchgeführt werden konnte. Dafür wurde der Ansatz 1. mit den ungefärbten Zellen verwendet. Die Zellen wurden anhand ihrer Größe (FSC) und Granulation (SSC) detektiert. 


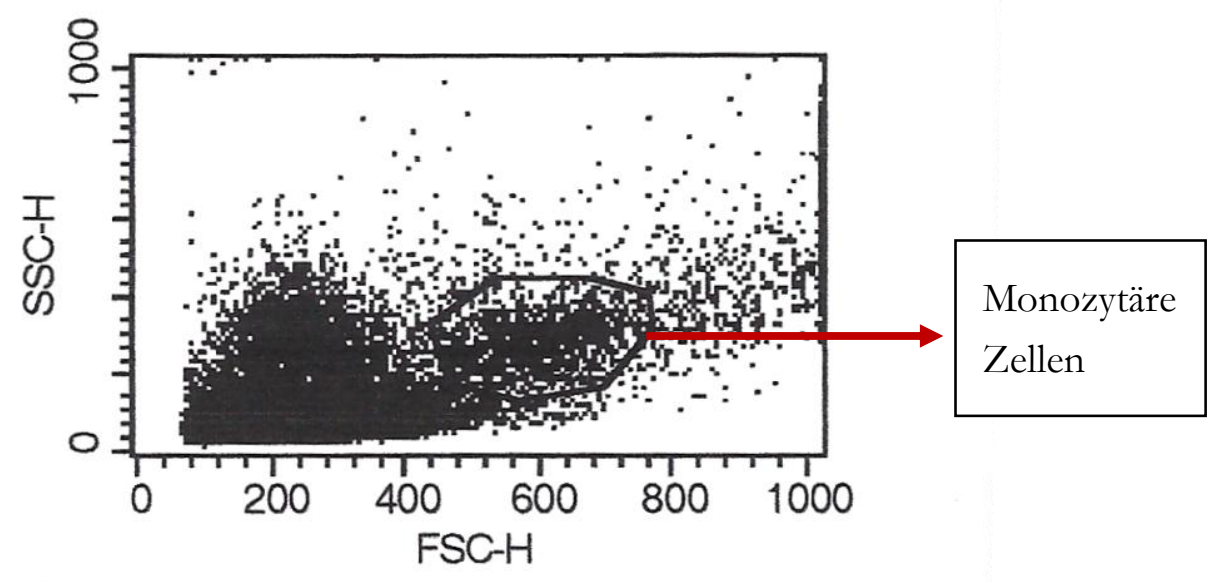

Abbildung 4: Dotplot-Analysefenster auf monozytäre Zellpopulation - "Gating" - durch Auftragung der jeweiligen Intensitäten auf der x-Achse (FSC) und y-Achse (SSC). Die umkreiste Region beinhaltet die gesuchte Zellpopulation.

Es folgte die Quantifizierung der umkreisten Zellen. Dabei wurden diese auf doppelt positive Fluoreszenz-gefärbte CD133-/VEGFR-2- und CD133-/c-KIT-Zellen in den Ansätzen 4. und 5. untersucht. Nach Ermittlung der Ergebnisse der jeweiligen Messansätze wurden die falsch positiven Zellen, die über die Isotypkontrolle - zur Detektion von unspezifischen Bindungen, unter Ansatz 2. und die Sekundärantikörperkontrolle, unter Ansatz 3., ermittelt wurden, von den doppelt positiven CD133-/VEGFR-2- und CD133/c-KIT-Zellen, abgezogen.

In Abbildung 5, Abbildung 6 und Abbildung 7 ist dargestellt wie die Berechnung der unter Abbildung 4 markierten monozytären Zellen im Einzelnen verlief. Die Darstellung erfolgte dabei in Form von Vier-Quadranten-Tafeln. Der untere linke Quadrant (LL) stellt dabei die doppelt negativen Zellen für zwei Fluoreszenzmarker dar. Der obere linke Quadrant (UL) und der untere rechte Quadrant (LR) enthalten die einfach positiven Fluoreszenz markierten Oberflächenmarker. Im oberen rechten Quadranten (UR) befinden sich schließlich doppelt positive Zellen. 


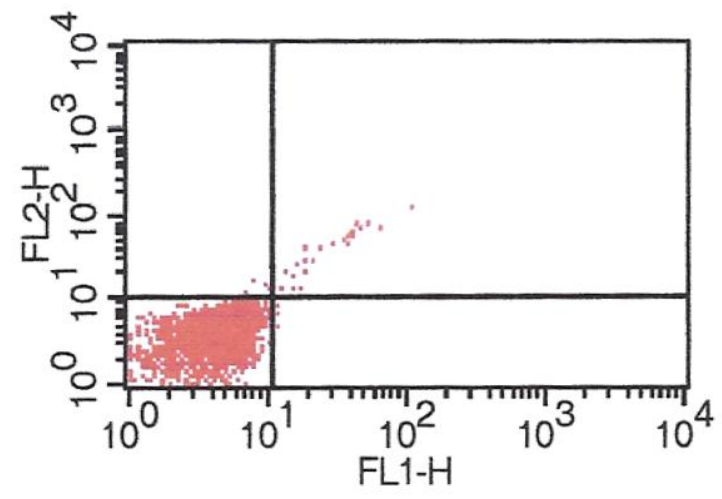

\begin{tabular}{|l|l|}
\hline Quadrant & Zellzahl „Gate“ $\%$ \\
\hline UL & 0,43 \\
\hline UR & 0,89 \\
\hline LL & 98,51 \\
\hline LR & 0,17 \\
\hline
\end{tabular}

Abbildung 5: Isotyp-Kontrolle zur Berechnung VEGFR-2-positiver Zellen

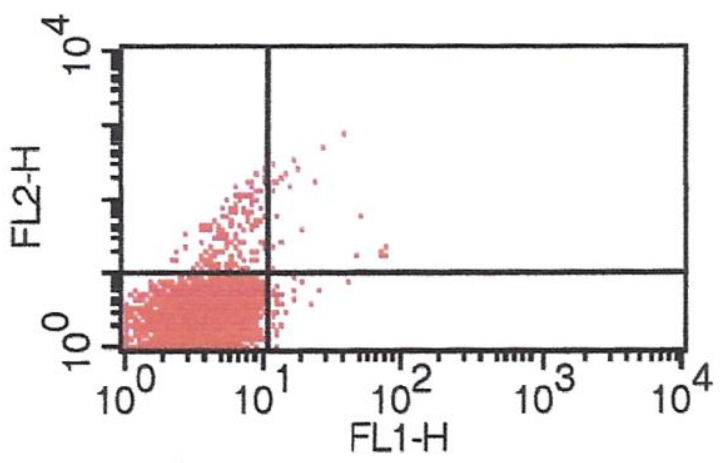

\begin{tabular}{|l|l|}
\hline Quadrant & Zellzahl „Gate“ \% \\
\hline UL & 2,43 \\
\hline UR & 0,42 \\
\hline LL & 96,52 \\
\hline LR & 0,62 \\
\hline
\end{tabular}

Abbildung 6: Sek PE-Kontrolle

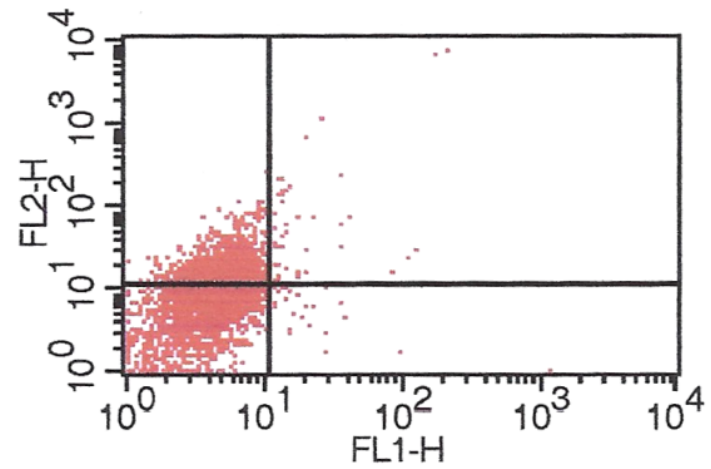

\begin{tabular}{|l|l|}
\hline Quadrant & Zellzahl „Gate“ \% \\
\hline UL & 48,4 \\
\hline UR & 0,99 \\
\hline LL & 50,14 \\
\hline LR & 0,47 \\
\hline
\end{tabular}

Abbildung 7: CD133-/VEGFR-2-positive Zellen 
Die Berechnung für CD133, VEGFR-2 und doppelt positiven Zellen erfolgte wie folgt:

CD133 $^{+} \quad=\mathrm{UL}(\mathrm{CD} 133 / \mathrm{VEGFR}-2)-\mathrm{UL}($ Sek PE)

(sek PE markiert) $\quad=48,4 \%-2,43 \%$

$$
=45,97 \%
$$

VEGFR-2 $^{+} \quad$ = LR (CD133/VEGFR2) - LR (Isotyp-Kontrolle)

(FITC-markiert) $\quad=0,47 \%-0,17 \%$

$$
=0,3 \%
$$

CD133 $^{+} /$VEGFR-2 $^{+}=\mathrm{UR}(\mathrm{CD} 133 /$ VEGFR-2) - UR $($ Sek PE)

$$
\begin{aligned}
& =0,99 \%-0,42 \% \\
& =0,57 \%
\end{aligned}
$$

Die hier berechneten peripher zirkulierenden endothelialen Vorläuferzellen wurden in Prozent angegeben und mit dem Statistik-Programm „R“ auf Signifikanzen hin ausgewertet.

\subsubsection{EPC-Proliferationsmessung durch Kolonie-Zählung}

Für diesen Arbeitsschritt benötigte man Kulturplatten. Eine 6-Well FALCON Platte wurde dafür mit je 1,5 ml einer Fibronektin - Lösung (1 $\mu \mathrm{g} / \mathrm{ml})$ pro benötigtem Well gefüllt und diese mindestens eine Stunde inkubiert. Weiterhin wurde eine 24-Well Platte nach gleichem Schema vorbereitet wobei hier zudem drei bis vier Glasplättchen mit $60 \mu$ l Fibronektin beschichtet wurden.

Das zweite Reagenzglas mit berechneter Zellzahl aus 2.3.1 sollte nun mit Kulturmedium in Resuspension gebracht werden. Dabei sollte ein Volumen mit der angestrebten Dichte von $5 \times 10^{6} \mathrm{MNCs} / 2 \mathrm{ml}$ vorliegen. Nach dem in 2.3.1 beschrieben Beispiel von 2x10 Zellen nach Zellzählung musste nun wie folgt für eine Verdünnung vorgegangen werden:

$$
\begin{aligned}
\frac{x}{2 \times 10^{7}} & =\frac{2 \mathrm{ml}}{5 \times 10^{6}} \\
x & =8 \mathrm{ml}
\end{aligned}
$$

Von diesen $8 \mathrm{ml}$ mit einer Zellzahl von $5 \times 10^{6} \mathrm{MNCs} / \mathrm{ml}$ wurden nun pro vorbereiteten Well, in der mit Fibronektin beschichteten 6-Well Platte, $2 \mathrm{ml}$ abpipettiert. Das oben genannte Kulturmedium setzt sich aus EndoCult Basal Medium ${ }^{\circledR}$ und EndoCultsupplements ${ }^{\circledR}$ zusammen und wird nach Mischung als EndoCult Liquid Medium ${ }^{\circledR}$ bezeichnet. Die in den Wells befindliche Suspension wurde bei $37{ }^{\circ} \mathrm{C}$ in $5 \%$ $\mathrm{CO}_{2}$ inkubiert. 
Nach einem Zeitraum von $48 \mathrm{~h}$ wurden nicht adhärente Zellen, die den endothelialen Vorläuferzellen entsprechen, abgenommen und der Überstand in die 24-Well-Platte übertragen und bei $37{ }^{\circ} \mathrm{C}$ über vier Tage kultiviert. Dabei musste das erste Well der 6-WellPlatte in das erste Well der 24-Well Platte pipettiert werden, um die berechnete Zellzahl beizubehalten. Die verbleibenden Wells der 6-Well-Platte konnten auf die übrigen Wells der 24-Well-Platte verteilt werden, wie Abbildung 8 zeigt.

\section{Glasplättchen}

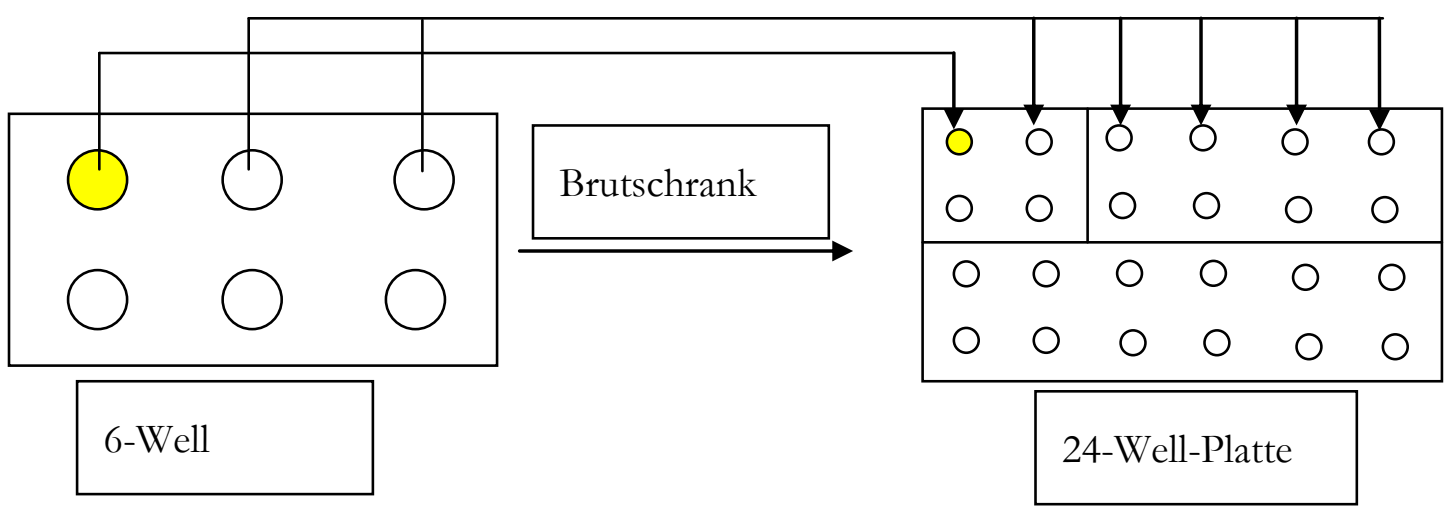

Abbildung 8: Darstellung des Übertrags nicht adhärenter Zellen der 6-Well-Platte in die 24-Well-Platte

Die darin ausgereiften Zellen stellen sich in Form von Kolonien dar. Diese zeigen sich typischerweise nach sechs Tagen durch im Zentrum angelagerte kugelförmige Zellen mit am Rand befindlichen lanzettförmigen Zellen, die dann am Leica-Mikroskop ausgezählt und schließlich dokumentiert wurden. Als Kolonie galt eine Mindestanzahl von zwanzig kugelförmigen Zellen im Zentrum mit lanzettförmigen angelagerten Zellen im Randbereich. Beispiele für solche Kolonien finden sich in Abbildung 9. Die mit Kolonien beschichteten Glas-Slides wurden bei $-20{ }^{\circ} \mathrm{C}$ Aceton-fixiert gelagert. 

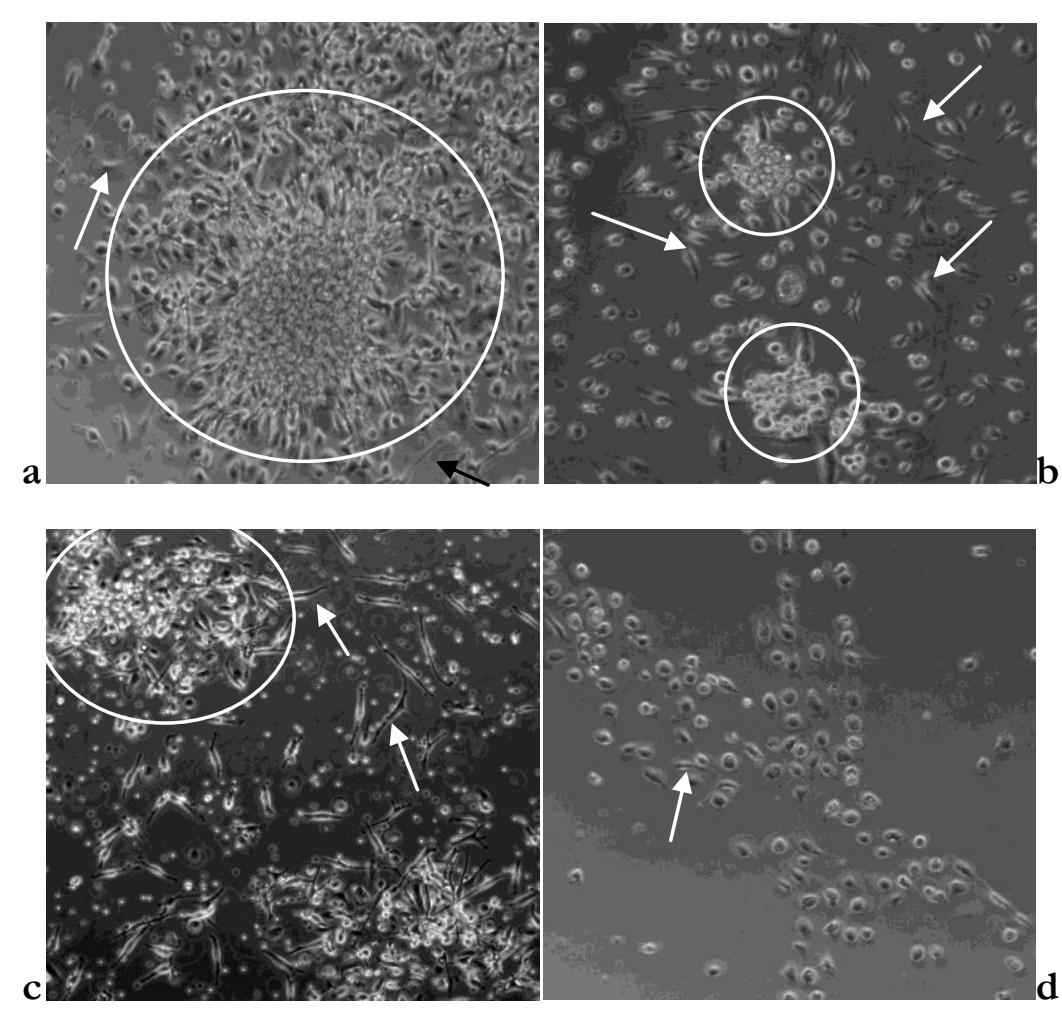

Abbildung 9: Darstellung der Kolonien in Abb 9 a-c (Kreise) Tag 5 mit lanzettförmigen Zellen in der Peripherie (Pfeile) und kugelförmigen Zellen im Zentrum; d: Kapillarisierung Tag 9

\subsubsection{Laser-Scanning Mikroskopie auf Gefäß- und EPC-Strukturproteine}

Zwei der Aceton-fixierten und tiefgefrorenen Glas-Slides aus der in 2.3.3 beschriebenen 24-Well-Platte wurden zunächst über zehn Minuten mit 1\%igem PBS-BSA versetzt. Danach wurde UEA-Lektin als Marker für humane Endothelzellen hinzugegeben. Das UEA-Lektin ist selbst über einen Sekundärantikörper FITC grün markiert bei $495 \mathrm{~nm}$. Die Slides wurden über zwei Stunden bei $37^{\circ} \mathrm{C}$ inkubiert und anschließend gewaschen.

Es folgte die dreißig minütige Inkubation mit anti CD31 als Marker für endotheliale Vorläuferzellen. Nach weiterem Waschen mit PBS wurde ein weiterer Sekundärantikörper PE anti Kaninchen über zehn Minuten hinzugegeben. Dieser wird bei $633 \mathrm{~nm}$ fluoreszenztechnisch gemessen.

Nach weiterem Waschen wurde permeabilisierendes Triton X 0,1\% hinzugegeben und die Slides erneut gewaschen. Schließlich wurde ein Slide mit SMA in der Verdünnung 1:100 als Antikörper gegen Aktinfasern - und das zweite Slide mit S100 in der Verdünnung 1:100, als Marker für das Zytoskelett und die Zelldifferenzierung, versetzt. Beide Primärantikörper inkubierten über Nacht, wurden anschließend mit PBS gewaschen und mittels zweistündiger Inkubation mit dem NL-Sekundärantikörper in der Verdünnung 1:500 fluoreszenztechnisch markiert. Beide Marker fluoreszieren im Spektrum für hoch-rot bei 
$637 \mathrm{~nm}$. Schließlich wurden Zellkerne mittels DAPI in einer Wellenlänge von $440 \mathrm{~nm}$ blau markiert.

Die Auswertung erfolgte im iCYS Laser-Scanning-Mikroskop, indem doppelt positive Zellen auf SMA/CD31 bzw. SMA/UEA-Lektin oder S100/CD31 bzw. S100/UEA-Lektin detektiert wurden. Die Ergebnisse wurden über die Cell-F Software visualisiert und berechnet. Die verwendeten Farbstoffe waren: Phycoerythrin für CD31 mit einem Wellenlängenspektrum zwischen 568-590 nm im roten Spektrum, weiterhin Lektin, das FITC-konjugiert bei $495 \mathrm{~nm}$ im grünen Wellenlängenspektrum lag und NL, das mit einer Wellenlänge von $637 \mathrm{~nm}$ für den hochroten Bereich, in dem SMA und S100 detektiert werden sollten, genutzt.

\subsubsection{ELISA aus Plasma}

In Abschnitt 2.3.1 wurde nach Zentrifugation des Patientenblutes der Überstand in Form von Plasma abpipettiert und eingefroren. Aus der vorhandenen Menge wurden, je nach Protokoll, 100 bis $200 \mu \mathrm{l}$ genutzt um das Plasma auf folgende angiogene Proteine hin zu untersuchen: Angiopoetin 1, CXCL16 und VEGF. Dabei wurden CXCL16 unter Abschnitt 1.4 und VEGF unter Abschnitt 1.3.2 kurz benannt und charakterisiert. Letzterer angiogener Faktor ist v.a. in die Mobilisierung hämatopoetischer Stamm- und Vorläuferzellen sowie VEGFR-2-positiver endothelialer Vorläufer involviert (Moore et al. 2001). Angiopoetin 1 spielt eine Rolle in Vaskulo- und Angiogenese. Es ist maßgeblich an der Reifung der Gefäße sowie Migration, Adhäsion und dem Überleben von endothelialen Zellen beteiligt (Fagiani und Christofori 2013).

Die Abkürzung ELISA steht für Enzyme-Linked Immunosorbent Assay und wird zur quantitativen und qualitativen Bestimmung von Antikörpern und Molekülen mit antigenen Eigenschaften herangezogen. Dabei genutzte Antikörper können gesuchte epitoptragende Antigene nachweisen (Hofmann 2006). Zur Detektion von Stimulations- und Wachstumsfaktoren wurde in dieser Arbeit der indirekte bzw. Sandwich-ELISA verwendet.

Dabei wird die Mikrotiterplatte mit einem Antikörper oder ein Antigen beschichtet. Enthält die zu untersuchende Probe entsprechende Antigene wie z. B. CXCL16 oder Angiopoetin 1 binden diese an den fixierten Antikörper. Die gebundenen AntigenAntikörper Komplexe werden auch durch Spülen oder Abwaschen nicht entfernt. Schließlich werden Antikörper-Enzym-Komplexe hinzugesetzt, die sich über den jeweiligen Antikörper an das Antigen binden, wobei die Konzentration der gebundenen Antigene der Menge an Antikörper-Enzymkomplexen entspricht (Bahadir et al. 2000). Als gekoppeltes Enzym wird z. B. ein Peroxid-gebundenes Substrat verwendet, das durch eine Peroxidase umgesetzt wird. Durch die chemische Reaktion kann ein darauf folgender Farbumschlag sichtbar werden. Kennt man die Aktivität der Peroxidase, kann man mittels Photometer die Farbbestimmung und damit die Konzentration der zu suchenden Substanz ermitteln (Bahadir et al. 2000). Anhand einer Verdünnungsreihe wie in Abbildung 10 aufgeführt, 
können ermittelte Fluoreszenzwerte anhand einer erstellten Standardkurve eingeordnet werden.

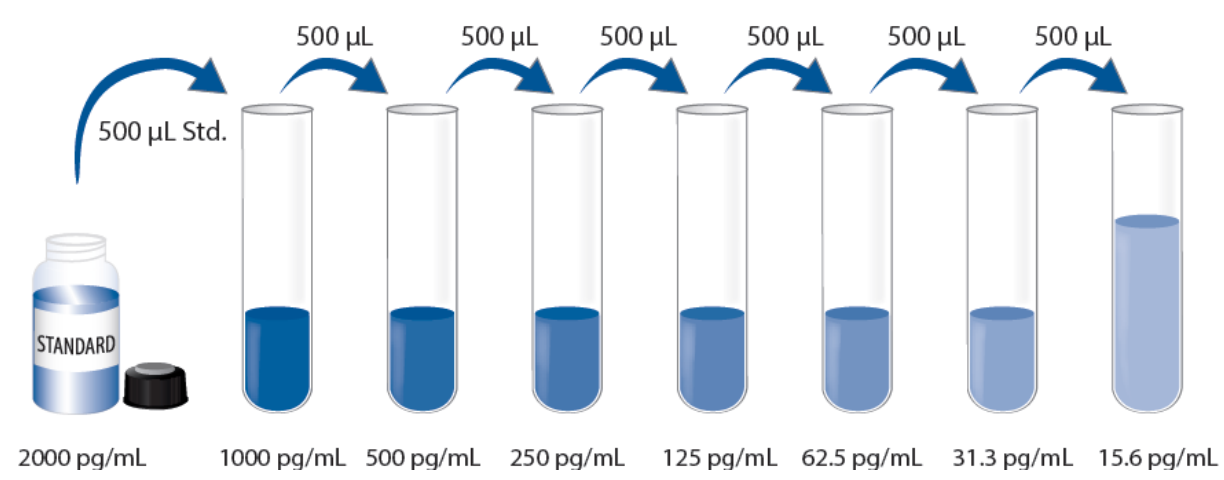

Abbildung 10: Verdünnungsreihe aus Tierserum mit Konservierungsstoff der Dichte 0 pg/ml mit humaner VEGF-Standard-Lösung der Dichte 2000 pg/ml nach dem Protokoll „Quantikine ELISA Human VEGF Immunoassay“.

Die genutzten Chemikalien und Antikörper sind in Tabelle 11 aufgeführt.

Tabelle 11: Immunoassays zur Bestimmung von Stimulations- und Wachstumsfaktoren

\begin{tabular}{ccc}
\hline Name & Hersteller & Katalognummer \\
\hline Angiopoetin 1 & $\begin{array}{c}\text { ELISA - KIT Firma R \& D } \\
\text { Systems }\end{array}$ & DANG10 540E \\
CXCL16 & ELISA - KIT Firma R \& D & DCX160 570E \\
& Systems & \\
VEGF & ELISA - KIT Firma R \& D \\
& Systems & \\
\hline
\end{tabular}

Folgende Verbrauchsmaterialien, Chemikalien und Geräte wurden, wie in Tabelle 12 aufgelistet, verwendet: 
Tabelle 12: Materialien, Chemikalien und Geräte zur Detektion von Stimulations- und Wachstumsfaktoren

\begin{tabular}{cc}
\hline Name & Hersteller \\
\hline Pipettenspitzen & Eppendorf \\
8-Kanal-Pipette & Eppendorf \\
Folie & Übliche Handelsfolie \\
Alufolie als Lichtschutz & Übliche Handels-Alufolie \\
ELISA Reader & Tecan \\
Schüttler Rotomax 120 & Heidolph \\
Microtiterplatten Reader & SPECTRA \\
\hline
\end{tabular}

Sämtliche ELISA Protokolle wurden entsprechend der Herstelleranleitung und dem zugehörigen ELISA-KIT durchgeführt. Die verschiedenen Protokolle unterschieden sich hinsichtlich Verdünnungsreihe, Anzahl der Waschungen und Inkubationszeiten. Bei VEGF wurde exemplarisch wie folgt vorgegangen:

30 min vor Beginn wurde das Plasma der Patienten aufgetaut. Zunächst erfolgte dann die Erstellung der Verdünnungsreihe nach Abbildung 10 um später eine Standardkurve der VEGF Menge pro Nanometer (nm) Peroxid-Farbumschlag zu ermitteln. Die Absorptionswerte der Verdünnungsreihe dienen als Referenzwert des zu untersuchenden Plasmas und haben zudem Kontrollcharakter, da sie einer Korrelation mit Ziel $r=0,99$ unterzogen werden. Anschließend wurde der 96-Mikrowellplatte mit beschichtetem primären VEGF Antikörper $100 \mu \mathrm{l}$ Puffer und anschließend $100 \mu \mathrm{l}$ des jeweiligen Plasmas hinzugeführt und dieses für zwei Stunden inkubiert. Danach erfolgten ein dreimaliger Waschgang sowie die anschließende zwei stündige Inkubation mit $200 \mu \mathrm{l}$ des humanen VEGF-Konjugates, einem humanen polyklonalen Antikörper gegen VEGF. Im Weiteren erfolgten erneut ein dreimaliger Waschgang und danach die Zugabe einer Substratmenge zum Farbumschlag, hier der Peroxidase. Die Mikrotiterplatte wurde dann für $25 \mathrm{~min}$ im Dunkeln inkubiert. Schließlich wurde Schwefelsäure zum Stoppen des chemischen Vorgangs hinzugefügt. Über einen Mikrotiterplatten-Reader wurde innerhalb von $30 \mathrm{~min}$ die optische Dichte bestimmt.

\subsection{Kapillarmikroskopie}

\subsubsection{Gerät und Materialien}

Zur Durchführung der Kapillarmikroskopie wurde das Digital-Kapillarmikroskop Di-Li 1100 mit 8 Zoll Monitor und 380-facher Vergrößerung verwendet. Weiterhin wurde zur 
Optimierung der Bildschärfe/-tiefe ein Tropfen eines handelsüblichen Öls pro Zeigefinger aufgetropft. Zur Dokumentation stand ein Bogen für kapillarmikroskopische Untersuchungen von O. Sander, C. Iking-Konert und B. Ostendorf zur Verfügung.

\subsubsection{Praktisches Vorgehen}

Pro Patient wurden die Digiti zwei bis fünf beider Hände unterhalb der Nagelpfalz der Lunula, am Übergang der Epidermis zur Dermis, wie in Abbildung 11 dargestellt, kapillarmikroskopiert. Es erfolgte zunächst die Ölimmersion an der jeweiligen Fingerstelle. Der Bereich wurde anschließend halbmondförmig zunächst makroskopisch und anschließend mikroskopisch auf etwaige Pathologien hin untersucht und dokumentiert. Dabei wurden die Dichte des Kapillarvorkommens, die Morphologie der Kapillaren, der Fluss des zirkulierenden Blutes und der Hintergrund auf mögliche Mikro- (Typ A) oder konfluierende (Typ B) Blutungen hin beschrieben. Anschließend erfolgte eine Reinigung der Hände.
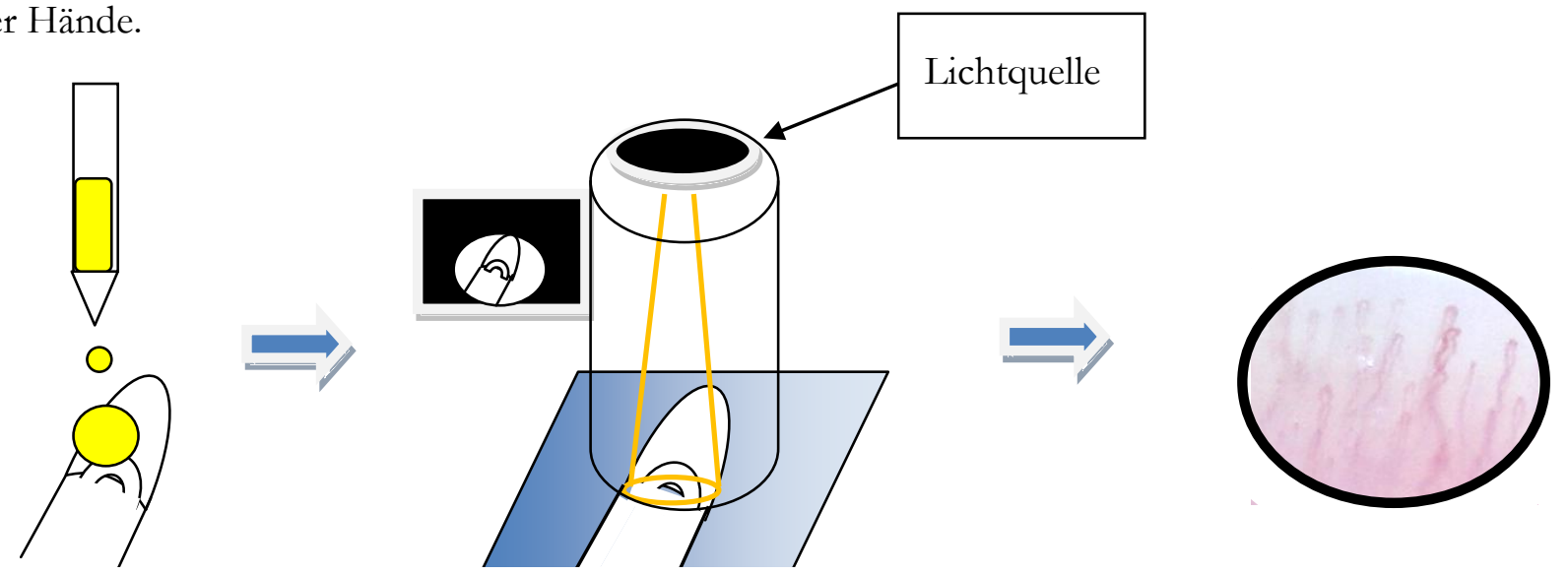

Abbildung 11: Vorgehen Kapillarmikroskopie

\subsection{Analyse von Muskel - Kryofaserschnitten}

\subsubsection{Geräte und Chemikalien für Muskelschnitt-Verarbeitung}

Für die Fluoreszenzmikroskopie der gefärbten Muskelfaserschnitte und Anfertigung der Fluoreszenzbilder wurde folgendes Gerät mit der Software Cell-D zur Bilderstellung verwendet:

Mikroskop: Carl Zeiss Axiovert S100 TV Inverted Microscope

Zur Anfertigung der Kryoschnitte wurde ein Leica Kryostat genutzt. Die angefertigten Kryoschnitte wurden dann auf Objekträgern tiefgefroren und zur weiteren Verarbeitung vorbereitet und im Gefrierschrank der Firma Sanyo bei minus $20^{\circ} \mathrm{C}$ gelagert.

Folgende Chemikalie wurde neben den in Tabelle 13 aufgeführten Antikörpern zur Bearbeitung der Muskelfaser-Kryoschnitte verwendet:

PBS mit pH 7,4 der Firma GIBCO mit der Herstellernummer: 10010-015. 


\subsubsection{Antikörper für Muskelbiopsiefärbung}

Tabelle 13: Zur Muskelfärbung genutzte Antikörper, $\mathrm{mk}=$ monoklonal, $\mathrm{pk}=$ polyklonal

\begin{tabular}{|c|c|c|}
\hline Primär-Antikörper & Spezies & Hersteller \\
\hline Anti Nestin antibody & Maus mk & Abcam-ab 6320 \\
\hline Anti CD31 antibody & Kaninchen pk & Abcam-ab 28364 \\
\hline Anti MHC class I antibody IgG & Ratte mk & AbdSerotec-MCA485G \\
\hline Anti CXCR6 (HU) & Maus mk & Dianova-CYT 74660 \\
\hline Anti CD4 & Kaninchen mk & Fa. Abcam-ab133616 \\
\hline Anti CD8 & Kaninchen pk & Fa.abcam-ab4055 \\
\hline \multicolumn{3}{|l|}{ Sekundär-Antikörper } \\
\hline $\begin{array}{c}\text { Nestin/CXCR6: Rot }=\text { goat IgG anti } \\
\text { mouse IgG }\end{array}$ & Ziege & Dianova-Nr. 115585003 \\
\hline $\begin{array}{c}\text { Nestin/CXCR6: } \text { Grün = goat IgG anti } \\
\text { mouse IgG }\end{array}$ & Ziege & Dianova-Nr. 115545003 \\
\hline MHC-I: Rot $=$ goat IgG anti rat IgG & Ziege & Dianova-Nr. 112585003 \\
\hline $\begin{aligned} \text { CD31: Grün }= & \text { goat } \operatorname{Ig} G \text { anti rabbit } \\
& \operatorname{IgG}\end{aligned}$ & Ziege & Dianova-Nr. 111545003 \\
\hline CD31: Rot = goat IgG anti rabbit IgG & Ziege & Dianova-Nr. 111585003 \\
\hline \multicolumn{3}{|l|}{ Zellkernfärbung } \\
\hline DAPI - Zellkernfärbung & & MoBiTec-Nr. D1306 \\
\hline \multicolumn{3}{|l|}{ Blocken } \\
\hline 5\%iges Ziege Serum & & Sigma Aldrich-Nr. G9023 \\
\hline Flourescent Mounting Medium & & Dako-Nr. S3023 \\
\hline
\end{tabular}

\subsubsection{Methodik: Muskelschnitt-Färbung, Fluoreszenzmikroskopie und} Auszählung

Zur feingeweblichen Beurteilung der Muskelfaserschnitte standen insgesamt siebenundzwanzig Muskelbiopsieblöcke zur Verfügung, aus denen je zehn Schnitte durch die Abteilung Neuropathologie der Universitätsmedizin Göttingen bereitgestellt wurden. Die Biopsien wurden mit der Fragestellung nach dem Vorliegen einer Muskelpathologie bei klinischer Symptomatik aus Muskelschmerz und Muskelschwäche im Zeitraum von 2006 bis 2014 an das Institut für Neuropathologie geschickt. Die Diagnose wurde entsprechend der ENMC-Kriterien durch die Neuropathologie nach Durchführung von histologischen 
und immunhistochemischen Standardfärbungen und zum Teil durch eine zusätzliche Elektronenmikroskopie erhoben. Als Kriterium an die fünf Kontrollmuskelbiopsien war gestellt, dass keine Myopathie diagnostiziert sein sollte.

Die bei $-20{ }^{\circ} \mathrm{C}$ gefrorenen Kryofaserschnitte tauten vor Beginn der Bearbeitung zehn Minuten auf. Zunächst erfolgte eine Anordnung der Patientenschnitte in die Gruppen der Zielfärbung: Färbegruppen für CD31/Nestin, CD31/CXCR6, Nestin/MHC-I, CXCR6/CD4 und CXCR6/CD8. CD4 und CD8 stellen dabei Rezeptoren von Immunzellen wie T-Zellen oder Makrophagen dar. Die Schnitte wurden dann nach Protokoll mit PBS über einen Zeitraum von zehn Minuten gewaschen und anschließend über dreißig Minuten mit einem 5\%igen Ziegeserum in PBS als Block benetzt um falsch positive Messungen durch den späteren, aus Ziege gewonnenen, Sekundärantikörper zu vermeiden. Dann wurden die Kryofaserschnitte mittels PBS gewaschen und die Schnitte über Nacht bei $4{ }^{\circ} \mathrm{C}$ mit den Primärantikörpern in den Verhältnissen: 1:50 (Hase anti CD31), 1:1000 (Maus anti Nestin), 1:2000 (Ratte anti MHC-I), 1:500 (Maus anti CXCR6) inkubiert.

Am nächsten Tag wurden die Schnitte dreimal mit PBS gewaschen. Die Kryoschnitte wurden anschließend mit den jeweiligen Sekundärantikörpern, die Fluoreszenzeigenschaften haben, über eine Stunde bei Raumtemperatur inkubiert. Für eine Gründarstellung des Strukturproteins Nestin wurde ein - Ziege anti Maus - Antikörper mit der Fluoreszenz-Wellenlänge von 488 nm verwendet. Für die Darstellung von Rot wurden zum einen der Antikörper - Ziege anti Kaninchen - für CD31 und - Ziege anti Ratte - für MHC-I mit der jeweiligen Fluoreszenzwellenlänge von 594 nm genutzt.

Die Zellkernfärbung wurde mit DAPI in einem Mischungsverhältnis mit PBS von 1:1000 über zehn Minuten vorgenommen. Im Fluoreszenzwellenlängenbereich von 358 - $461 \mathrm{~nm}$ konnte Blau detektiert werden.

Schließlich erfolgte das Eindeckeln mit Fluorescent Mounting Medium zum Schutz des Schnittes. Um eine optimale Färbequalität zu nutzen, erfolgte im Anschluss die Fluoreszenzmikroskopie. Über die Software Cell-D konnten durch das Mikroskop dargestellte Bilder visualisiert, fotografiert und ausgemessen werden. Bei der Bilderstellung zur späteren Muskelfaser und -gefäßauszählung wurden die vorliegenden Schnitte, je nach Größe, in drei bis vier Abschnitte geteilt, um bei der Auswertung den gesamten Biopsiequerschnitt vorliegen zu haben. Die Auswertung selbst erfolgte verblindet, wie in Abbildung 12 gezeigt, durch manuelle Auszählung aller Muskelfasern und Muskelgefäße pro Schnittbild in den oben genannten Doppelfärbegruppen. Dabei wurden in einer ExcelTabelle einfach- und doppelt positive bzw. -negative Fasern und Gefäße statistisch dokumentiert und schließlich in „R“, wie unter 2.6 beschrieben, ausgewertet. 


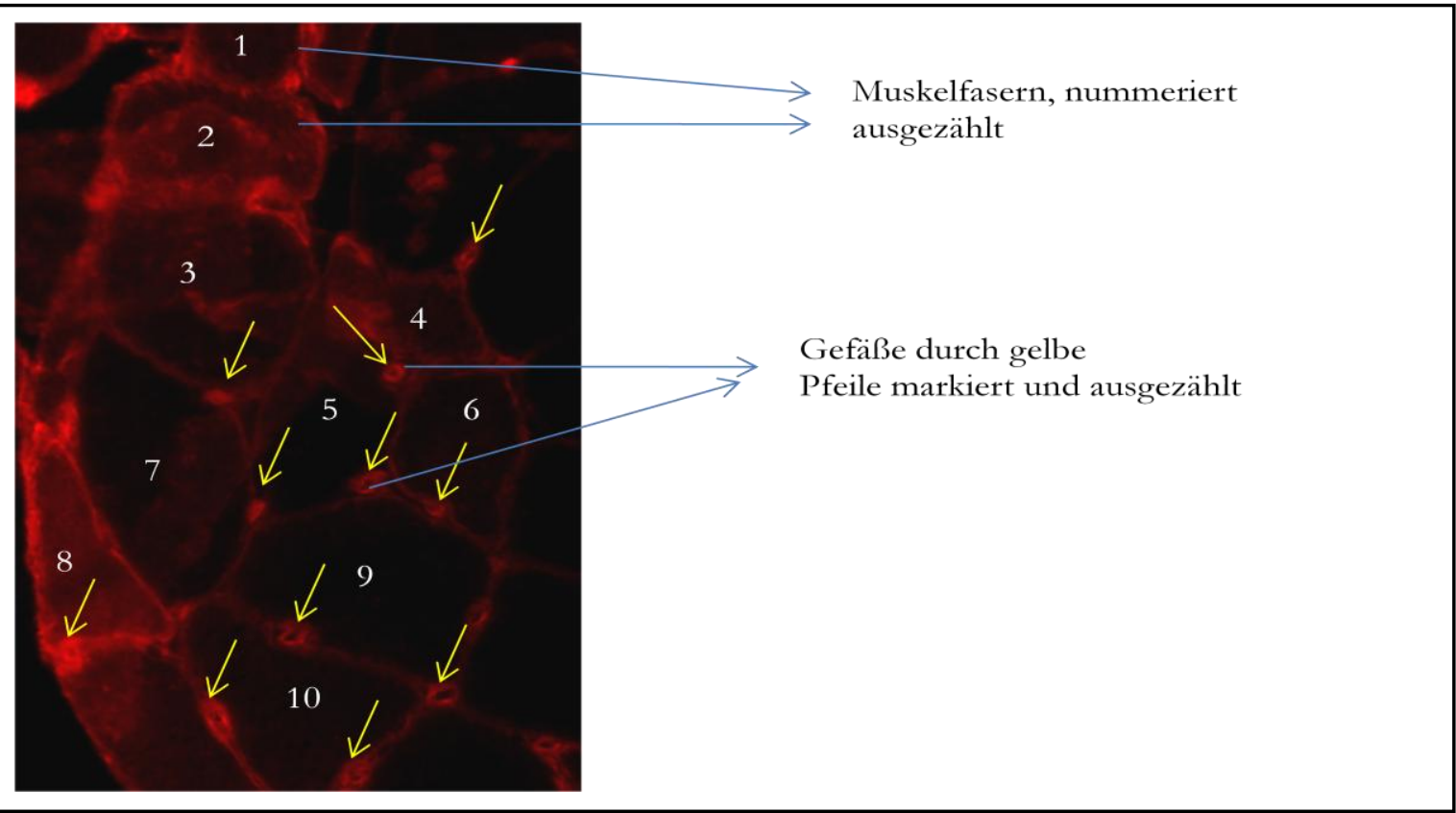

Abbildung 12: CD31-Fluoreszenz bei nekrotisierender Myopathie, Auszählung von Muskelfasern und -gefäßen anhand einer Nummerierung der Muskelfasern und Markierung der Gefäße durch Pfeile 
In Abbildung 13 ist dargestellt, wie sich die Farbgebung der Sekundärantikörper Rot und Grün in der Doppelfärbung in Orange/Gelb färbt. Als positiv galten Muskelfasern, die vollständig umrahmt oder durch den Fluoreszenzmarker auf das jeweils nachzuweisende Protein vollständig ausgefüllt, angefärbt waren. Gefäße galten als positiv, wenn sie durch den Marker CD31 angefärbt in loco typico lagen.

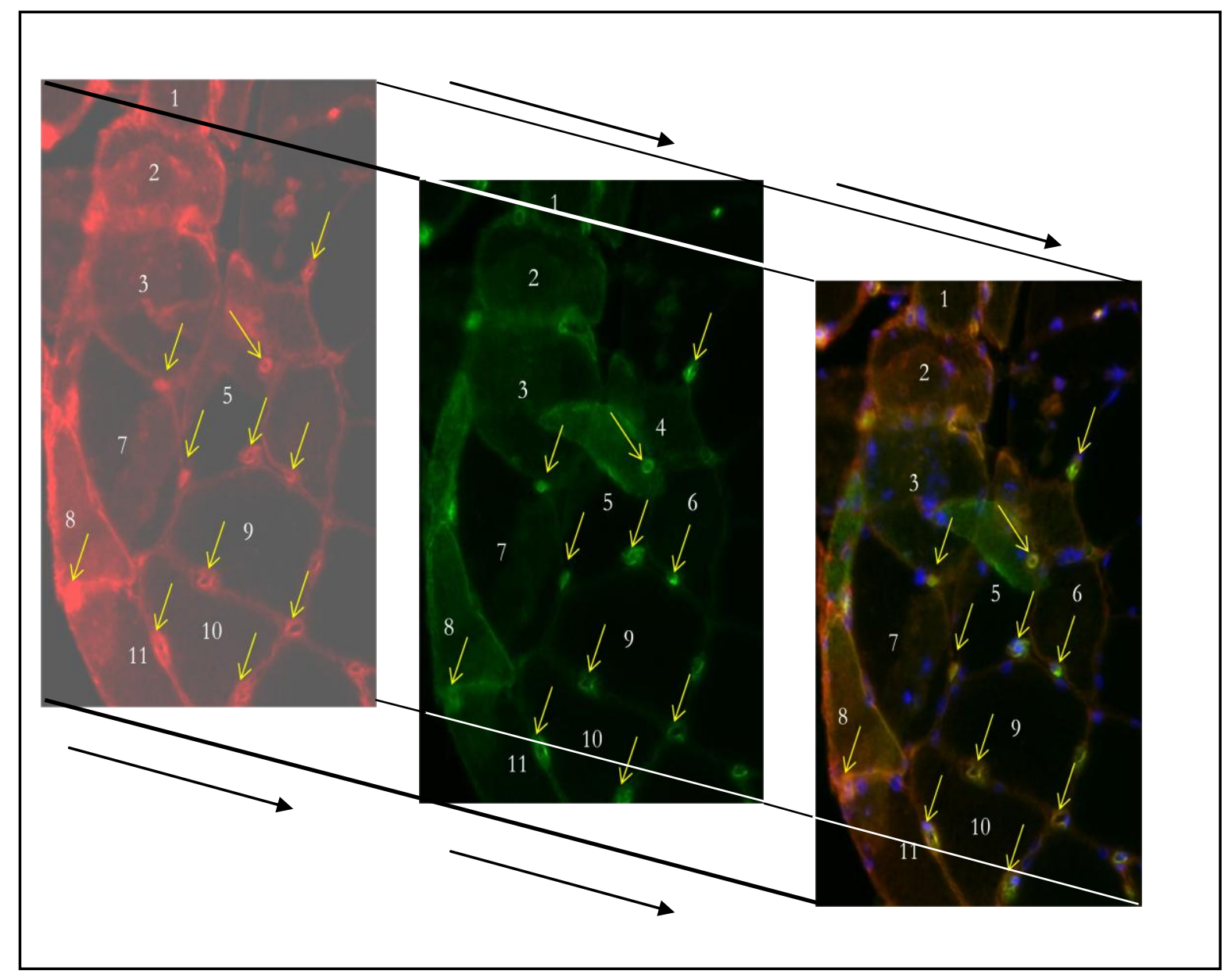

Abbildung 13: Doppelfärbung bei nekrotisierender Myopathie: links - Marker eins (rotCD31), Mitte - Marker zwei (grün-CXCR6), rechts - Doppelfärbung, Darstellung der Auswertung von doppelt positiven Fasern und Gefäßen, die sich orange-gelb darstellen 
In Abbildung 14 und Abbildung 15 werden schließlich die fluoreszenztechnisch dargestellten Gefäße (gelber Pfeil) und Muskelfasern gezeigt.

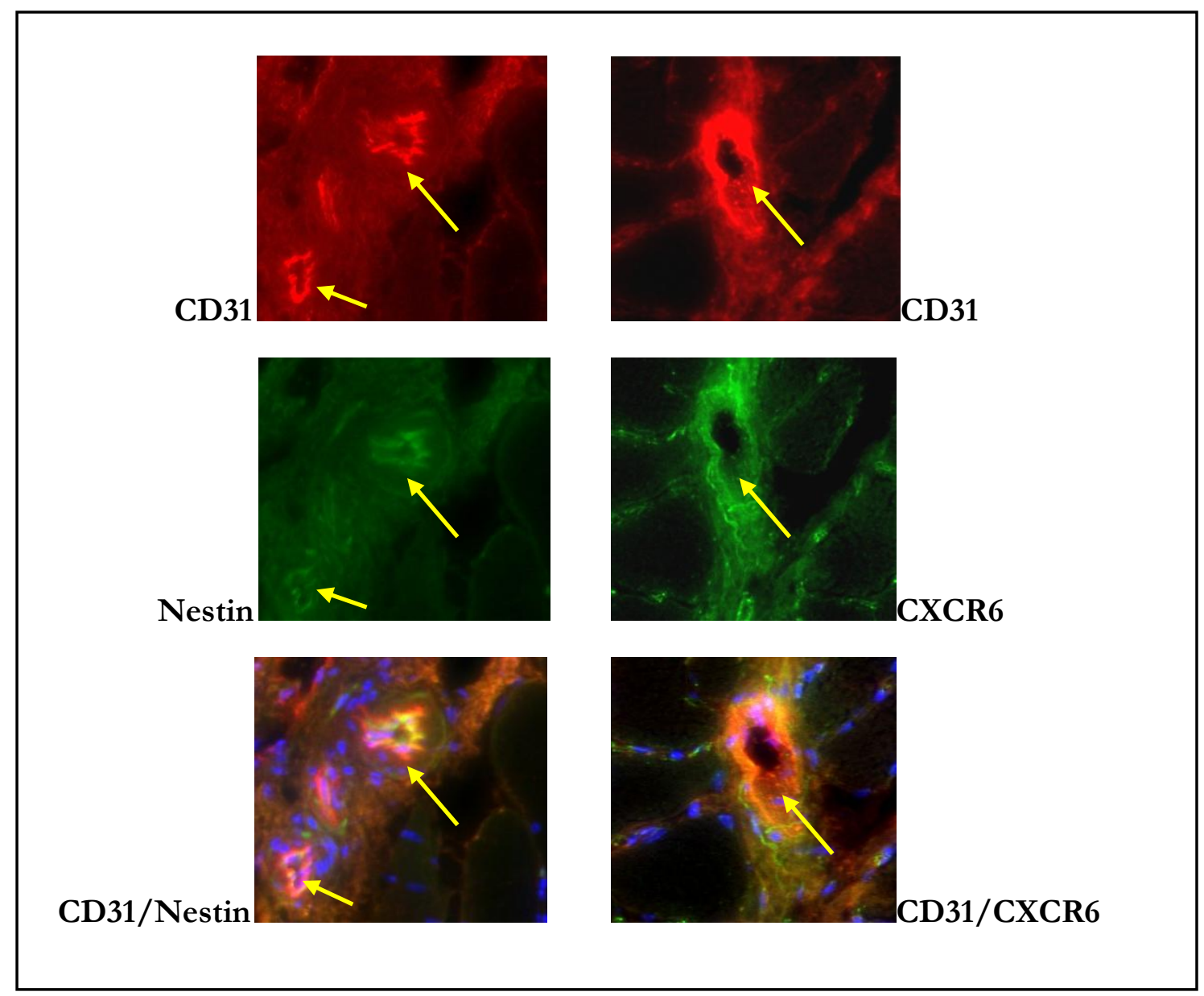

Abbildung 14: Biopsie-Fluoreszenz mit CD31 (oben links) und Nestin (Mitte links) sowie CD31 (oben rechts) und CXCR6 (Mitte rechts) bei einem Patienten mit nekrotisierender Myopathie, Gefäßdarstellung in der Muskelbiopsie (gelbe Pfeile), doppelt positive Gefäßfärbung (unten links und rechts) in orange-Darstellung 


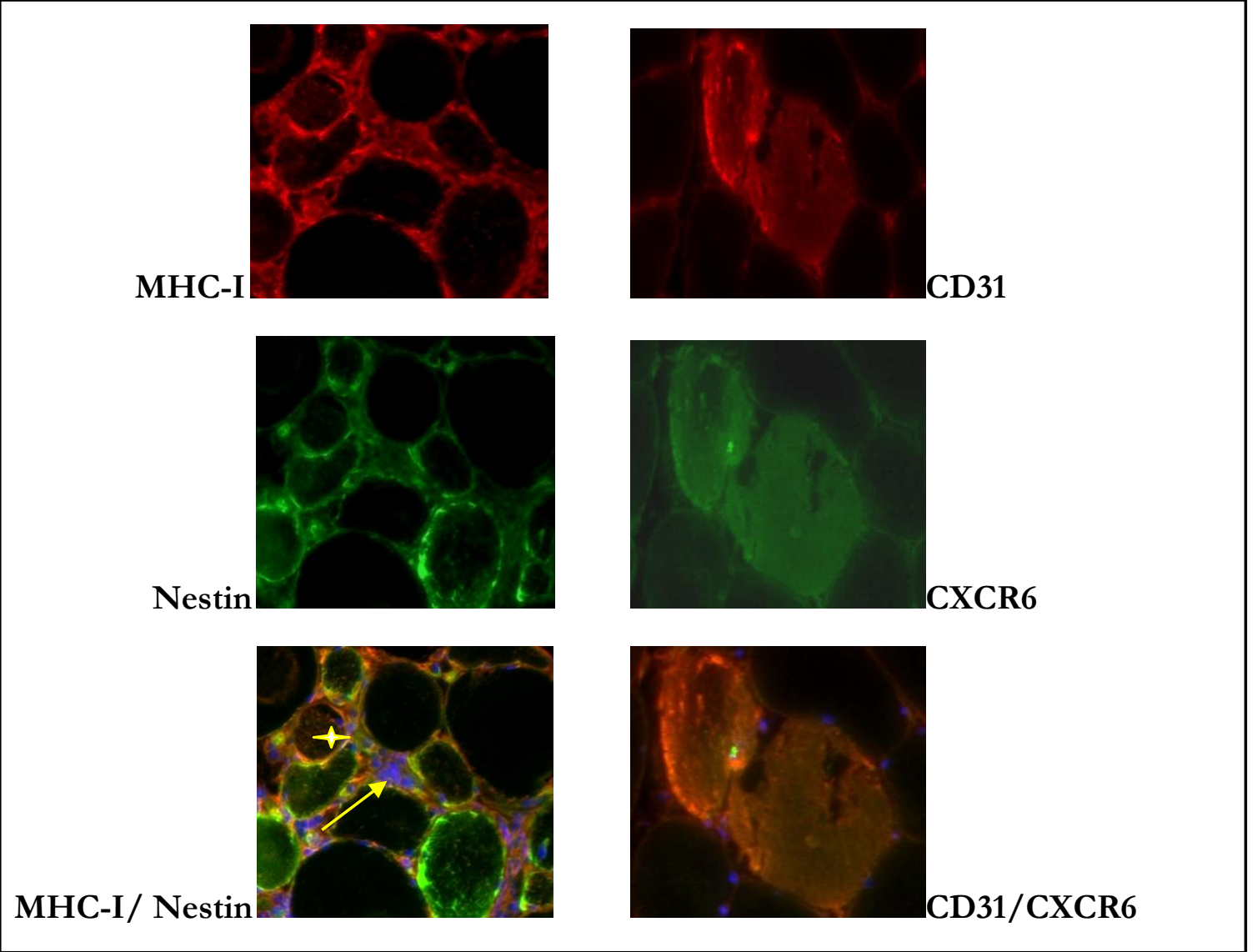

Abbildung 15: Darstellung von Muskelfasern durch Fluoreszenzmarker

linke Säule: Muskelfaserdarstellung in der Muskelbiopsie durch die Fluoreszenzmarker MHC-I und Nestin in Einzel- und Doppelfärbung: mit blau durch gelben Pfeil markiert in MHC-I/Nestin/DAPI-Färbung - Zellkerne, hier Entzündungszellen im Areal mit Aufregulation von MHC-I und Nestin bei einem Patienten mit Polymyositis -, Muskelfaser (Stern) mit gleichzeitiger MHC-I- und Nestin-Positivität.

rechte Säule: Muskelfaserdarstellung durch die Fluoreszenzmarker CD31 und CXCR6 in Einzel- und Doppelfärbung: hier deutliche endomysiale CXCR6-Aufregulation sowie unerwarteter Weise endomysiale CD31-Anfärbbarkeit der unregelmäßig geformten Muskelfaser bei einem Patienten mit Polymyositis, unten rechts in der CD31/CXCR6/DAPI-Darstellung kaum Immunzellen nachweisbar

Zur Berechnung der gesamten Gefäßzahl wurde zum einen die Muskelfaserzahl, zum anderen die Fläche des Biospieschnittes herangezogen. Für letztere Berechnung wurden Länge und Breite eines Schnittes unter dem Mikroskop in zwanzig facher Vergrößerung ausgemessen. Da die Schnitte jedoch teils asymmetrisch ausfielen, ist hier, wie in Abbildung 16 dargestellt, eine Messungenauigkeit zu erwarten. Weiterhin schwankt die Größe der einzelnen Muskelfasern pro $\mathrm{mm}^{2}$ bei erkrankten Patienten je nach Krankheitsprogress unterschiedlich stark, so dass auch hier eine statistische Ungenauigkeit entstehen kann. Eine Aussage über die Dichte der Muskelfaserversorgung kann dann nicht genau getroffen werden. Eine statistische korrekte Aussage kann bei der Berechnung der 
Gefäße pro $\mathrm{mm}^{2}$ Biopsieschnitt nur getroffen werden, wenn man annimmt, dass die Muskelfasern bei den untersuchten Patienten alle gleich groß sind.

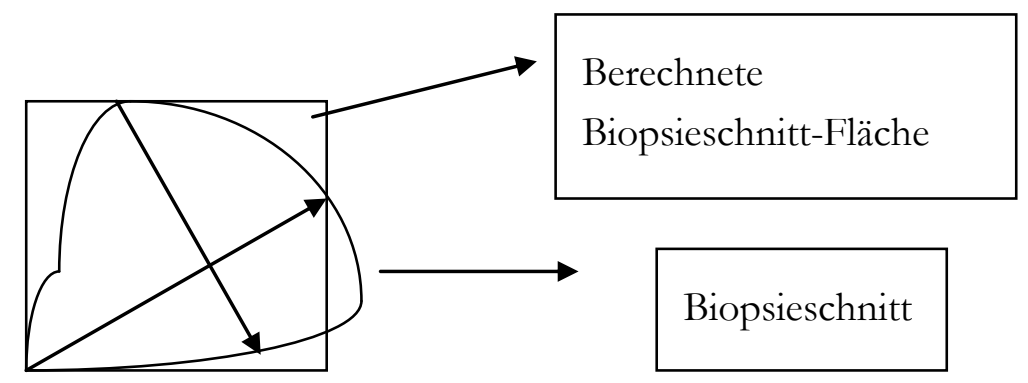

Abbildung 16: Messungenauigkeit bei Berechnung der Gefäßzahl $/ \mathrm{mm}^{2}$

\subsubsection{HE-Färbung Muskelbiopsie}

Die für die HE-Färbung genutzten Chemikalien sind in Tabelle 14 aufgeführt.

Tabelle 14: Chemikalien für HE-Färbung, EtOH = Ethanol

\begin{tabular}{cc}
\hline Chemikalie & Hersteller \\
\hline Hämatoxylin nach Meyer & Hämalaunserum nach Meyer, Fa. Roth-Nr. \\
Tosin G Lösung 5\%ig & Fa. Roth-Nr. X883.1 \\
EtOH $80 \%$, 96\%, 100\% & Über UMG SAP-Nr. 2002234 \\
Xylol I und II & Fa. Roth-Nr. 2662.2 \\
Entellan & Fa. Merck-Nr. 1.07961.0100 \\
Bleuen & \\
\hline
\end{tabular}

Die HE-Färbung ist eine klassische Übersichtsfärbung und stellt Bindegewebsstrukturen hellrosa, Zellkerne mit nukleinsäurehaltigen Strukturen blau und Zytoplasmabestandteile in Abhängigkeit vom pH-Wert dunkel bis hell rosa dar. Folgendes Protokoll wurde für die HE-Färbung an den Muskelbiopsien vorgenommen:

Aufgetaute Schnitte wurden auf Objektträgern über zehn Minuten in PBS gestellt. Anschließend wurden sie über fünf Minuten mit Hämatoxylin nach Meyer benetzt. Danach erfolgte das zehnminütige Bläuen unter fließendem Leitungswasser sowie die Benetzung mit Eosin G über acht Minuten. Es folgte in aufsteigender Alkoholreihe kurz 80\%iges Ethanol (EtOH), kurz 96\%iges EtOH und 100\%iges EtOH. Vor dem Eindeckeln mit Entellan und Deckgläschen wurde über je drei Minuten Xylol I und Xylol II zum Entwässern hinzugefügt. 
In Abbildung 17 ist die Untersuchung mit Hämatoxylin-Eosin-Färbung (HE-Färbung) im Vergleich zu Fluoreszenz-Färbungen der jeweiligen Marker CD31, Nestin, MHC-I, CXCR6 und DAPI bei einem Patienten mit Dermatomyositis und perivaskulären Infiltraten, fibrillären Kaliberschwankungen, Muskelfaseratrophie dargestellt. Die HE-Schnitte wurden neben dem unter 2.5.1 genannten Mikroskop auch unter dem Olympus-Mikroskop Nummer U-CMAD3 über die Software Cell-A mikroskopiert. Bildaufnahmen erfolgten in zwanzig- und vierzig-facher Vergrößerung.

HE-Übersicht 20x

HE-Übersicht 40x

CD31
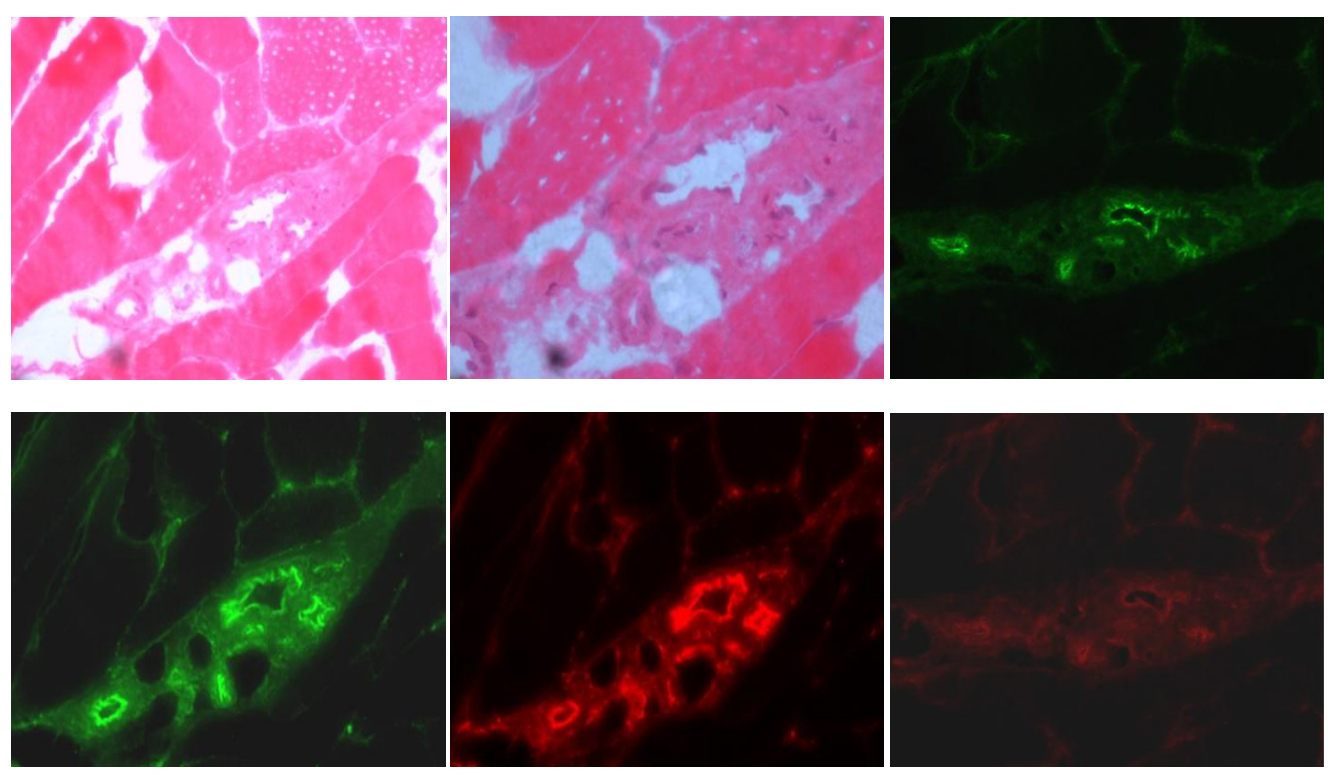

MHC-I

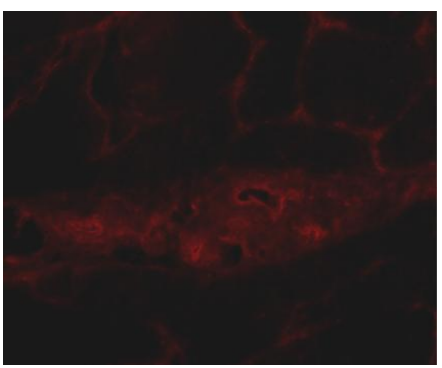

Nestin

CXCR6

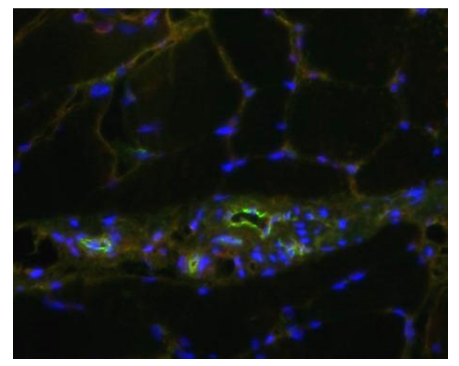

\section{DAPI - Zellkernfärbung (blau)}

Abbildung 17: Auswahl eines perivaskulären Areals bei einem Patienten mit Dermatomyositis zur Veranschaulichung der Ergebnisinterpretation zwischen der Hämatoxylin-Eosin-Färbung (HE) und den Fluoreszenzfärbungen.

Von links nach rechts sind in Abbildung 17 dargestellt: HE-Färbung mit vereinzelten Lymphozyten, CD31-Fluoreszenz mit Gefäß-Endotheldarstellung oben rechts, NestinFluoreszenz Mitte links mit deutlicher Anfärbbarkeit der Gefäße sowie perivaskulärer und perifibrillärer Aufregulation, ebenfalls vaskuläre Aufregulation in der MHC-I-Fluoreszenz Mitte, CXCR6-Fluoreszenz hier Mitte rechts mit nur schwacher Gefäßaufregulation, in der DAPI-Färbung unten links ist die Anreicherung perivaskulärer Immunzellen zu sehen. 


\subsection{Statistik}

Die statistischen Auswertungen erfolgten mittels des Programms „R“. Hauptziel der Untersuchungen ist der Test verschiedener Verteilungen auf Kompatibilität. Getestet wird für alle Vergleiche die Nullhypothese der Gleichheit der Mittelwerte a und b der Grundgesamtheiten der untersuchten Stichproben $(\mathrm{a}=\mathrm{b})$. Im Vergleich zu einseitigen Hypothesentests $(\mathrm{a}<\mathrm{b} ; \mathrm{a}>\mathrm{b})$ macht diese Hypothese keine weiteren Annahmen und ist daher konservativer. Für die Hypothesentests zum Vergleich mehrerer Gruppen (in der Regel Krankheits- und Kontrollgruppen) wird der Kruskal-Wallis-Test verwendet. Er gehört zur Gruppe der Varianzanalysen (ANOVA), setzt allerdings keine Normalverteilung der zugrundeliegenden Daten voraus, die in den hier untersuchten Fällen auch nicht allgemein gegeben ist.

Im Rahmen eines Kruskal-Wallis-Tests zwischen den Krankheits- und Kontrollgruppen wird eine signifikante Abweichung mindestens einer Gruppe von der Nullhypothese im Falle eines p-Wertes $<0,05$ festgestellt. P-Werte $<0,01$ entsprechen einer stark signifikanten Abweichung. Im Fall eines signifikanten Tests werden daraufhin alle Teilgruppen untereinander auf Kompatibilität geprüft. Hierfür wird der WilcoxonRangsummentest verwendet, der auch wiederum im Vergleich zum bekannten t-Test keine Normalverteilung der Werte voraussetzt.

Die Darstellung des Vergleichs der Gruppen erfolgt bei geringer Statistik (Muskelfaserauswertung, S100-/SMA-Zell-Fluoreszenzdarstellung sowie Darstellung angiogener Mediatoren) mittels Dotplots. Hierbei wird die Kohorte einer Gruppe als Punkte in Form von geometrischen Figuren dargestellt. Der Median ist dabei als querverlaufender dicker roter Strich dargestellt.

Im Falle der Auswertung der endothelialen Vorläuferzellen liegt eine höhere Statistik vor. Daher wurden hier Box Plots zur Darstellung gewählt. Sie zeigen den Median (dicker, schwarzer, querverlaufender Strich) und die Quartile der Verteilungen in Form einer Box. Die Begrenzungen der Box entsprechen den beiden zentralen Quartilen. Die sogenannten Whisker (dünne Linien außerhalb der Box) begrenzen den größten und kleinsten Wert der Verteilung. Die Länge der Whisker ist jedoch auf das 1,5fache der Box-Länge begrenzt. Weiter außerhalb liegende Werte (Ausreißer) werden als farblose Kreise hinter den Whiskern dargestellt. Bei den Box Plots sind auf der x-Achse die Krankheitsgruppen und auf der y-Achse der prozentuale Anteil positiv gefärbter CD133-, VEGFR-2- oder c-KITZellen bzw. die Menge an Kolonien dargestellt.

Darüber hinaus erfolgten Korrelationsanalysen zum Vergleich der EPC- und Muskelergebnisse sowie der Koloniezahl zu klinischen Parametern wie Rauchen, Krankheitsdauer und CK im Verlauf. Dabei stellt C den linearen Korrelationskoeffizienten dar. Hierbei entspricht der Wert $C=-1$ einer Antikorrelation, $C=1$ einer Korrelation und $\mathrm{C}=0$ einer unkorrelierten Verteilung. Die Korrelationskoeffizienten werden zusammen mit den dazugehörigen p-Werten ihrer Signifikanz mittels des Pearson-Tests bestimmt. 


\section{Ergebnisse}

\subsection{Patientenkollektiv}

In der nachfolgenden Tabelle 15 sind sämtliche erhobene Patientendaten dargestellt.

Tabelle 15: Übersicht Patientenkollektiv, *Methotrexat, Azathiprin, Cyclophosphamid, Mycophenolat-Mofetil; ** Adeno-Karzinom, CUP-Syndrom, Mamma-Karzinom

\begin{tabular}{|c|c|c|c|c|}
\hline & DM & $\mathbf{P M}$ & $\mathbf{N M}$ & Kontrolle \\
\hline Patienten & 17 & 11 & 7 & 40 \\
\hline Erkrankungsalter & $56 \pm 14$ & $60 \pm 12$ & $47 \pm 16$ & $44 \pm 12$ \\
\hline $\mathrm{M}: \mathrm{F}$ & $6: 11$ & $2: 9$ & $3: 4$ & $10: 30$ \\
\hline Muskelbiopsie & $59 \%$ & $55 \%$ & $86 \%$ & $12,5 \%$ \\
\hline Neudiagnose & $29 \%$ & $18 \%$ & $43 \%$ & $0 \%$ \\
\hline $\begin{array}{l}\text { Krankheitsjahre im } \\
\text { Mittel }\end{array}$ & 5,6 & 2,9 & 2,6 & 0 \\
\hline ANA (positiv) & $69 \%$ & $27 \%$ & $57 \%$ & Nicht verfügbar \\
\hline Antikörperprofil & & & 6 von 7 Patienten & \\
\hline Anti-Jo-1 & $24 \%$ & $10 \%$ & $33 \%$ & $0 \%$ \\
\hline Anti-Mi-2 & $29 \%$ & $10 \%$ & $0 \%$ & $0 \%$ \\
\hline Anti-HMGCR & $0 \%$ & $0 \%$ & $17 \%$ & $0 \%$ \\
\hline Anti-SRP & $0 \%$ & $0 \%$ & $33 \%$ & $0 \%$ \\
\hline Anti-Ku & $0 \%$ & $10 \%$ & $17 \%$ & $0 \%$ \\
\hline Anti-RO52 & $0 \%$ & $10 \%$ & $17 \%$ & $0 \%$ \\
\hline \multicolumn{5}{|l|}{ Medikamente } \\
\hline Statine & $18 \%$ & $18 \%$ & $0 \%$ & Nicht verfügbar \\
\hline Prednisolon - täglich & $88 \%$ & $81 \%$ & $86 \%$ & $7,5 \%$ \\
\hline$<7,5 \mathrm{mg}$ & $64 \%$ & $63 \%$ & $43 \%$ & $7,5 \%$ \\
\hline$>7,5 \mathrm{mg}$ & $24 \%$ & $18 \%$ & $43 \%$ & $0 \%$ \\
\hline Immunsuppressiva * & $77 \%$ & $72 \%$ & $71 \%$ & $9 \%$ \\
\hline Rauchen & $29 \%$ & $36 \%$ & $29 \%$ & Nicht verfügbar \\
\hline Paraneoplasie ** & $29 \%$ & $9 \%$ & $0 \%$ & $0 \%$ \\
\hline
\end{tabular}




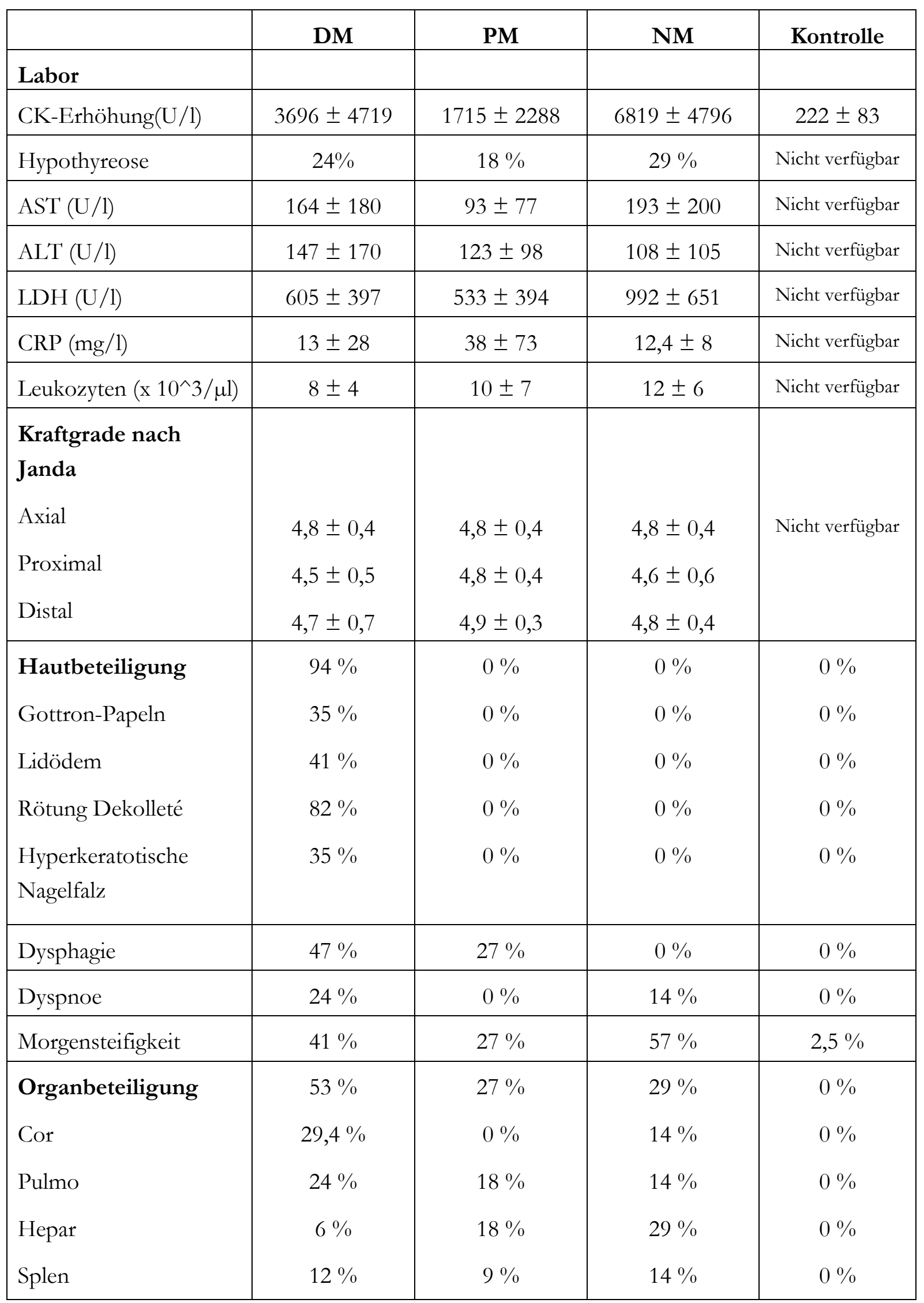




\subsection{EPCs}

Endotheliale Vorläuferzellen wurden aus dem Serum der Patienten zum einen mittels Durchflusszytometrie in der Gruppe peripher zirkulierender Blutmonozyten detektiert, zum anderen via Koloniezellzüchtung auf deren Regenerationspotential hin untersucht.

\subsubsection{Peripher zirkulierende endotheliale Vorläuferzellen}

Diese CD133+-/VEGFR-2 ${ }^{+}$-EPCs zeigten im Vergleich zur Kontrollgruppe eine Tendenz zur Reduktion ohne Signifikanz, wie in Tabelle 16 und Abbildung 18 dargestellt.

Tabelle 16: Vergleich der CD133+-/VEGFR-2 ${ }^{+}$-Zellen. Dargestellt sind der p-Wert des Kruskal-Wallis-Tests für den Gesamtvergleich aller Untergruppen sowie die p-Werte des Wilcoxon-Rangsummentests für die Einzelvergleiche der Gruppen.

\begin{tabular}{cccccc}
\hline Kruskal-Wallis & p-Wert & Kontrolle & DM & PM & NM \\
\hline 0,1902 & KG & --- & 0,223 & 0,091 & 0,151 \\
& DM & --- & --- & 0,531 & 1 \\
& PM & --- & --- & --- & 0,607 \\
\hline
\end{tabular}

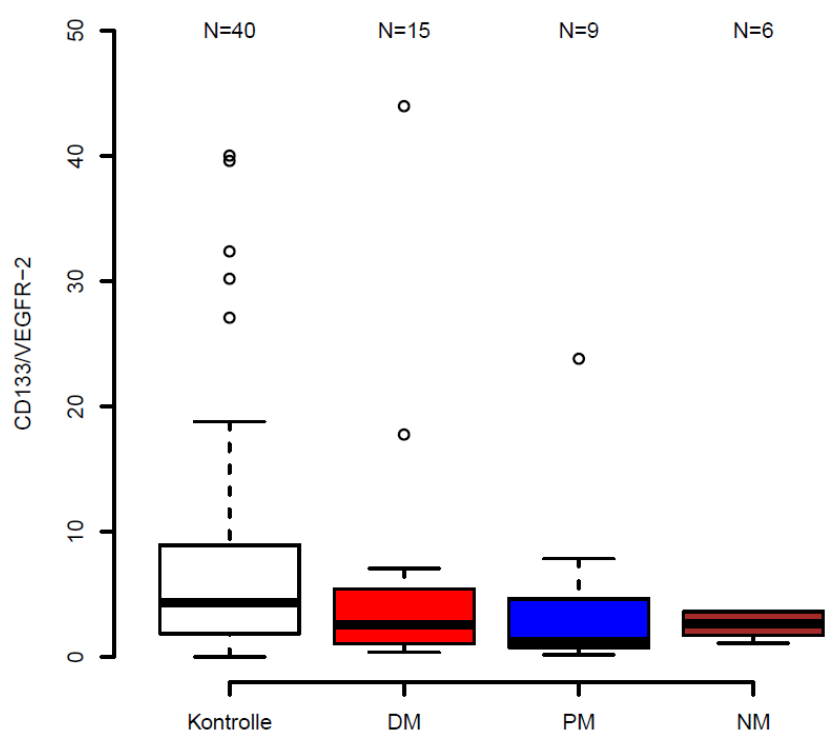

Abbildung 18: Anzahl der CD133+-/VEGFR-2 ${ }^{+}$-Zellen in den Vergleichsgruppen DM, PM, NM sowie Kontrollgruppe.

Die Auswertung von Zellen, die anstelle des frühen EPC-Markers VEGFR-2-positiv auf cKIT als Marker für hämatopoetische Stammzellen und CD133 waren, fiel in der DMGruppe signifikant erniedrigt gegenüber der Kontrollgruppe aus, wie in Tabelle 17 und Abbildung 19 zu sehen: 
Tabelle 17: Vergleich der CD133+-/c-KIT ${ }^{+}$-Zellen. Dargestellt sind der p-Wert des Kruskal-Wallis-Tests für den Gesamtvergleich aller Untergruppen sowie die p-Werte des Wilcoxon-Rangsummentests für die Einzelvergleiche der Gruppen.

\begin{tabular}{cccccc}
\hline Kruskal-Wallis & p-Wert & Kontrolle & DM & PM & NM \\
\hline 0,0693 & KG & --- & 0,04 & 0,133 & 0,075 \\
& DM & --- & --- & 0,952 & 0,907 \\
& PM & --- & --- & --- & 1 \\
\hline
\end{tabular}

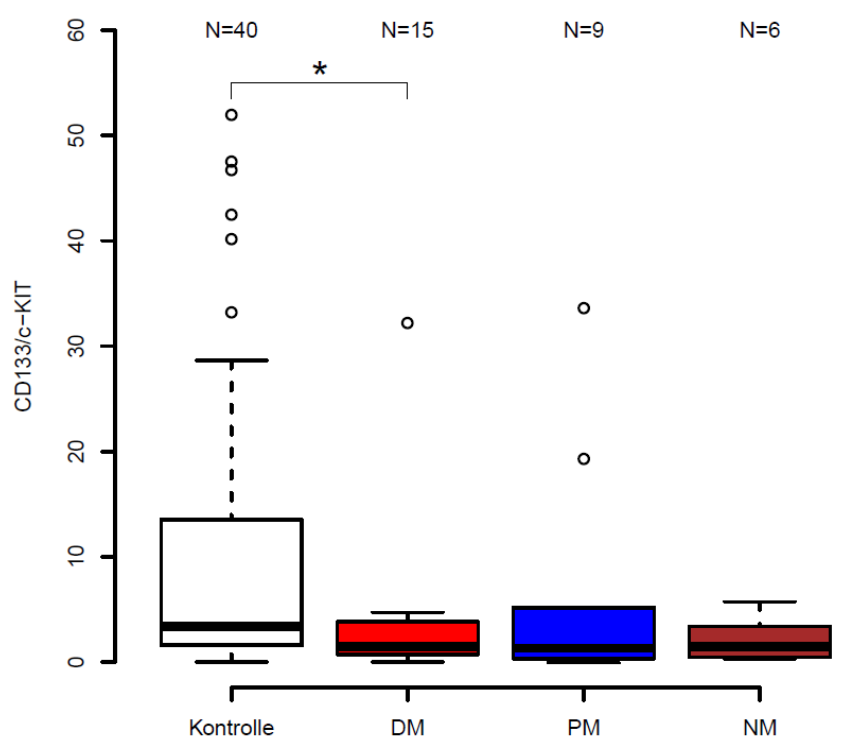

Abbildung 19: Anzahl der CD133+-/c-KIT ${ }^{+}$-Zellen in den Vergleichsgruppen DM, PM, NM sowie Kontrollgruppe. [Signifikante Unterschiede der Verteilungen mittels WilcoxonRangsummentest: * $\mathrm{p}<0,05]$

\subsubsection{EPC-Kolonien als Regenerationsparameter}

Die Koloniezahl gilt als Maß für die Regenerationsfähigkeit von EPCs. In der untersuchten Kohorte fiel diese bei allen den drei Krankheitsgruppen (DM, PM, NM) signifikant erniedrigt aus, wie in

Tabelle 18 und Abbildung $20 \mathrm{zu}$ sehen. Dabei gab es auch innerhalb der Krankheitsgruppen signifikante Unterschiede, wobei die Koloniezahl der NM-Gruppe gegenüber der PM-Gruppe signifikant vermindert ausfiel. 
Tabelle 18: Vergleich der Kolonien. Dargestellt sind der p-Wert des Kruskal-Wallis-Tests für den Gesamtvergleich aller Untergruppen sowie die p-Werte des WilcoxonRangsummentests für die Einzelvergleiche der Gruppen.

\begin{tabular}{cccccc}
\hline Kruskal-Wallis & p-Wert & Kontrolle & DM & PM & NM \\
\hline 0,0002 & KG & --- & 0,004 & 0,015 & 0,001 \\
& DM & --- & --- & 0,579 & 0,129 \\
& PM & --- & --- & --- & 0,014 \\
\hline
\end{tabular}

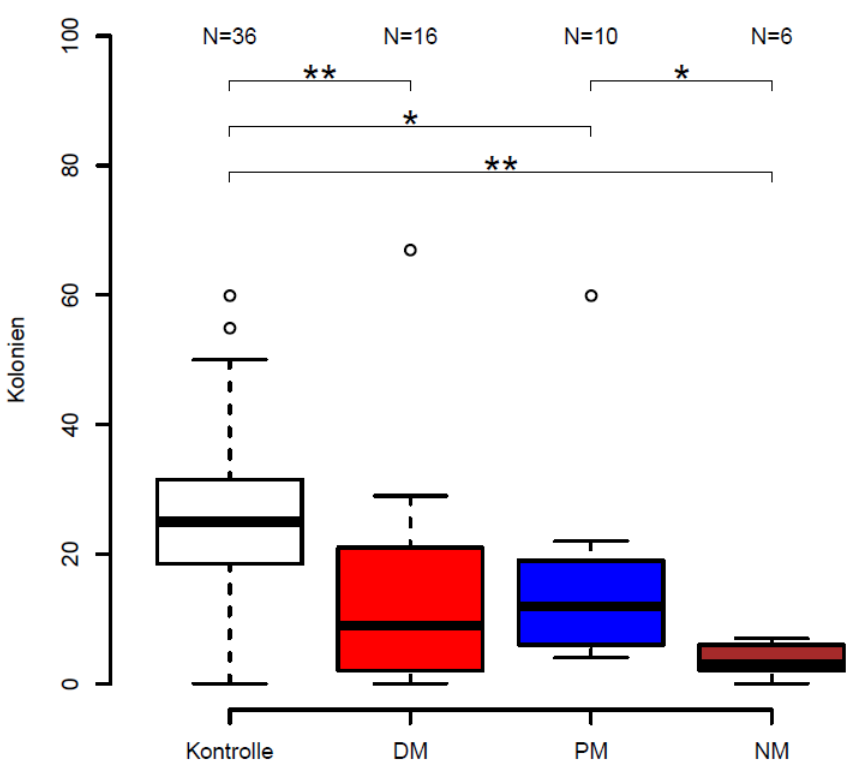

Abbildung 20: Anzahl der Kolonien in den Vergleichsgruppen DM, PM, NM sowie Kontrollgruppe. [Signifikante Unterschiede der Verteilungen mittels WilcoxonRangsummentest: $\left.{ }^{*} \mathrm{p}<0,05 ;{ }^{* *} \mathrm{p}<0,01\right]$

\subsubsection{S100- und SMA-Aufregulation in EPCs}

S100:

Die an Zellzyklus und an Angiogenese beteiligten S100-Proteine, die Marker für eine EndoMT sind, stellten sich ohne signifikante Aufregulation, wie in Tabelle 19 und Abbildung 21 dargestellt, gegenüber der Kontrollgruppe dar. In der DM-Gruppe ist eine Tendenz zur Verminderung im Vergleich zur Kontrollgruppe angedeutet. 
Tabelle 19: Vergleich der S100A4 ${ }^{+}$-Zellen. Dargestellt sind der p-Wert des Kruskal-WallisTests für den Gesamtvergleich aller Untergruppen sowie die p-Werte des WilcoxonRangsummentests für die Einzelvergleiche der Gruppen.

\begin{tabular}{cccccc}
\hline $\begin{array}{c}\text { Kruskal- } \\
\text { Wallis }\end{array}$ & p-Wert & Kontrolle & DM & PM & NM \\
\hline 0,3566 & KG & --- & 0,082 & 0,222 & 0,389 \\
& DM & --- & --- & 1 & 1 \\
& PM & --- & --- & --- & 0,712 \\
\hline
\end{tabular}

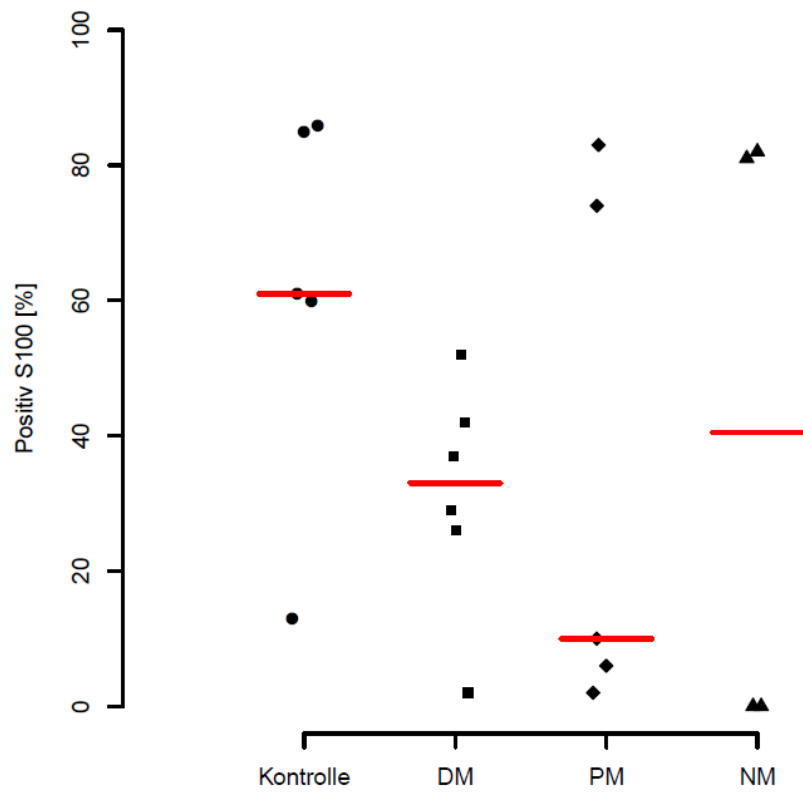

Abbildung 21: Anzahl der S100+-Zellen als Anteil der CD31 ${ }^{+}$- und UEA-Lektin ${ }^{+}$-Zellen in den Vergleichsgruppen DM, PM, NM sowie Kontrollgruppe. Die rote Linie stellt den Median dar.

\section{SMA:}

Der Antikörper gegen Aktinfasern, der im Rahmen der EndoMT aufreguliert wird, wies im Vergleich zur Kontrolle keine signifikante Veränderung auf, wie Tabelle 20 und Abbildung 22 zeigen. 
Tabelle 20: Vergleich der SMA ${ }^{+}$-Zellen. Dargestellt sind der p-Wert des Kruskal-WallisTests für den Gesamtvergleich aller Untergruppen sowie die p-Werte des WilcoxonRangsummentests für die Einzelvergleiche der Gruppen.

\begin{tabular}{cccccc}
\hline Kruskal-Wallis & p-Wert & Kontrolle & DM & PM & NM \\
\hline 0,5055 & KG & --- & 0,792 & 0,402 & 0,712 \\
& DM & --- & --- & 0,784 & 0,52 \\
& PM & --- & --- & --- & 0,108 \\
\hline
\end{tabular}

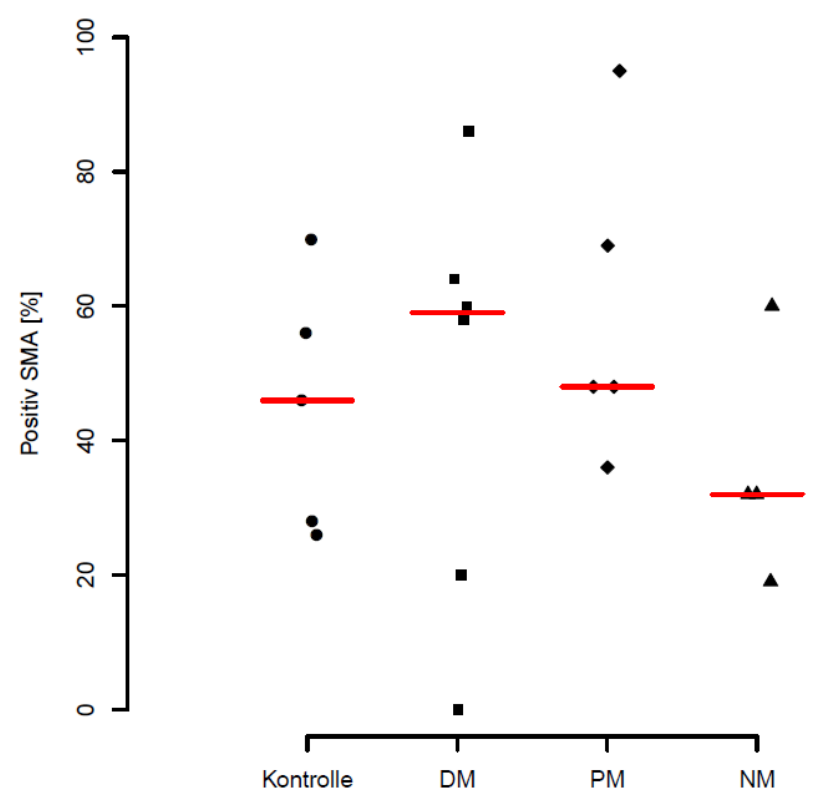

Abbildung 22: Anzahl der SMA ${ }^{+}$-Zellen als Anteil der CD31+- und UEA-Lektin ${ }^{+}$- Zellen in den Vergleichsgruppen DM, PM, NM sowie Kontrollgruppe. Die rote Linie stellt den Median dar.

\subsection{Muskelgefäß- und Muskelfaserauswertung}

\subsubsection{CD31 - Gefäßzahl pro Krankheitsgruppe}

Die Gefäßzahl wurde via CD31 als Endothelzellmarker zum einen über die Muskelfasergesamtzahl ermittelt, zum anderen pro Quadratmillimeter $\left(\mathrm{mm}^{2}\right)$ bestimmt.

In der folgenden statistischen Auswertung, Tabelle 21, Abbildung 23, wurde zunächst ersterer Zusammenhang dargestellt, wobei eine signifikante Verminderung der Gefäßzahl pro Muskelfaserzahl in der DM- und PM-Gruppe zu verzeichnen ist. In der NM-Gruppe ist eine Tendenz zur Verminderung zu sehen. 
Tabelle 21: Vergleich der Gefäßzahl pro Muskelfasergesamtzahl. Dargestellt sind der pWert des Kruskal-Wallis-Tests für den Gesamtvergleich aller Untergruppen sowie die pWerte des Wilcoxon-Rangsummentests für die Einzelvergleiche der Gruppen.

\begin{tabular}{cccccc}
\hline Kruskal-Wallis & p-Wert & Kontrolle & DM & PM & NM \\
\hline 0,0005 & KG & --- & 0,001 & 0,03 & 0,537 \\
& DM & --- & --- & 0,003 & 0,001 \\
& PM & --- & --- & --- & 0,24 \\
\hline
\end{tabular}

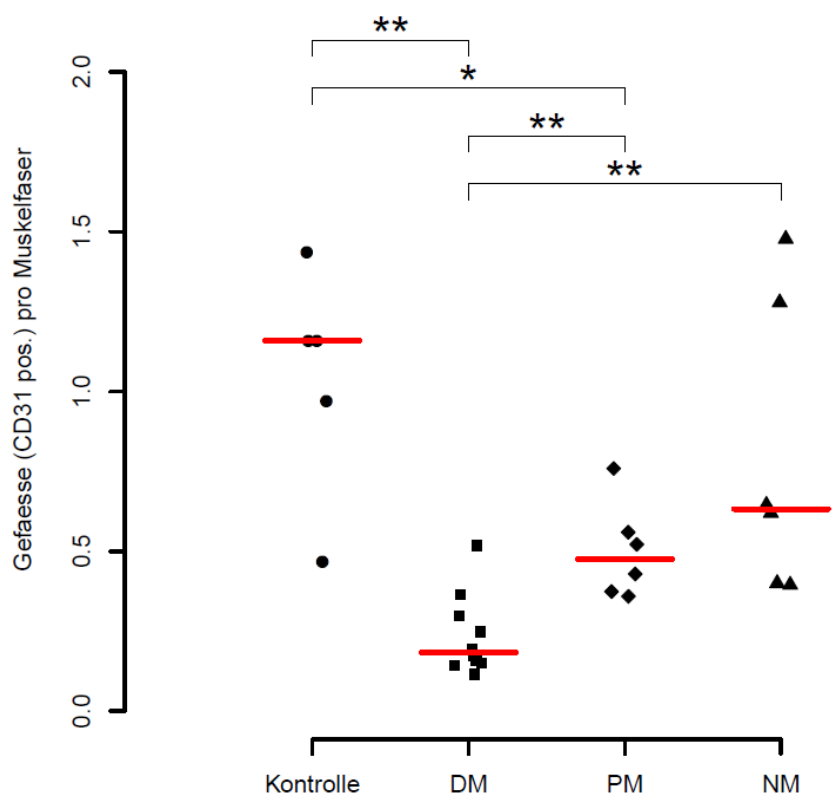

Abbildung 23: Anzahl der $\mathrm{CD} 31^{+}$-Gefäße pro Muskelfasergesamtzahl in den Vergleichsgruppen DM, PM, NM sowie Kontrollgruppe. Die rote Linie stellt den Median dar. [Signifikante Unterschiede der Verteilungen mittels Wilcoxon-Rangsummentest: * $\mathrm{p}<$ $0,05 ; * * \mathrm{p}<0,01]$

In der Darstellung der Gefäßzahl pro $\mathrm{mm}^{2}$ zeigte sich ebenfalls eine signifikante Verminderung der Gefäßzahl in der DM-Gruppe gegenüber der Kontrollgruppe sowie gegenüber der PM-Gruppe. Hierbei wurde, aufgrund der in 2.5.3 anzunehmenden Messungenauigkeit, keine Gefäßreduktion in der PM-Gruppe nachgewiesen, wie in Tabelle 22 und Abbildung 24 gezeigt. 
Tabelle 22: Vergleich der Gefäßzahl pro $\mathrm{mm}^{2}$ Biopsiequerschnitt. Dargestellt sind der pWert des Kruskal-Wallis-Tests für den Gesamtvergleich aller Untergruppen sowie die pWerte des Wilcoxon-Rangsummentests für die Einzelvergleiche der Gruppen.

\begin{tabular}{cccccc}
\hline Kruskal-Wallis & p-Wert & Kontrolle & DM & PM & NM \\
\hline 0,0337 & KG & --- & 0,013 & 0,662 & 0,429 \\
& DM & --- & --- & 0,039 & 0,073 \\
& PM & --- & --- & --- & 0,937 \\
\hline
\end{tabular}

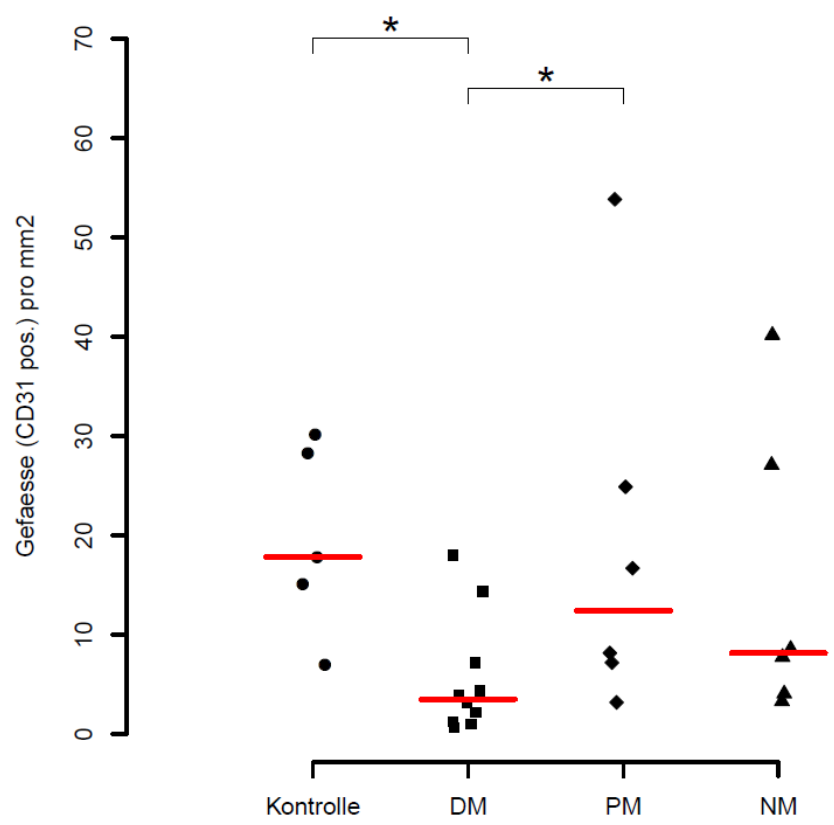

Abbildung 24: Anzahl der $\mathrm{CD} 31^{+}$-Gefäße pro $\mathrm{mm}^{2}$ Biopsiequerschnitt in den Vergleichsgruppen DM, PM, NM sowie Kontrollgruppe. Die rote Linie stellt den Median dar. [Signifikante Unterschiede der Verteilungen mittels Wilcoxon-Rangsummentest: * $\mathrm{p}<$ $0,05]$

Im Folgenden wurde ebenfalls die Muskelfaserzahl pro $\mathrm{mm}^{2}$ Biopsiefläche dargestellt. Hier zeigten sich keine Signifikanzen zwischen den untersuchten Gruppen, wie Tabelle 23 und Abbildung 25 darstellen. 
Tabelle 23: Vergleich der Muskelfaserzahl pro $\mathrm{mm}^{2}$ Biopsiequerschnitt. Dargestellt sind der p-Wert des Kruskal-Wallis-Tests für den Gesamtvergleich aller Untergruppen sowie die p-Werte des Wilcoxon-Rangsummentests für die Einzelvergleiche der Gruppen.

\begin{tabular}{cccccc}
\hline Kruskal-Wallis & p-Wert & Kontrolle & DM & PM & NM \\
\hline 0,5247 & KG & --- & 0,679 & 0,537 & 0,537 \\
& DM & --- & --- & 0,313 & 0,958 \\
& PM & --- & --- & --- & 0,18 \\
\hline
\end{tabular}

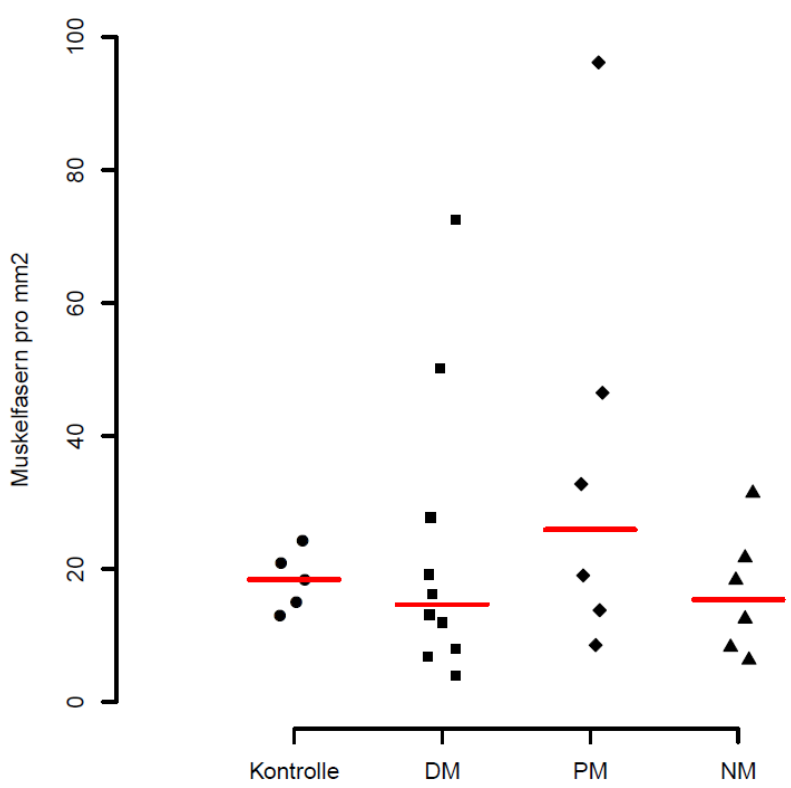

Abbildung 25: Anzahl der Muskelfasermenge pro $\mathrm{mm}^{2}$ Biopsiequerschnitt in den Vergleichsgruppen DM, PM, NM sowie Kontrollgruppe. Die rote Linie stellt den Median dar.

\subsubsection{Vaskuläres CXCR6 - EPC-Rekruitment}

Der Rekruitmentfaktor CXCR6 wurde in der Doppelfärbung mit dem Endothelzellmarker CD31 verglichen. In der Statistik zeigte sich für CD $31^{+}{ }^{-} /$CXCR $6^{+}$-Gefäße eine signifikante Erhöhung in allen drei Krankheitsgruppen. Dabei lag eine starke Signifikanz in der PMund NM-Gruppe vor, wie Tabelle 24 und Abbildung 26 zeigen. 
Tabelle 24: Vergleich der $\mathrm{CD} 31^{+}$-/CXCR6 ${ }^{+}$-Gefäße. Dargestellt sind der p-Wert des Kruskal-Wallis-Tests für den Gesamtvergleich aller Untergruppen sowie die p-Werte des Wilcoxon-Rangsummentests für die Einzelvergleiche der Gruppen.

\begin{tabular}{cccccc}
\hline Kruskal-Wallis & p-Wert & Kontrolle & DM & PM & NM \\
\hline 0,0097 & KG & --- & 0,023 & 0,004 & 0,004 \\
& DM & --- & --- & 0,254 & 0,786 \\
& PM & --- & --- & --- & 0,093 \\
\hline
\end{tabular}

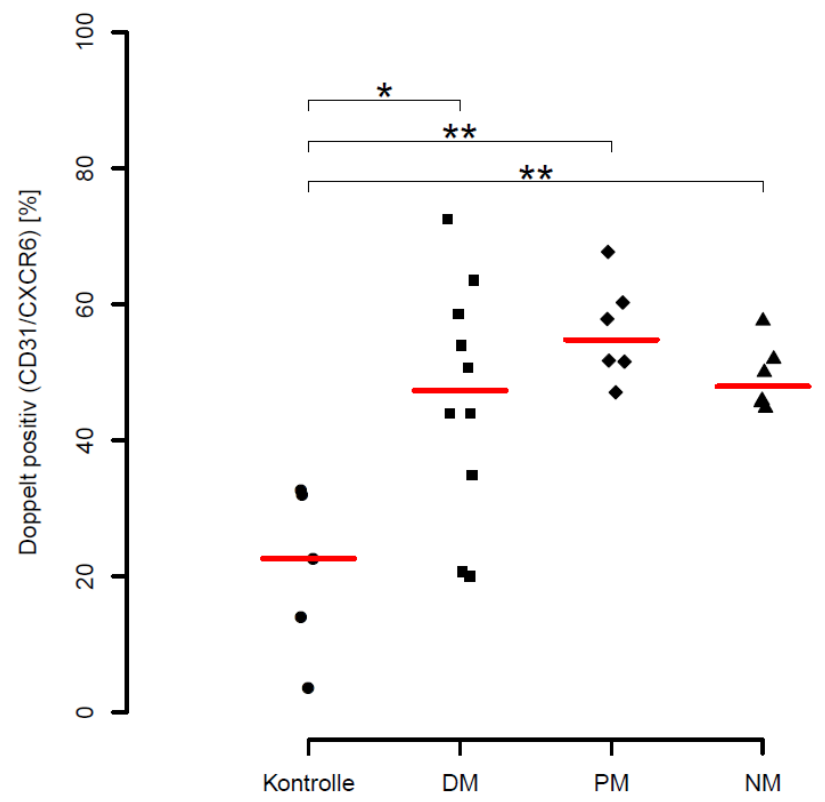

Abbildung 26: Anzahl der $\mathrm{CD} 31^{+}$-/CXCR $6{ }^{+}$-Muskelgefäße in den Vergleichsgruppen DM, PM, NM sowie Kontrollgruppe. Die rote Linie stellt den Median dar. [Signifikante Unterschiede der Verteilungen mittels Wilcoxon-Rangsummentest: * $\mathrm{p}<0,05$; ** $\mathrm{p}<0,01]$

\subsubsection{Vaskuläres Nestin - Gefäßregeneration}

Die Anfärbbarkeit auf den Marker Nestin ergab in der Statistik eine Tendenz zur Reduktion für die DM-Gruppe im Vergleich zur Kontrollgruppe, wie Tabelle 25 und Abbildung 27 darstellen. Ein signifikanter Unterschied wurde nicht detektiert. 
Tabelle 25: Vergleich der $\mathrm{CD}_{31}{ }^{+}$-/Nestin ${ }^{+}$-Gefäße. Dargestellt sind der $\mathrm{p}$-Wert des Kruskal-Wallis-Tests für den Gesamtvergleich aller Untergruppen sowie die p-Werte des Wilcoxon-Rangsummentests für die Einzelvergleiche der Gruppen.

\begin{tabular}{cccccc}
\hline Kruskal-Wallis & p-Wert & Kontrolle & DM & PM & NM \\
\hline 0,5324 & KG & --- & 0,125 & 0,855 & 0,927 \\
& DM & --- & --- & 0,55 & 0,415 \\
& PM & --- & --- & --- & 0,687 \\
\hline
\end{tabular}

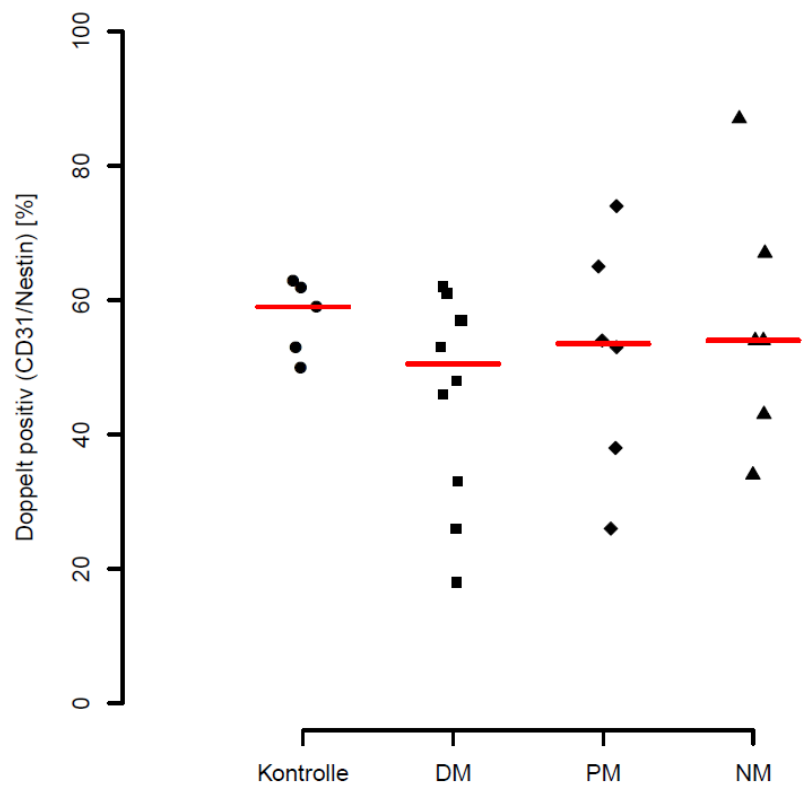

Abbildung 27: Anzahl der CD31 ${ }^{+}$-/Nestin ${ }^{+}$-Muskelgefäße in den Vergleichsgruppen DM, PM, NM sowie Kontrollgruppe. Die rote Linie stellt den Median dar.

\subsubsection{Muskuläre Aufregulation von MHC-I}

Der Standardmarker für muskuläre Entzündung wies eine signifikante Aufregulation in allen drei Erkrankungsgruppen nach. Die signifikante Aufregulation des Markers konnte am stärksten für die DM- und PM-Gruppen, am schwächsten für die NM-Gruppe nachgewiesen werden. Die DM-Gruppe zeigte zudem eine signifikante Aufregulation des Markers gegenüber der NM-Gruppe, wie Tabelle 26 und Abbildung 28 zu entnehmen sind. 
Tabelle 26: Vergleich der MHC-I ${ }^{+}$-Muskelfasern pro Muskelfaserzahl. Dargestellt sind der p-Wert des Kruskal-Wallis-Tests für den Gesamtvergleich aller Untergruppen sowie die pWerte des Wilcoxon-Rangsummentests für die Einzelvergleiche der Gruppen.

\begin{tabular}{cccccc}
\hline Kruskal-Wallis & p-Wert & Kontrolle & DM & PM & NM \\
\hline 0,002 & KG & --- & 0,003 & 0,008 & 0,021 \\
& DM & --- & --- & 0,368 & 0,031 \\
& PM & --- & --- & --- & 0,18 \\
\hline
\end{tabular}

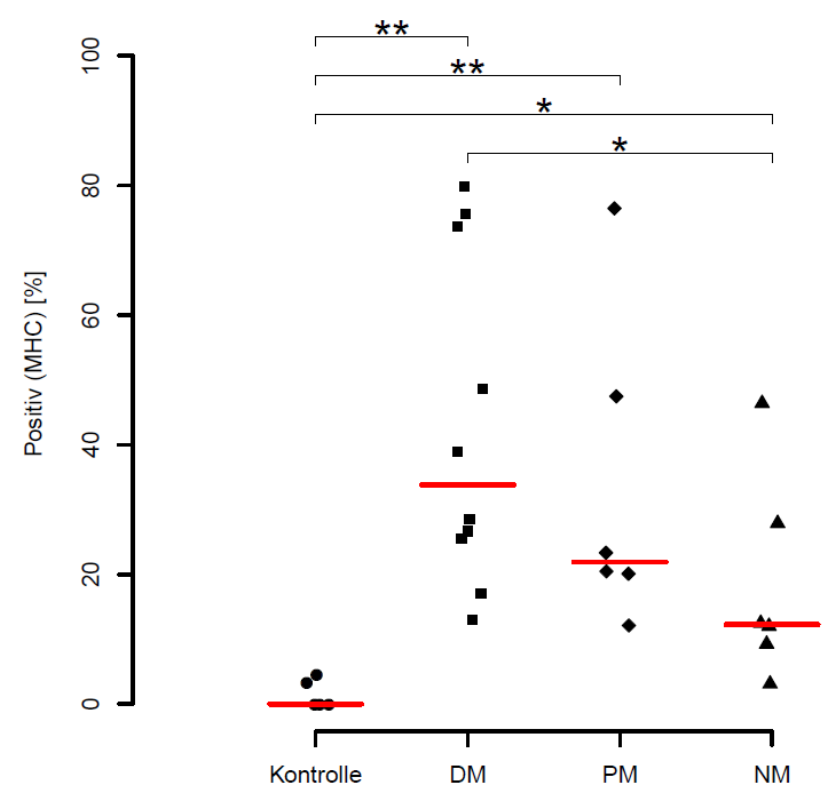

Abbildung 28: Anzahl der $\mathrm{MHC}^{+} \mathrm{I}^{+}$-Muskelfasern pro Muskelfaserzahl in den Vergleichsgruppen DM, PM, NM sowie Kontrollgruppe. Die rote Linie stellt den Median dar. [Signifikante Unterschiede der Verteilungen mittels Wilcoxon-Rangsummentest: ${ }^{*} \mathrm{p}<$ $0,05 ; * * \mathrm{p}<0,01]$

\subsubsection{Muskuläre Aufregulation von Nestin - muskuläre Regeneration}

In der Auswertung für Nestin ${ }^{+}$-Muskelfasern, als Marker für muskuläre Regeneration, wurde in allen drei Erkrankungsgruppen eine signifikante Aufregulation in den Muskelfasern beobachtet, wie Tabelle 27 und Abbildung 29 darstellen. 
Tabelle 27: Vergleich der Nestin ${ }^{+}$-Muskelfasern pro Muskelfaserzahl. Dargestellt sind der p-Wert des Kruskal-Wallis-Tests für den Gesamtvergleich aller Untergruppen sowie die pWerte des Wilcoxon-Rangsummentests für die Einzelvergleiche der Gruppen.

\begin{tabular}{cccccc}
\hline Kruskal-Wallis & p-Wert & Kontrolle & DM & PM & NM \\
\hline 0,008 & KG & --- & 0,001 & 0,004 & 0,004 \\
& DM & --- & --- & 0,562 & 0,958 \\
& PM & --- & --- & --- & 0,485 \\
\hline
\end{tabular}

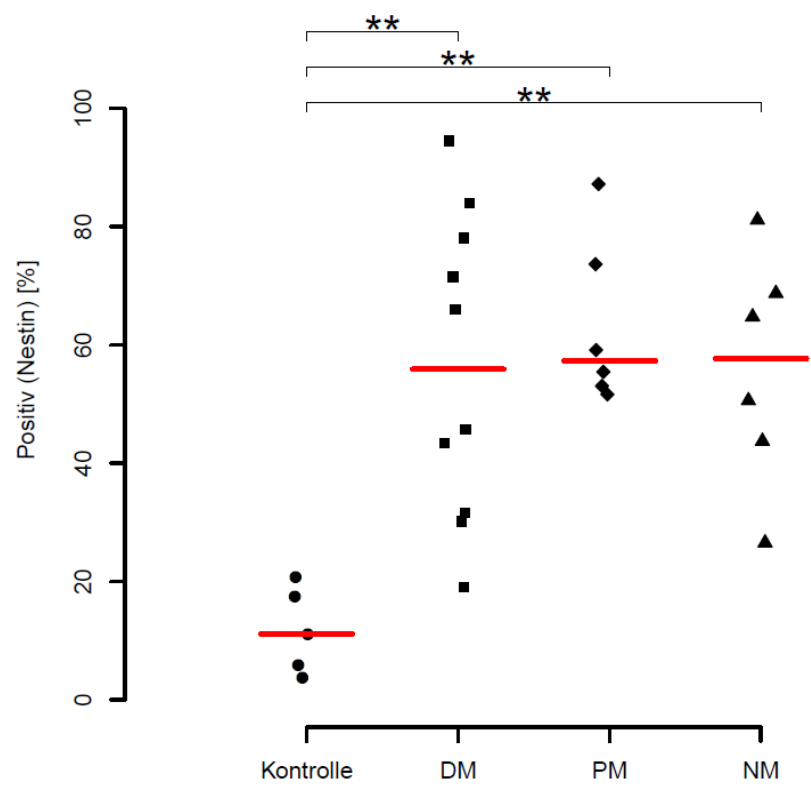

Abbildung 29: Anzahl der Nestin ${ }^{+}$-Muskelfasern pro Muskelfaserzahl in den Vergleichsgruppen DM, PM, NM sowie Kontrollgruppe. Die rote Linie stellt den Median dar. [Signifikante Unterschiede der Verteilungen mittels Wilcoxon-Rangsummentest: ${ }^{* *} \mathrm{p}<$ $0,01]$

Auch in der Doppelfärbung Nestin/MHC-I wurde eine signifikante Aufregulation der doppelt positiven Fasern beobachtet, wobei stark ausgeprägt in der DM- und der PMGruppe, wie in Tabelle 28 und Abbildung 30 zu sehen. 
Tabelle 28: Vergleich der Nestin ${ }^{+}-/ \mathrm{MHC}^{+} \mathrm{I}^{+}$-Muskelfasern pro Muskelfaserzahl. Dargestellt sind der p-Wert des Kruskal-Wallis-Tests für den Gesamtvergleich aller Untergruppen sowie die p-Werte des Wilcoxon-Rangsummentests für die Einzelvergleiche der Gruppen.

\begin{tabular}{cccccc}
\hline Kruskal-Wallis & p-Wert & Kontrolle & DM & PM & NM \\
\hline 0,0033 & KG & --- & 0,003 & 0,008 & 0,021 \\
& DM & --- & --- & 0,635 & 0,056 \\
& PM & --- & --- & --- & 0,31 \\
\hline
\end{tabular}

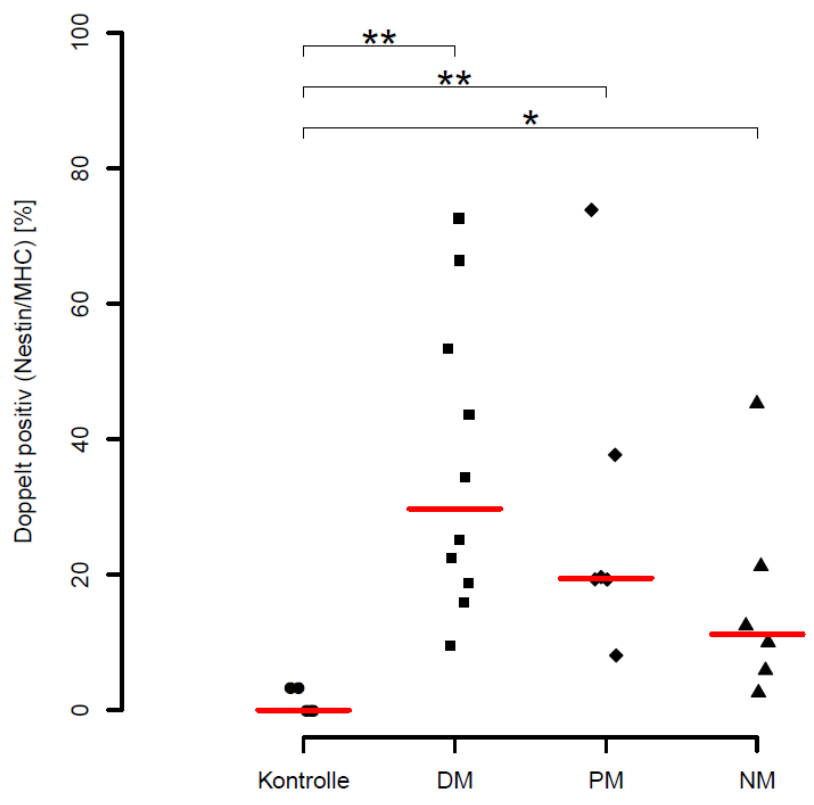

Abbildung 30: Anzahl der Nestin ${ }^{+}-\mathrm{MHC}^{+} \mathrm{I}^{+}$-Muskelfasern pro Muskelfaserzahl in den Vergleichsgruppen DM, PM, NM sowie Kontrollgruppe. Die rote Linie stellt den Median dar. [Signifikante Unterschiede der Verteilungen mittels Wilcoxon-Rangsummentest: * $\mathrm{p}<$ $0,05 ; * * \mathrm{p}<0,01]$

\subsubsection{Muskuläre Aufregulation von CXCR6}

Der Chemokinrezeptor CXCR6 wies eine signifikante Aufregulation in den Muskelfasern der PM-Gruppe sowohl gegenüber der Kontrollgruppe als auch gegenüber der NMGruppe auf, wie Tabelle 29 und Abbildung 31 zu entnehmen sind. 
Tabelle 29: Vergleich der CXCR6 ${ }^{+}$-Muskelfasern pro Muskelfaserzahl. Dargestellt sind der p-Wert des Kruskal-Wallis-Tests für den Gesamtvergleich aller Untergruppen sowie die pWerte des Wilcoxon-Rangsummentests für die Einzelvergleiche der Gruppen.

\begin{tabular}{cccccc}
\hline Kruskal-Wallis & p-Wert & Kontrolle & DM & PM & NM \\
\hline 0,0394 & KG & --- & 0,254 & 0,004 & 0,329 \\
& DM & --- & --- & 0,093 & 0,958 \\
& PM & --- & --- & --- & 0,041 \\
\hline
\end{tabular}

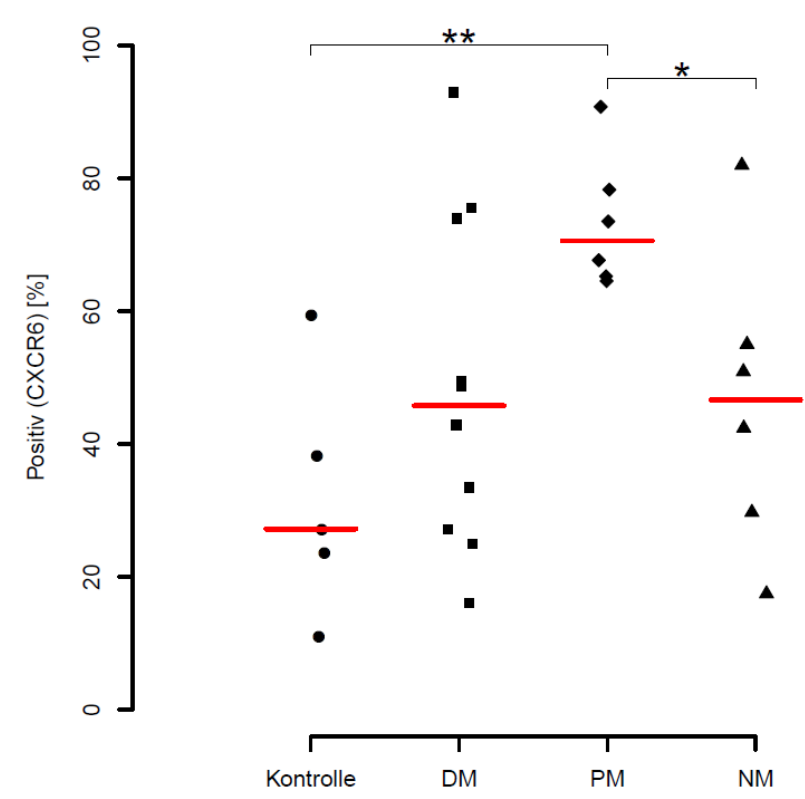

Abbildung 31: Anzahl der CXCR6 ${ }^{+}$-Muskelfasern pro Muskelfaserzahl in den Vergleichsgruppen DM, PM, NM sowie Kontrollgruppe. Die rote Linie stellt den Median dar. [Signifikante Unterschiede der Verteilungen mittels Wilcoxon-Rangsummentest: * $\mathrm{p}<$ $0,05 ; * * \mathrm{p}<0,01]$

\subsubsection{Muskuläres CXCR6 im Vergleich zu CD4 und CD8}

Die in den Muskelfasern dargestellte CXCR6-Aufregulation wurde in einer Doppelfärbung mit CD4 und CD8 verglichen. Das ebenfalls auf TH1- und TH2-Zellen vorkommende CXCR6 wurde dabei auf doppelte Positivität hin mit diesen Immunzell-Rezeptoren verglichen. Dabei wurden keine signifikanten Unterschiede der doppelt positiven Fasern im Vergleich zur Kontrollgruppe nachgewiesen, wie Tabelle 30 und Abbildung 32 zu entnehmen sind. 
Tabelle 30: Vergleich doppelt positiver $\mathrm{CXCR}^{+}-/ \mathrm{CD} 4^{+}-$und $\mathrm{CXCR} 6^{+}-/ \mathrm{CD} 8^{+}-$ Muskelfasern. Dargestellt sind der $\mathrm{p}$-Wert des Kruskal-Wallis-Tests für den Gesamtvergleich aller Untergruppen sowie die p-Werte des Wilcoxon-Rangsummentests für die Einzelvergleiche der Gruppen.

\begin{tabular}{cccccc}
\hline $\begin{array}{c}\text { Kruskal-Wallis } \\
\text { CD4 }\end{array}$ & p-Wert & Kontrolle & DM & PM & NM \\
\hline 0,2455 & KG & --- & 0,339 & 0,099 & 0,271 \\
& DM & --- & --- & 0,219 & 0,56 \\
& PM & --- & --- & --- & 0,423 \\
$\begin{array}{c}\text { Kruskal-Wallis } \\
\text { CD8 }\end{array}$ & p-Wert & Kontrolle & DM & PM & NM \\
0,307 & KG & --- & 0,371 & 0,792 & 0,464 \\
& DM & --- & --- & 0,431 & 0,116 \\
& PM & --- & --- & --- & 0,24 \\
\hline
\end{tabular}
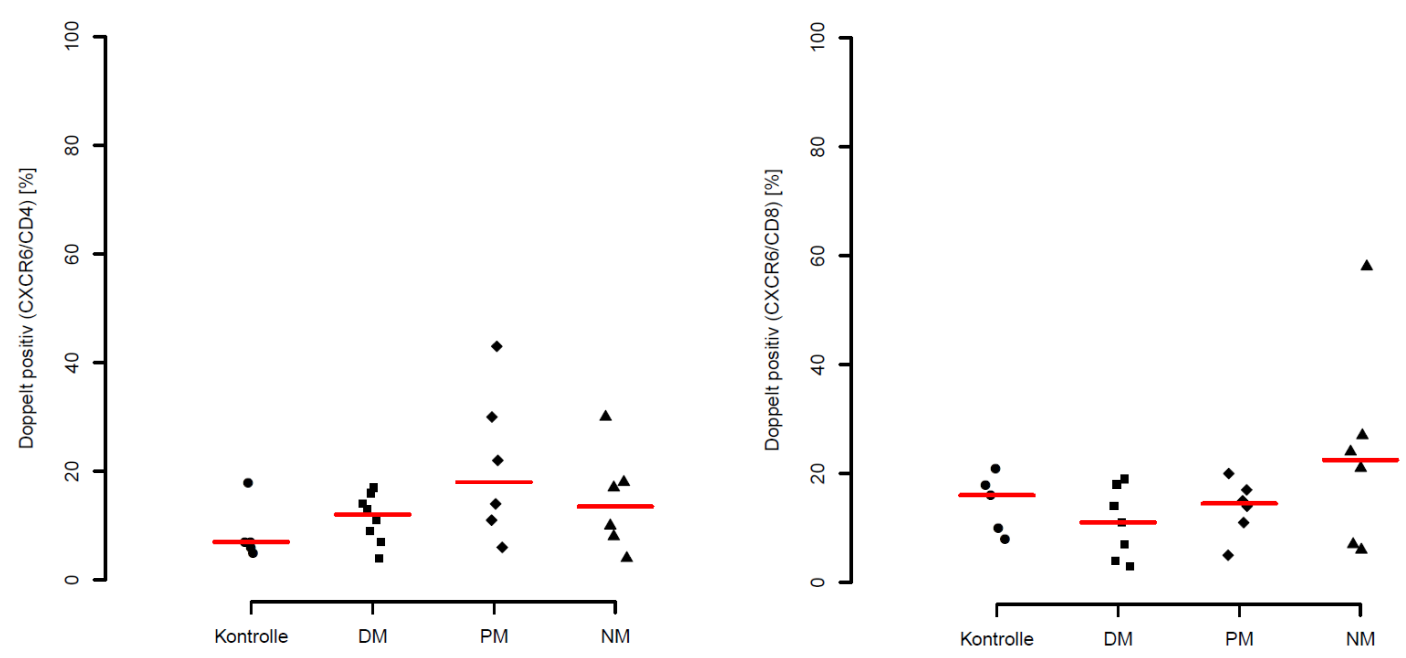

Abbildung 32: Anzahl der $\mathrm{CXCR}^{+}-/ \mathrm{CD}^{+}-$(links) und $\mathrm{CXCR}^{+}-/ \mathrm{CD}^{+}-$(rechts) Muskelfasern pro Muskelfaserzahl in den Vergleichsgruppen DM, PM, NM sowie Kontrollgruppe. Die rote Linie stellt den Median dar.

\subsection{Angiogene Mediatoren bei Patienten mit inflammatorischen Myositiden}

Angiogene Mediatoren sind in die Mobilisierung hämatopoetischer Stamm- und Vorläuferzellen und damit in die Prozesse von Vaskulo- und Angiogenese involviert. Im Folgenden sind statistische Analysen auf die Mediatoren CXCL16, VEGF und Angiopoetin 1 dargestellt. 


\section{CXCL16:}

Der einzige Ligand von CXCR6 wird u. a. auf Makrophagen, dendritischen Zellen, endothelialen und glatten Muskellzellen exprimiert (Hattermann et al. 2008). Aufgrund seiner proangiogenen Aktivität wurde es im Plasma der Patientengruppen DM, PM und NM untersucht. Dabei wurde für alle drei Patientengruppen eine signifikante Erhöhung gegenüber der Kontrollgruppe nachgewiesen wie Tabelle 31 und Abbildung 2 zeigen. Dabei fiel die Erhöhung für die DM-Gruppe gegenüber gesunden Probanden hoch signifikant aus.

Tabelle 31: Vergleich von CXCL16 im Plasma von Patienten mit DM, PM, NM. Dargestellt sind der p-Wert des Kruskal-Wallis-Tests für den Gesamtvergleich aller Untergruppen sowie die p-Werte des Wilcoxon-Rangsummentests für die Einzelvergleiche der Gruppen.

\begin{tabular}{cccccc}
\hline $\begin{array}{c}\text { Kruskal- } \\
\text { Wallis }\end{array}$ & p-Wert & Kontrolle & DM & PM & NM \\
\hline 0,0035 & KG & --- & 0,001 & 0,028 & 0,031 \\
& DM & --- & --- & 0,042 & 0,397 \\
& PM & --- & --- & --- & 0,368 \\
\hline
\end{tabular}

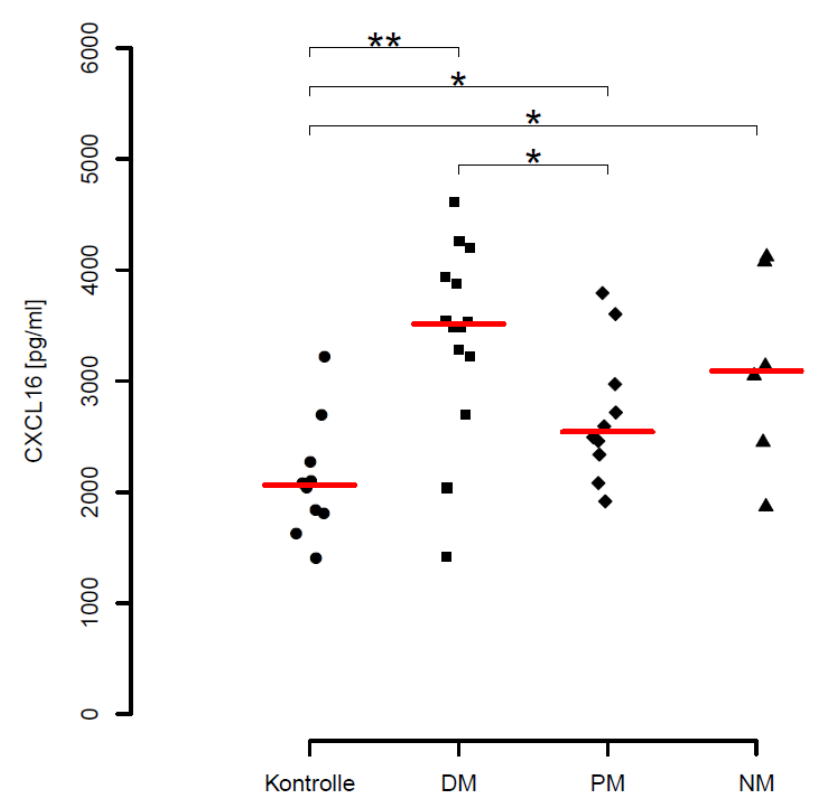

Abbildung 33: Vorkommen von CXCL16 in den Vergleichsgruppen DM, PM, NM sowie Kontrollgruppe. Die rote Linie stellt den Median dar. [Signifikante Unterschiede der Verteilungen mittels Wilcoxon-Rangsummentest: $\left.{ }^{*} \mathrm{p}<0,05 ;{ }^{* *} \mathrm{p}<0,01\right]$ 


\section{VEGF:}

VEGF ist in die Mobilisierung hämatopoetischer Stamm- und Vorläuferzellen sowie VEGFR-2-positiver endothelialer Vorläufer involviert (Moore et al. 2001). In dieser Arbeit wurde im Vergleich zur Kontrollgruppe in der NM-Gruppe eine Tendenz zur Aufregulation nachgewiesen. Es zeigten sich keine Signifikanzen zwischen den untersuchten Gruppen, wie in Tabelle 32 und Abbildung 34 zu entnehmen.

Tabelle 32: Vergleich von VEGF im Plasma. Dargestellt sind der p-Wert des KruskalWallis-Tests für den Gesamtvergleich aller Untergruppen sowie die p-Werte des WilcoxonRangsummentests für die Einzelvergleiche der Gruppen.

\begin{tabular}{cccccc}
\hline Kruskal-Wallis & p-Wert & Kontrolle & DM & PM & NM \\
\hline 0,1565 & KG & --- & 0,341 & 0,971 & 0,118 \\
& DM & --- & --- & 0,108 & 0,312 \\
& PM & --- & --- & --- & 0,073 \\
\hline
\end{tabular}

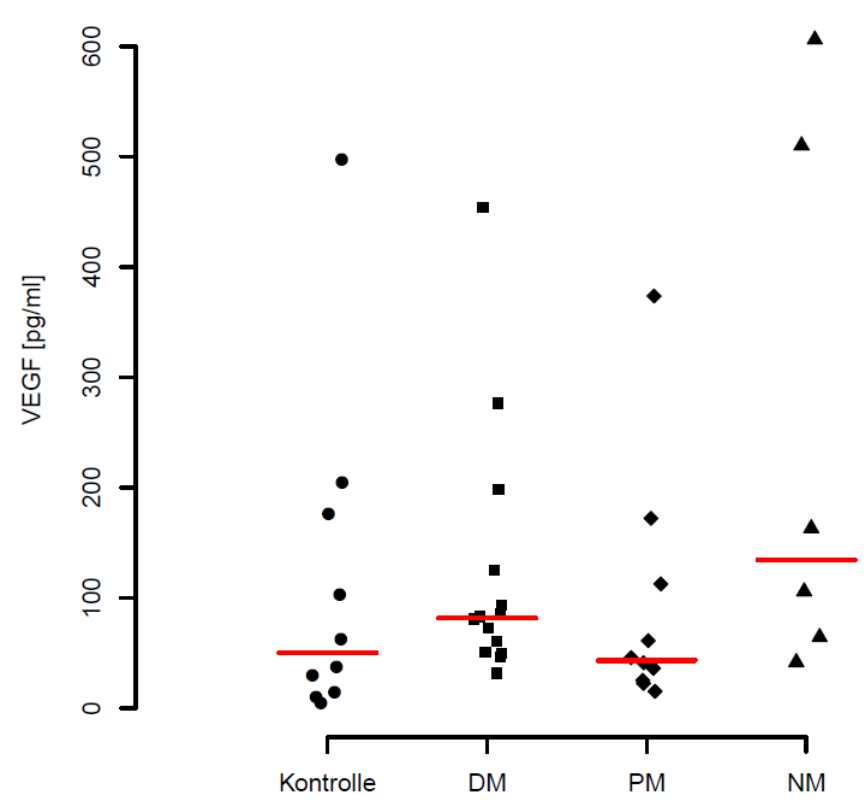

Abbildung 34: VEGF im Plasma in den Vergleichsgruppen DM, PM, NM sowie Kontrollgruppe. Die rote Linie stellt den Median dar.

\section{Angiopoetin 1:}

Das in Vaskulo- und Angiogenese eine wichtige Rolle spielende Angiopoetin 1 zeigte in der DM- und PM-Gruppe eine Tendenz zur Reduktion, wohingegen in der NM-Gruppe eine Tendenz zur Erhöhung gegenüber der Kontrollgruppe nachgewiesen wurde. Die NMGruppe stellte sich gegenüber der PM-Gruppe signifikant erhöht dar. Die Ergebnisse zeigen Tabelle 33 und Abbildung 35. 
Tabelle 33: Vergleich von Angiopoetin 1 im Plasma. Dargestellt sind der p-Wert des Kruskal-Wallis-Tests für den Gesamtvergleich aller Untergruppen sowie die p-Werte des Wilcoxon-Rangsummentests für die Einzelvergleiche der Gruppen.

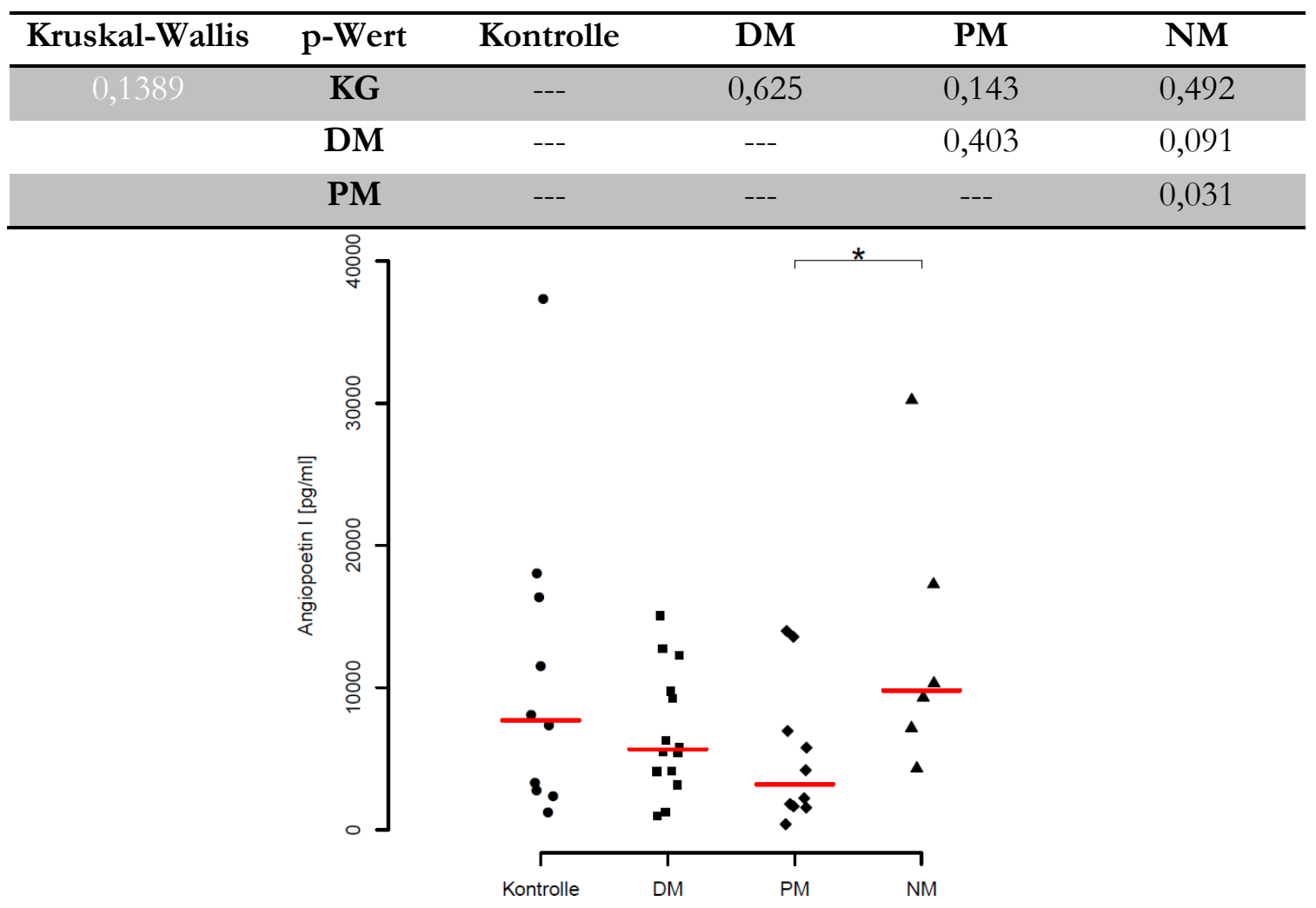

Abbildung 35: Angiopoetin 1 im Plasma in den Vergleichsgruppen DM, PM, NM sowie Kontrollgruppe. Die rote Linie stellt den Median dar. [Signifikante Unterschiede der Verteilungen mittels Wilcoxon-Rangsummentest: $\left.{ }^{*} \mathrm{p}<0,05\right]$ 


\subsection{Korrelationsanalysen innerhalb der Ergebnisgruppen}

In den Vergleichen der EPC- und Muskelbiopsie-Färbeergebnisse ergaben sich keine signifikanten Korrelationen, auch innerhalb der Muskelauswertung in Bezug auf Muskelfasern und -gefäße nicht. Eine starke Tendenz zur Anti-Korrelation wies der Vergleich zwischen Koloniezahl und dem EPC-Rekruitmentfaktor CXCL16 in der NMGruppe nach. Hierbei sank CXCL16 im Plasma der Patienten mit zunehmender Koloniezahl. Diese Korrelation wird in Tabelle 34 und Abbildung 36 dargestellt.

Tabelle 34: Korrelationsanalyse zwischen Koloniezahl und CXCL16 im Plasma. Dargestellt sind der Korrelationskoeffizient berechnet nach Pearson sowie der p-Wert für die Signifikanz der Abweichung von der Nullhypothese (keine Korrelation).

\begin{tabular}{ccc}
\hline $\begin{array}{c}\text { Koloniezahl } \\
\text { vs. CXCL16 }\end{array}$ & $\begin{array}{c}\text { Korrelations- } \\
\text { Koeffizient }\end{array}$ & p-Wert \\
\hline DM & 0 & 1 \\
PM & $-0,13$ & 0,77 \\
NM & $-0,8$ & 0,057 \\
\hline
\end{tabular}

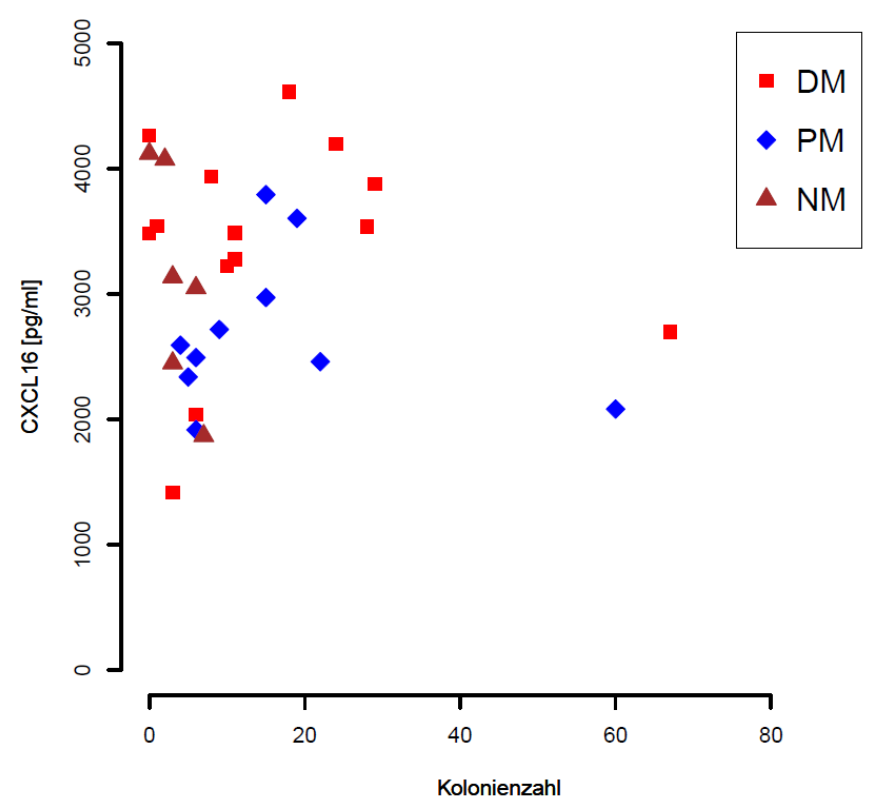

Abbildung 36: Korrelationsanalyse - Koloniezahl versus CXCL16 im Plasma

\subsubsection{Vergleiche der Koloniezahl zu Patientendaten}

In dieser Analyse wurde die Zahl der Kolonien nach Rauchern bzw. Nichtrauchern aufgeteilt und die Koloniezahl mit dem CK-Wert zum Abnahmezeitpunkt der LithiumHeparin-Röhrchen verglichen. Weiterhin wurde die Koloniezahl auf den Einfluss von Prednisolon untersucht sowie eine Korrelation zwischen Koloniezahl versus 
Krankheitsdauer analysiert. Hier zeigten sich keine signifikanten Korrelationen und Tendenzen. Dabei ist anzumerken, dass Infektwerte und EPCs nur zu einem geringen Anteil gleichzeitig bestimmt wurden.

In Abbildung 37 sind die Koloniezahlen bei Rauchern und Nichtrauchern pro Krankheitsgruppe dargestellt. Hierbei gibt es keinen signifikanten Unterschied zwischen den Gruppen.

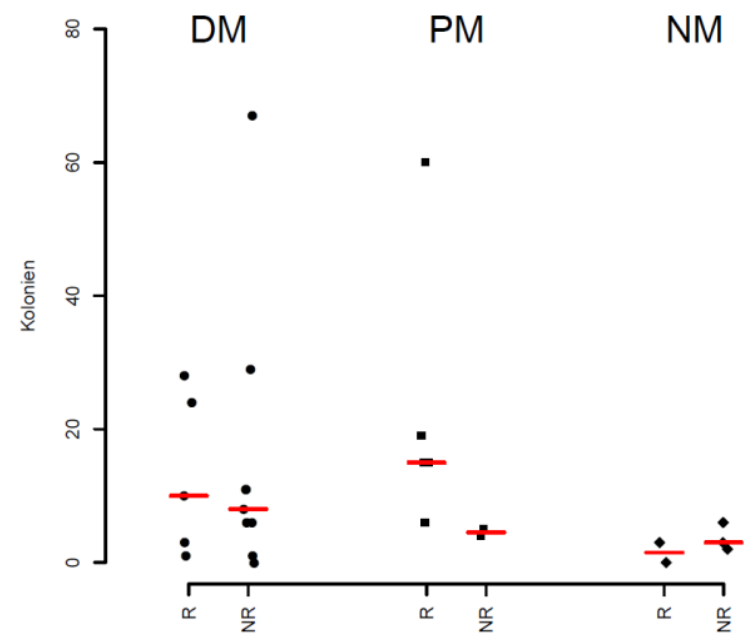

Abbildung 37: Darstellung der Koloniezahlen bei Rauchern (R) und Nichtrauchern (NR) Die rote Linie stellt den Median dar.

Zwischen Koloniezahl und CK zum Abnahmezeitpunkt der EPCs gibt es, wie in Abbildung 38 dargestellt, keine Korrelation.

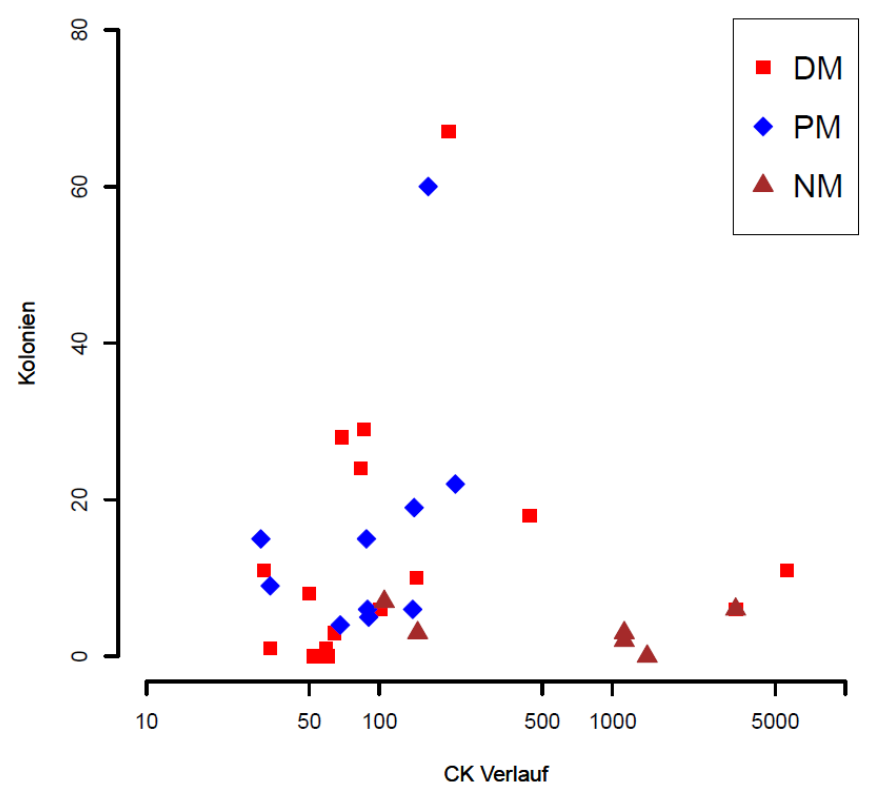

Abbildung 38: Koloniezahl versus CK zum Abnahmezeitpunkt der EPC-Bestimmung 
In Abbildung 39 sind die Koloniezahlen bei Prednisolongaben über und unter 7,5 mg, der Cushing-Schwelle, in den Krankheitsgruppen angegeben. Dabei gibt es keine signifikanten Unterschiede zwischen den Gruppen.

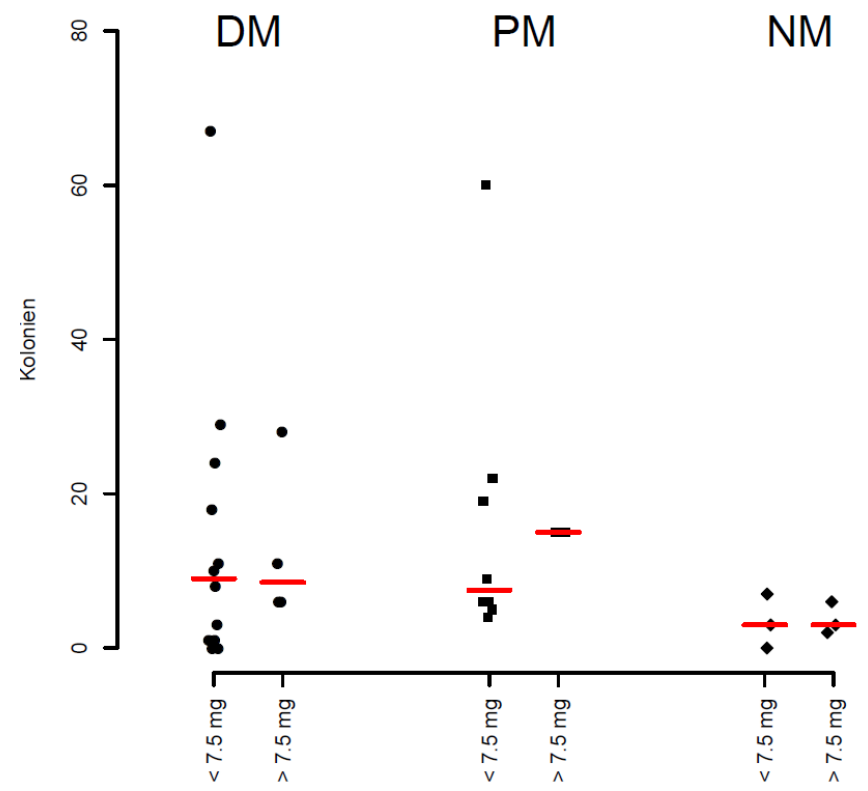

Abbildung 39: Darstellung der Koloniezahlen bei Prednisolontherapie $>7,5 \mathrm{mg}$ und $<7,5 \mathrm{mg}$. Die rote Linie stellt den Median dar.

In Abbildung 40 wird die Korrelationsanalyse zwischen Koloniezahl und Krankheitsdauer analysiert. Dabei ist keine Korrelation detektierbar. Es gibt eine Tendenz zur Abnahme der Koloniezahl mit zunehmender Krankheitsdauer.

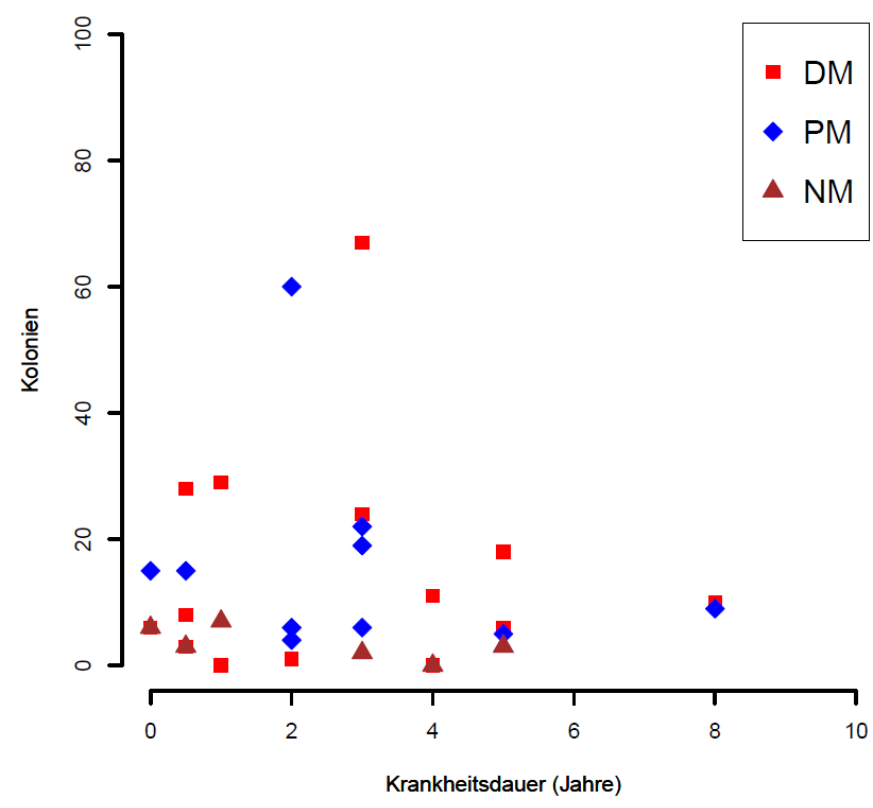

Abbildung 40: Darstellung der Korrelation zwischen Koloniezahl und Krankheitsdauer 


\subsubsection{Zellkernhäufung und Gefäßabnahme an MHC-I- und Nestin-positiven Muskelfasern}

Tabelle 35: Darstellung von Zellkernanhäufungen mittels DAPI Fluoreszenz sowie Gefäßverminderung an Nestin- und MHC-I-positiven Muskelfasern, Angabe in Prozent $(\%)$

\begin{tabular}{|c|c|c|c|c|}
\hline & DAPI $^{+}$ & DAPI $^{+}$ & Gefäßabnahme & Gefäßabnahme \\
\hline Anteil an & Nestin $^{+}$ & ${\mathrm{MHC}-\mathrm{I}^{+}}^{+}$ & Nestin $^{+}$ & ${\mathrm{MHC}-\mathrm{I}^{+}}^{+}$ \\
\hline Kohorte & Muskelfasern & Muskelfasern & Muskelfasern & Muskelfasern \\
\hline DM & $40 \%$ & $30 \%$ & $40 \%$ & $70 \%$ \\
\hline PM & $40 \%$ & $20 \%$ & $40 \%$ & $80 \%$ \\
\hline NM & $33 \%$ & $33 \%$ & $50 \%$ & $83 \%$ \\
\hline KG & $0 \%$ & $0 \%$ & $0 \%$ & $0 \%$ \\
\hline
\end{tabular}

Zellkernhäufungen konnten anhand der HE-Färbung als Immunzellinvasion interpretiert werden. Diese Infiltrate lagen bei der DM vor allem perivaskulär und perifaszikulär, bei der PM vorrangig perimysial und teils endomysial, bei der NM Gruppe in deutlich geringer Ausprägung ebenfalls eher peri- und endomysial.

\subsubsection{Kapillarmikroskopie bei inflammatorischen Myositiden}

Die Befunde der in die Untersuchung eingewilligten Patienten sind in Tabelle 36 dargestellt. Die typischen kapillarmikroskopischen Befunde, die in Abschnitt 1.7 beschrieben wurden, sind vorrangig in der DM-Gruppe, aber zum Teil auch in der PMGruppe nachweisbar. Es ist zu beachten, dass über $90 \%$ der untersuchten Patienten bereits mit Prednisolon oder einem anderen Immunsuppressivum therapiert wurden. In die Gruppe der nekrotisierenden Myopathie konnten nur zwei Patienten eingeschlossen werden. Diese wiesen Verzweigungen und Ektasien auf. In Abbildung 41 sind typische kapillarmikroskopische Befunde bei Dermatomyositis aufgenommen. 
Tabelle 36: Kapillarmikroskopie - Ergebnisse, Pat. = Patient

\begin{tabular}{|c|c|c|c|c|}
\hline & DM & $\mathbf{P M}$ & NM & Kontrolle \\
\hline Kapillarmikroskopie & $\begin{array}{l}47 \% \text { (8 von } 17 \\
\text { Pat.) }\end{array}$ & $\begin{array}{l}64 \% \text { (7 von } 11 \\
\text { Pat.) }\end{array}$ & $\begin{array}{l}29 \% \text { (2 von } 7 \\
\text { Pat.) }\end{array}$ & $0 \%$ \\
\hline Raynaud-Symptomatik & 18 \% (3/17 Pat.) & 27 \% (3/11 Pat.) & $0 \%$ & \\
\hline Kapillarreduktion & $50 \%$ (4/8 Pat.) & $29 \%$ (2/7 Pat.) & $0 \%$ & \\
\hline Einblutung & $25 \%$ (2/8 Pat.) & $29 \%$ (2/7 Pat.) & $0 \%$ & \\
\hline Megakapillaren & $50 \%$ (4/8 Pat.) & $14 \%$ (1/7 Pat.) & $0 \%$ & \\
\hline Verzweigung & $37,5 \%$ (3/8 Pat.) & $43 \%$ (3/7 Pat.) & $50 \%$ (1/2 Pat.) & \\
\hline $\begin{array}{l}\text { Ektasie (aff. und eff. } \\
\text { Schenkel) }\end{array}$ & 75 \% (6/8 Pat.) & $43 \%$ (3/7 Pat.) & $0 \%$ (0/2 Pat.) & \\
\hline
\end{tabular}

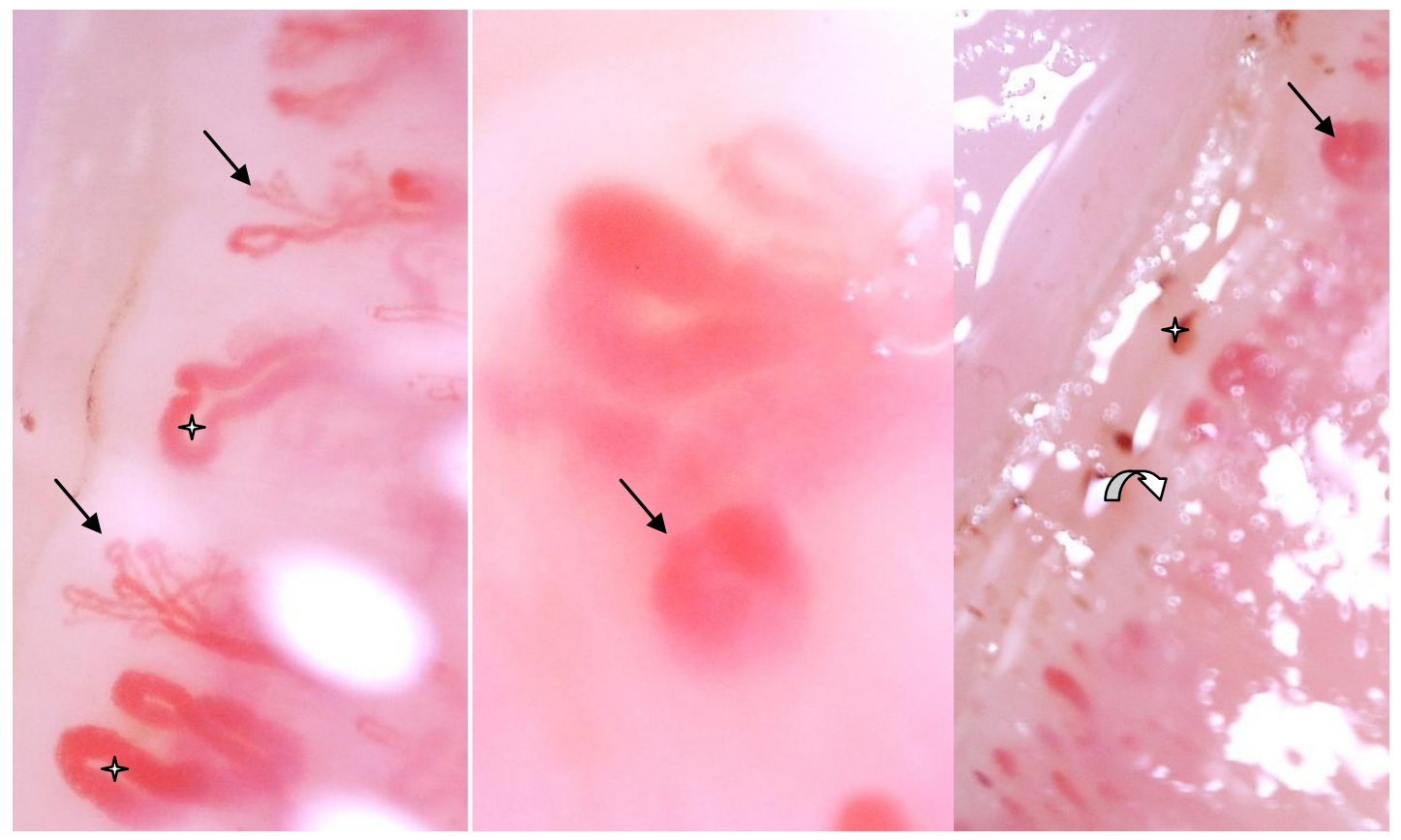

Abbildung 41: Kapillarmikroskopie bei Dermatomyositis

links: Verzweigung (Pfeil) bis hin zur Büschelkapillare und Elongation (Stern) mit gleichmäßiger Ektasie des afferenten und efferenten Kapillarschenkels, Mitte: Megakapillare (Pfeil), rechts: Megakapillare und Einblutungen (Typ A) (Stern) und avaskuläres Areal (großer Pfeil) bei Kapillarreduktion

In Abbildung 42, Abbildung 43 und Abbildung 44 wird die Koloniezahl in Abhängigkeit von den typischen kapillarmikroskopischen Befunden bei Dermatomyositis dargestellt. Dabei zeigt sich eine Tendenz zur Koloniezahlabnahme bei Patienten mit Megakapillaren 
(Dermatomyositis-Gruppe), wie Abbildung 44 zeigt, sowie bei Patienten mit Einblutungen (Polymyositis-Gruppe), wie Abbildung 42 darstellt.

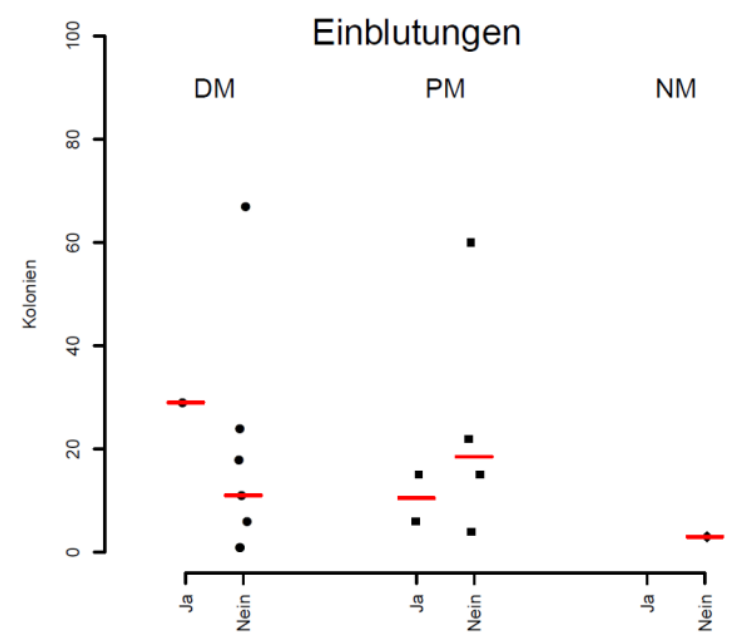

Abbildung 42: Darstellung der Koloniezahl bei Patienten mit Einblutungen in der Kapillarmikroskopie (Ja) bzw. ohne Einblutungen (Nein). Die rote Linie stellt den Median dar.

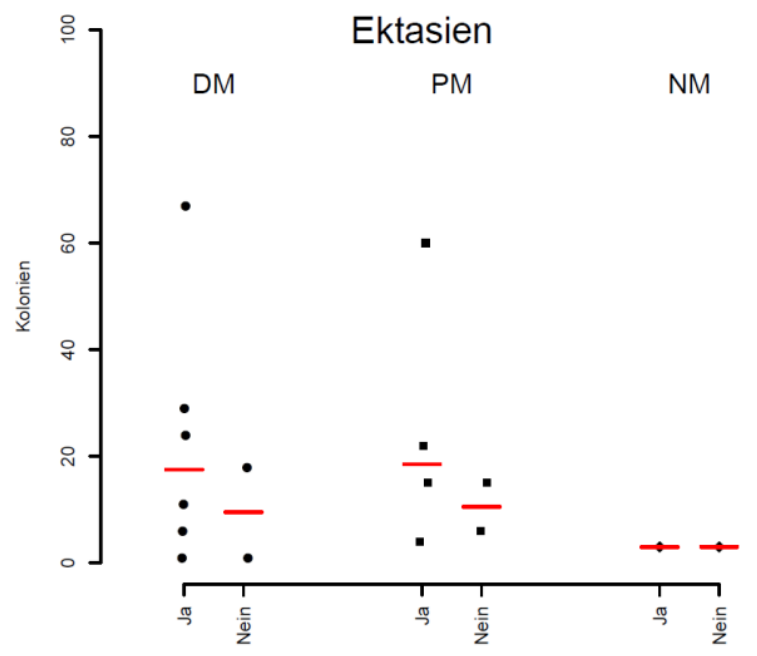

Abbildung 43: Darstellung der Koloniezahl bei Patienten mit Ektasie des afferenten und efferenten Kapillarschenkels in der Kapillarmikroskopie (Ja) bzw. ohne Ektasie (Nein). Die rote Linie stellt den Median dar. 


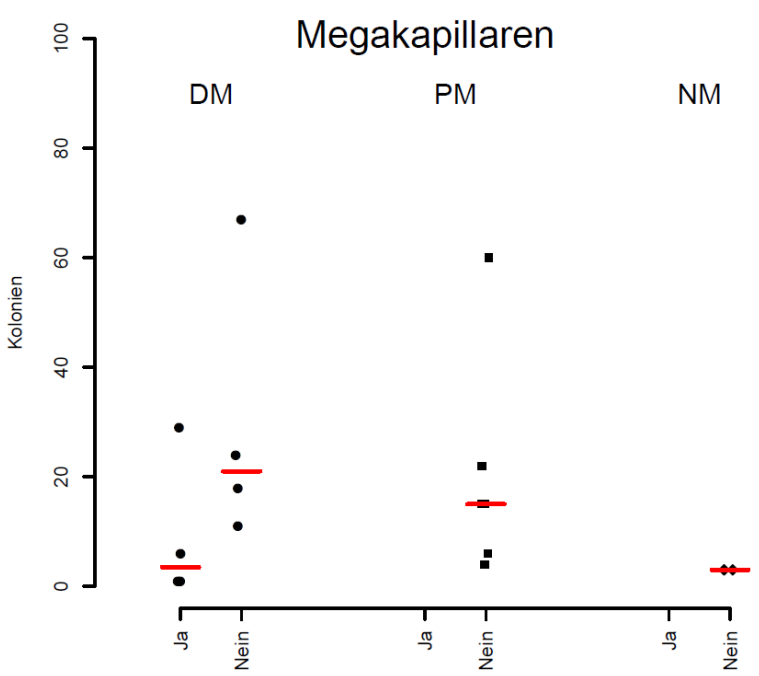

Abbildung 44: Darstellung der Koloniezahl bei Patienten mit Megakapillaren in der Kapillarmikroskopie (Ja) bzw. ohne Megakapillaren (Nein). Die rote Linie stellt den Median dar. 


\section{Diskussion}

\subsection{Zusammenfassung der Ergebnisse}

Die unter Abschnitt 3 dargestellten Ergebnisse lassen sich wie folgt zusammenfassen:

I. Die EPC-Regenerationsfähigkeit zeigte sich nach Untersuchung der Koloniezahl bei allen drei untersuchten Myositisformen signifikant reduziert. Peripher zirkulierende EPCs wiesen auf Ebene der angio- und hämangiopoetischen Vorläufer eine Tendenz zur Reduktion auf.

II. Bei den IIM der Dermatomyositis (DM) und Polymyositis (PM) stellte sich eine Kapillarreduktion pro Muskelfaseranteil dar. Bei Patienten mit nekrotisierender Myopathie (NM) wurde hingegen nur eine Tendenz zur Kapillarreduktion nachgewiesen.

III. Die Koloniezahl zeigte sich unter folgenden Gegebenheiten tendenziell vermindert: steigendes CXCL16 als angiogener Mediator (NM-Gruppe), zunehmende Länge der Krankheitsdauer, Vorhandensein von Megakapillaren (DM-Gruppe) und Einblutungen (PM-Gruppe) in der Kapillarmikroskopie

IV. Die tendenziell verminderte Aufregulation von S100A4 an EPCs bei Patienten mit DM gibt den Hinweis auf ein reduziertes angiogenes Potential und eine gestörte Zell-Differenzierung. Die zusätzliche Untersuchung auf $\alpha \mathrm{SMA}$ wies keine signifikanten Unterschiede nach, so dass sich insgesamt durch die beiden Marker kein Hinweis auf eine EndoMT ergab.

V. Vaskuläres CXCR6 als EPC-Rekruitmentfaktor war in allen drei Entitäten signifikant aufreguliert. Zudem zeigte sich sein Ligand CXCL16 als proangiogener Mediator ebenfalls signifikant erhöht.

VI. Im Vergleich zur Kontrollgruppe ergaben sich dementgegen bei den angiogenen Mediatoren VEGF und Angiopoetin 1 keine signifikanten Ergebnisse. In der NM-Gruppe sah man lediglich eine tendentielle Aufregulation von VEGF, in der PM-Gruppe sogar eine Tendenz zur Abregulation von Angiopoetin 1.

VII. Vaskuläres Nestin wurde als Regenerationsmarker in der DM-Gruppe mit Tendenz zur Verminderung nachgewiesen, die Anf ärbbarkeit in der PM- und NM-Gruppe zeigte sich gleich derjenigen bei gesunden Probanden.

VIII. In den Muskelfaserfärbungen zeigte sich Nestin in allen untersuchten IIM signifikant aufreguliert, MHC-I zeigte dies wie erwartet bei den DM- und PMGruppen, am schwächsten jedoch in der NM-Gruppe.

IX. Muskuläres CXCR6 konnte in der PM-Gruppe signifikant aufreguliert nachgewiesen werden. Die Kontrolle auf eine fälschliche signifikante T-ZellDarstellung konnte anhand der CXCR6-/CD4- und CXCR6-/CD8-Färbungen ausgeschlossen werden. 


\subsection{Endotheliale Vorläuferzellen bei inflammatorischen Myositiden}

1997 wurden erstmals von Asahara et al. CD34+-Zellen aus humanem peripheren Blut isoliert. Nach Kultivierung auf Fibronektin unter proendothelialen Bedingungen wurden in vitro endotheliale Charakteristika nachgewiesen. In vivo konnte nach Infusion der Zellen in iatrogen herbeigeführte ischämische Gewebe eine verbesserte postischämische Reperfusion erzielt werden (Asahara et al. 1997). Seither wurde viel zu diesen Zellen geforscht und kontroverse Diskussionen um deren Untergruppen und die jeweiligen Eigenschaften, Marker sowie Kultivierungsprotokolle geführt. Richardson und Yoder postulierten daher den Begriff der „ProAngiogenicCells“ (PACs) (Richardson und Yoder 2011), die Unterformen der frühen endothelialen Vorläuferzellen zusammenfassen. Diese Zellen können die vaskuläre Regeneration unter physiologischen und pathophysiologischen Bedingungen durch parakrine Mechanismen fördern. Dies wurde bereits im Rahmen von ischämischen Erkrankungen wie Myokardinfarkt, Apoplex, bei Nierenerkrankungen oder bei rheumatischen Erkrankungen untersucht (Assmus et al. 2007; Fan et al. 2010; S Patschan et al. 2013; Schuleri et al. 2008).

Ausgehend von der Annahme, dass Immunzellen über kleinste Gefäße des Muskels diesen infiltrieren, kann bei inflammatorischen Myositiden eine endotheliale Dysfunktion angenommen werden. Bei der Dermatomyositis ist zudem bekannt, dass muskuläre Gefäße direkt geschädigt werden. Die Arbeitsgruppe um Ekholm hat eine solche Verminderung zirkulierender EPCs bei Patienten mit Dermato- und Polymyositis beschrieben. Weiterhin war die Differenzierung zu reifen Endothelzellen gestört (Ekholm et al. 2016). Im Serum der Patienten wurde zudem eine erhöhte Typ I-Interferon-Aktivität gemessen, was das Pathogenesemodell nach Greenberg mit vermehrten Typ I-Interferon-Ablagerungen an der Muskulatur von Patienten mit Dermatomyositis stützt (Ekholm et al. 2016; Greenberg 2010). Neutralisierende Antikörper gegen Interferon Typ I-Rezeptor und IL-18 zeigten zumindest in einer kleinen Kohorte einen neutralisierenden Effekt auf die gestörte EPCRegeneration (Ekholm et al. 2016).

Auch in der vorliegenden Arbeit wurde eine endotheliale Regenerationsstörung beobachtet. Diese bezog sich hochsignifikant auf die Gruppen der nekrotisierenden Myopathie und der Dermatomyositis. Auch die Polymyositis-Gruppe wies eine signifikant verminderte Regenerationsfähigkeit der EPCs auf. Dementgegen stand nur eine Tendenz zur Verminderung peripher zirkulierender $\left(\right.$ VEGFR $\left.-2^{+} / \mathrm{CD} 133^{+}\right)$endothelialer Vorläuferzellen bei den drei inflammatorischen Myositiden, die im Gegensatz zu den Beobachtungen von Ekholm et al. standen.

Die Auswertung der primär zu untersuchenden Krankheitsgruppen (DM, PM, NM) wies für c-KIT ${ }^{+}-/ C D 133^{+}$-Vorläufer eine signifikante Verminderung in der DM-Gruppe nach. Diese Beobachtung sowie die gestörte Regenerationsfähigkeit von EPCs kann für den Verbrauch dieser Vorläuferzellen, eine Bildungsstörung oder möglicherweise eine 
veränderte Überlebensrate vor dem Hintergrund der Grunderkrankung sprechen, was zukünftig zu ermitteln ist.

\subsection{Angiogene Mediatoren von frühen EPCs im Plasma}

Angiogene Mediatoren wie VEGF wurden im Serum von Tiermodellen bei induzierter Ischämie sowie bei Patienten mit akutem Myokardinfarkt erhöht nachgewiesen (Asahara et al. 1999; Shintani et al. 2001). Dabei fördert VEGF die Proliferation von EPCs (Asahara et al. 1999), die Migration dieser sowie die Gefäßbildung (Hoeben et al. 2004). In der Kohorte der Myositis-Patienten mit signifikanter EPC-Regenerations- und Reifungsstörung in allen drei Patientengruppen wurde lediglich für die NM-Gruppe eine Tendenz zur Erhöhung von VEGF gesehen. In den Gruppen mit Kapillarreduktion, vorrangig der DM-Gruppe, aber nach Literatur und den vorliegenden Ergebnissen auch der PM-Gruppe, scheint die VEGF-Aktivierung entgegen den Erwartungen inadäquat, vermindert oder anteilig verbraucht. Hypoxische Zustände, die zur VEGF-Aufregulation im Serum (Hoeben et al. 2004) oder an Muskelfasern führen (Grundtman et al. 2008), werden nach aktueller Datenlage für die DM und PM vermutet.

Das CXCL16/CXCR6-Paar wird mit EPC-Rekruitment assoziiert (Isozaki et al. 2013). Neben der Fluoreszenzfärbung der Gefäße auf CXCR6 wurde CXCL16 im Plasma der Patienten bestimmt. Es konnte eine signifikante Aufregulation für alle drei Patientengruppen, dabei hochsignifikant in der DM-Gruppe, nachgewiesen werden. Zudem wurde eine starke Tendenz zur Antikorrelation zwischen Koloniezahl und CXCL16 im Plasma von Patienten mit nekrotisierender Myopathie gesehen. Dies bedeutet, dass höhere Koloniezahlen mit einer verminderten Konzentration an CXCL16 im Plasma einhergehen. Trotz der hochregulierten Werte von CXCL16 zeigt sich insbesondere in der DM-Gruppe eine Kapillarreduktion mit ausgeprägter EPC-Regenerationsstörung. Es stellt sich daher die Frage nach der Stärke des Rekrutierens bei inflammatorischen Myositiden. Zumindest auf T-Zellen, auf denen CXCR6 ebenfalls exprimiert wird, ist dieser Rezeptor für CXCL16 nur als schwacher Mediator beschrieben, die Chemotaxis zu CXCL16 schwach (Latta et al. 2007). Isozaki et al. hatten CXCL16 hingegen als potenten angiogenen Mediator bei Patienten mit rheumatoider Arthritis hinsichtlich der SynoviaVaskularisierung proklamiert (Isozaki et al. 2013). Vor dem Hintergrund der uns vorliegenden Ergebnisse lässt sich die potente angiogene Eigenschaft in der hier bearbeiteten Untersuchungskonstellation nicht bestätigen.

Angiopoetin 1 ist an der Reifung von Gefäßen, der Migration, der Adhäsion und dem Überleben endothelialer Zellen beteiligt (Fagiani und Christofori 2013). In der untersuchten Kohorte wies es für die DM- und PM-Gruppe eine Tendenz zur Verminderung auf. Die NM-Gruppe hatte der Kontrollgruppe gegenüber äquivalente Werte. Wie auch bei VEGF ist hier ein in der Literatur potenter angiogener Mediator bei 
einem Krankheitsbild mit vermuteten hypoxischen Arealen nicht aufreguliert. Es ist unklar, ob die Aktivierung inadäquat, gestört oder produziertes Angiopoetin 1 verbraucht wird.

\subsection{Einflüsse auf EPCs}

Es gibt Hinweise darauf, dass EPCs durch Medikamente beeinflusst werden können. Da über $80 \%$ der in dieser Arbeit eingeschlossenen Patienten lang- oder auch kurzfristig Prednisolon einnahmen, ist der Einfluss der Medikamentengruppe auf EPCs von Interesse. Der Effekt von Glukokortikoiden wurde z. B. bei Patienten mit rheumatoider Arthritis untersucht. Dabei beobachtete man, dass sich verminderte EPC-level unter einer siebentägigen Prednisolon-Therapie mit $50 \mathrm{mg}$ täglich über je drei Tage und anschließend 25 mg täglich über vier Tage normalisierten (Grisar et al. 2007). Diese Normalisierung ging zudem mit einer klinischen Verbesserung und sinkenden IL-6- sowie TNF-Werten einher. Eine low-dose-Therapie hingegen zeigte keinen Effekt auf die EPCs (Grisar et al. 2007). Dies spricht für einen vaskulogenen Effekt von vorübergehend hohen Glukokortikoiddosen. Dementgegen steht ein negativer Effekt von Glukokortikoiden auf den Prozess der Angiogenese (Small et al. 2005) und vaskuläre Komplikationen durch Störung des NOAngebotes unter hohen Kortisondosen (Iuchi et al. 2003). In dieser Arbeit lag, entgegen der vorliegenden Literatur, nur ein einzelner Koloniewert der PM-Gruppe bei Prednisolongabe $>7,5 \mathrm{mg}$ im Bereich der Kontrollgruppe. Dies ist Abbildung $39 \mathrm{zu}$ entnehmen, jedoch aufgrund der geringen Statistik nicht verwertbar. Weiterhin müssten aufgrund der geringen Statistik und EPC-Bestimmung zu einem einzigen Zeitpunkt für weitergehende Aussagen Verlaufskontrollen der Koloniezahl unter Prednisolontherapie untersucht werden.

Andere antiinflammatorische Therapien wie Methotrexat und Etanercept hatten bei Patienten mit juveniler idiopathischer Arthritis keinen Einfluss auf die EPC-level. Allerdings wirkten bei diesen Patienten Glukokortikoidtherapien eher reduzierend auf EPCs (Rusak et al. 2015). Es fehlten jedoch genaue Angaben zur Dauer der Glukokortikoideinnahme. Medikamentöse Einflüsse auf EPCs bei Patienten mit inflammatorischen Myositiden sind bisher nicht beschrieben.

Neben diesen antiinflammatorischen Therapien haben auch Statine einen stimulierenden Effekt auf EPCs. Dieser konnte durch Vasa et al. bei Patienten mit koronarer Herzkrankheit nachgewiesen werden (Vasa et al. 2001). Dimmler et al. fanden Hinweise dafür, dass Statine die Differenzierung und Anzahl von EPCs bis auf Ebene c-KITpositiver hämatopoetischer Stammzellen beeinflussen (Dimmler et al. 2001). In der Literatur werden bei inflammatorischen Myositiden Statine vorrangig als mögliche Auslöser der nekrotisierenden Myopathie diskutiert. Da in der vorliegenden Kohorte insgesamt nur fünf Patienten der DM- und PM-Gruppe Statine einnahmen und die Patienten der NMGruppe gar nicht, wurde aufgrund geringer Fallzahlen hier keine Untergruppierung vorgenommen. 
Weiterhin gibt es auch Hinweise, dass die Gabe von Erythropoetin die Mobilisierung von EPCs stimulieren kann (Heeschen et al. 2003).

Auch das Rauchen hat einen EPC-reduzierenden Effekt (Grisar et al. 2007). In dieser Arbeit konnte eine solche Tendenz in der DM- und NM-Gruppe gesehen werden. In der PM-Gruppe war der Effekt bei kleiner Fallzahl, wie in Abbildung 37 gezeigt, eher umgekehrt.

Wie Abbildung 38 und Abbildung 40 ebenfalls zu entnehmen ist, gibt es zwischen Krankheitsdauer und Kolonizahl bzw. Höhe der CK-Werte und Koloniezahl keine signifikante Korrelation. Im Zusammenhang mit der Krankheitsdauer ist lediglich eine Tendenz zur gestörten EPC-Regenerationsfähigkeit bei zunehmender Krankheitsdauer zu sehen.

Ein weiterer zu diskutierender Einfluss auf EPCs stellt die Inflammation dar. Bisher wurde vor allem im Rahmen der Arteriosklerose Entstehung eine endotheliale Dysfunktion mit verminderter Stickstoffmonoxidproduktion (NO) im Zusammenhang mit Inflammation durch kardiovaskuläre Risikofaktoren erforscht (Szmitko et al. 2003). Als Risikofaktoren auf EPCs wurde dabei erhöhtes CRP beschrieben, das in der Folge eine verminderte NO Produktion auslöst (Verma et al. 2002). In dieser Arbeit zeigte die Korrelationsanalyse zwischen CRP und Regenerationsfähigkeit der EPCs eine Unkorrelation, was mit den verschiedenen Abnahmezeitpunkten der jeweiligen Parameter zusammenhängen kann. Das gleiche Ergebnis wurde in der Analyse zwischen Leukozyten und Koloniezahl beschrieben.

Im Rahmen von Autoimmunerkrankungen beschrieben Kahlenberg et al. eine endotheliale Dysfunktion bei Patienten mit systemischem Lupus erythematodes. Diese führten sie auf Typ I-Interferon und das durch das Inflammasom produzierte Interleukin-18 zurück (Kahlenberg und Kaplan 2014). Der Begriff Inflammasom fasst dabei einen Komplex an Molekülen zusammen, die in der Folge die Caspase-1 und damit die folgende Aktivierung inflammatorischer Zytokine wie Interleukin-18 auslöst (Kahlenberg und Kaplan 2014). Aufgrund erhöhter Typ I-Interferonwerte bei Patienten mit DM und anti-Jo-1 bzw. antiRo 52-/anti-Ro-60-assoziierter PM (Eloranta et al. 2007) sowie erhöhtem Nachweis von Interleukin-18 an endo- und perimysialen Makrophagen wurde der Zusammenhang zur endothelialen Dysfunktion auch durch Ekholm et al. bei Patienten mit DM und PM vermutet. In der Untersuchung bestätigte sich schließlich eine endotheliale Dysfunktion. Diese konnte durch neutralisierende Antikörper gegen Typ I-Interferon und Interleukin-18 relativiert werden (Ekholm et al. 2016). Diese Beobachtungen lassen einen inflammatorischen Einfluss auf EPCs vermuten.

\subsection{Gefäße bei inflammatorischen Myositiden}

Bei der Dermatomyositis tritt, wie unter 1.2.1 beschrieben, frühzeitig der C5b-9 MAC (membrane attack complex) auf. Im Anschluss an diese Komplementaktivierung kommt es zu 
einem Gefäßschaden, dem Ischämie und Muskelfibrillenatrophie folgen (Malik et al. 2016). Weiterhin tritt eine Kapillarreduktion mit hypoxiebedingter perifaszikulärer Atrophie und Nekrose auf (Rider und Miller 2011). Auch in der vorliegenden Arbeit wurde die Dichte der Gefäße ermittelt. Dafür wurden Biopsieschnitte auf den Endothelzellmarker CD31 gefärbt. In der Gruppe der Dermatomyositis bestätigte sich die in der Literatur beschriebene Kapillarbettreduktion. Aufgrund der signifikanten EPC-Regenerationsstörung lässt sich hier ein Zusammenhang zwischen endothelialer Dysfunktion und Kapillarbettreduktion annehmen. Die eingeschlossenen Patienten hatten eine Krankheitsdauer von im Mittel 5,6 Jahren, wovon vier Fälle mit einem schweren Verlauf und hohen Prednisolondosen $>7,5 \mathrm{mg}$ einhergingen. Eine Patientin verstarb zudem an den Folgen von Krankheit, immunsuppressiver Therapie und verkomplizierendem septischen Verlauf. In Bezug auf die Kapillarreduktion gibt es in der Literatur jedoch auch Hinweise darauf, dass diese nicht der einzige ursächliche Prozess der Ischämieentstehung ist. Gitiaux et al. beschrieben eine Einengung auf Höhe der perimysialen Arkardenarterien, die von inflammatorischen Infiltraten umgeben waren und diese Arterien einengten (Gitiaux et al. 2013). Aufgrund der ausgeprägten endothelialen Dysfunktion, der Kapillarreduktion pro Muskelfaser und verminderter VEGF- und Angiopoetin-Produktion ist zumindest ein starker Einfluss dieser pathologischen Umstände auf die fibrilläre Ischämie zu erwarten.

Die nekrotisierende Myopathie weist ebenfalls den Komplementkomplex C5b-9 an Kapillaren auf (Luo und Mastaglia 2015). Auf vaskulärer Ebene sind zudem Fälle mit sogenannten bleistiftförmigen Kapillaren beschrieben, was auf eine Mikroangiopathie hindeutet (Schroder et al. 2013). In der vorliegenden Arbeit wurde via CD31-Färbung, entgegen der genannten Annahme, jedoch nur eine Tendenz zur Kapillarreduktion trotz ausgeprägter EPC-Regenerationsstörung gesehen. Hier lässt die tendenzielle Abnahme peripher zirkulierender EPCs vermuten, dass in späteren Stadien des Krankheitsverlaufs eine Kapillarreduktion auftreten kann. Angiogene Mediatoren zeigten sich entgegen der übrigen Krankheitsgruppen tendenziell erhöht oder wenigstens äquivalent zu gesunden Probanden. Die in der Gruppe befindlichen Patienten litten im Mittel 2,5 Jahre an der nekrotisierenden Myopathie und hatten im Vergleich überdurchschnittlich häufig einen schweren Krankheitsverlauf mit hohen Prednisolongaben > 7,5 mg.

Für die Gruppe der Polymyositispatienten sind v.a. CD8 ${ }^{+}$-T-Zell Infiltrate vaskulär, perimysial und endomysial beschrieben. Auf vaskulärer Ebene wurde zudem durch Grundtman et al. in Anfangsstadien sowie bei chronischen Verläufen eine verminderte Kapillardichte gesehen, wie sie bereits bei der Dermatomyositis genannt wurde (Grundtman et al. 2008). In der vorliegenden Untersuchung differierte das Ergebnis der Kapillardichte von dem Verhältnis der Gefäßzahl zur Gesamtmuskelfaserzahl versus Gefäßzahl pro $\mathrm{mm}^{2}$ Biopsiequerschnitt. In erstem Vergleich lag eine Kapillarreduktion vor. Dies spricht für eine verminderte Gefäßversorgung pro Muskelfaser. Bei der Berechnung der Kapillardichte pro Biopsiequerschnitt lag jedoch keine signifikante Reduktion vor. Da 
die Schnitte teils asymmetrisch ausfielen, ist hier, wie in Abbildung 16 unter Abschnitt 2.5.3 dargestellt, eine Messungenauigkeit zu erwarten. Da die Größe einzelner Muskelfasern weiterhin bei pathologischen Muskelprozessen pro $\mathrm{mm}^{2}$ unterschiedlich stark schwankt, können auch hier Fehler in der statistischen Auswertung entstehen. Warum man nun bei der Dermatomyositis dennoch bei beiden Berechnungsmethoden eine Kapillarreduktion sieht, kann darin begründet sein, dass die deutlichere Kapillarreduktion durch den Effekt der vielen kleinen Muskelfasern und ihren noch vorhandenen Gefäßen nicht kompensiert werden kann. Die Patienten litten im Mittel 2,9 Jahre an einer PM, darunter waren zwei Patienten mit schweren Krankheitsverläufen und hohen Prednisolongaben > 7,5 mg.

Da die peripher zirkulierenden EPCs in der PM-Gruppe wie bei der DM und NM eine Tendenz zur Reduktion aufwiesen, eine signifikante EPC-Regenerationsstörung vorlag und angiogene Mediatoren wie VEGF und Angiopoetin inadäquat erhöht waren, lässt sich auch bei Patienten mit Polymyositis ein Zusammenhang aus endothelialer Dysfunktion und Kapillarbettreduktion pro Muskelfaserzahl vermuten.

\subsection{Nestin- und CXCR6-Fluoreszenz in Gefäßen inflammatorischer Myositiden}

Nestin stellt einen wichtigen Bestandteil des Zytoskeletts in schnell teilenden Progenitorzellen dar (Michalczyk und Ziman 2005). Nachgewiesen wurde es dabei in endothelialen Zellen (Mokrý et al. 2004; Suzuki et al. 2010) oder kürzlich geformten Blutgefäßen. Diesem Prozess kommt z. B. bei der Tumorangiogenese eine wichtige Rolle zu (Xie et al. 2015). Auch bei Adulten konnte eine mikrovaskuläre muskuläre NestinAufregulation gezeigt werden (Day et al. 2007). Aktuell ist die Nestinexpression selbst noch Gegenstand von Diskussionen. Ob die Expression nun auf endotheliale Zellen oder glatte Muskelzellen des Gefäßes zurückzuführen ist, wird derzeit diskutiert, denn reife Endothelzellen werden als Nestin-negativ beschrieben (Mokrý et al. 2004). In dieser Arbeit wurde Nestin mit CD31 in einer Doppelfärbung ausgewertet und die farblich eindeutig doppelt positiven Gefäße statistisch betrachtet. Dabei lag im Vergleich zur Kontrollgruppe in der DM-Gruppe eine Tendenz zur verminderten Aufregulation vor, die PM- und NMGruppen verhielten sich äquivalent der gesunden Probanden. Vor dem Hintergrund der ausgeprägten endothelialen Dysfunktion in allen drei Erkrankungsgruppen ist diese Beobachtung von Interesse. Wenn man der Annahme von Mokrý et al. folgt und annimmt, dass die Expression von Nestin zwischen differenzierten und undifferenzierten Zellen unterscheiden lässt (Mokrý et al. 2004), kann hier von einer verminderten Regenerationsfähigkeit der Gefäße durch weniger undifferenzierte Vorläuferzellen wie z. B. EPCs ausgegangen werden.

Isozaki et al. vermuteten in ihrer Arbeit, dass CXCR6 neben der Fähigkeit der Adhäsionsund Rekruitmentfunktion von Lymphozyten auch mesenchymale Stammzellen (MSCs) in inflammatorische Areale lockt und diese in der Folge am Prozess der Vaskulogenese oder 
in Gewebsreparaturprozesse involviert sind (Isozaki et al. 2013). Sein einziger Ligand, CXCL16 wird auf Makrophagen, endothelialen und glatten Muskellzellen exprimiert (Hattermann et al. 2008). Dabei konnte eine proangiogene Aktivität von CXCL16 durch Induktion humaner Umbilikalvenen-Endothelzellen (HUVECs) (Jovanovic et al. 2015) sowie die Eigenschaft als wichtiger Mediator für EPCs in die Synovia von Patienten mit rheumatoider Arthritis nachgewiesen werden (Isozaki et al. 2013). Die Fähigkeit, endotheliale Vorläuferzellen zu rekrutieren, wurde in der vorliegenden Arbeit genutzt, um an den inflammatorischen Myositiden einen möglichen Einfluss auf die endotheliale Gefäßregeneration zu untersuchen. Dabei wurde eine signifikante Aufregulation des Markers in allen drei Krankheitsgruppen gegenüber der Kontrollgruppe beobachtet. Stark signifikant fiel das Ergebnis dabei für die PM und NM aus, d. h. in jenen Gruppen in welchen die Kapillarreduktion geringer ausfiel als bei der DM-Gruppe. Inwiefern v.a. bei der PM als T-Zell-mediierte Erkrankung auch fälschlicherweise Immunzellen in der Gefäßwand detektiert wurden, muss zukünftig evaluiert werden. Weitere Ergebnisse zu CXCL16 sind unter Abschnitt 4.2 aufgeführt.

\subsection{Nestin- und CXCR6-Fluoreszenz in Muskelfasern inflammatorischer Myositiden}

Während der Entwicklung kann in der Muskulatur Nestin nachgewiesen werden. Der Muskel des Adulten exprimiert dieses Intermediärfilament jedoch nicht mehr (Sejersen und Lendahl 1993). Sechs Stunden nach einem Trauma mit Muskelzellverletzung wird es neben dem Intermediärfilament Vimentin in Myoblasten jedoch wieder nachgewiesen (Vaittinen et al. 2001). In den drei Krankheitsgruppen konnte eine signifikant erhöhte Aufregulation des Markers in den Muskelfasern detektiert werden. Im Vergleich zum Entzündungsmarker MHC-I wurde diese Signifikanz ebenfalls bei Nestin ${ }^{+}-/$MHC-I $^{+}$-Muskelfasern nachgewiesen, wobei diese für die NM-Gruppe am schwächsten ausfiel. Es ist von den Ergebnissen her von einem muskulären Regenerationspotential, v.a. auch in entzündeten Regionen, auszugehen.

Dem Chemokin/Chemokinrezeptor-Paar CXCL16 und CXCR6 kommt vermutlich neben den unter Abschnitt 1.4 genannten Funktionen eine wichtige Aufgabe bei der T-ZellBewegung und dem Zell-Zell-Kontakt bei Entzündungs- und Immunprozessen zu (Latta et al. 2007). Im Rahmen dieser Arbeit wurde CXCR6 bei der Polymyositis signifikant aufreguliert nachgewiesen. Dies kann als Ausdruck einer der Polymyositis zu Grunde liegenden zellulären Immunreaktion betrachtet werden. Allerdings wird CXCR6 zum einen als schwacher Mediator auf T-Zellen beschrieben (Latta et al. 2007), zum anderen haben die Doppelfärbungen auf CXCR6/CD4 und CXCR6/CD8 keine signifikante Erhöhung von doppelt positiven Muskelfasern in der PM-Gruppe nachgewiesen. Dies spricht gegen eine fälschliche Auszählung von Immunzellen, die die Muskelfasern umgeben. Für die Aufregulation des muskulären CXCR6 in der PM-Gruppe ist daher zu diskutieren, ob 
Mechanismen der EndoMT oder ein humoraler Faktor, der über die Zellfärbung nicht detektiert wurde, in Frage kommen.

\subsection{Hinweise für endothelial-mesenchymale Transition}

Die endothelial-mesenchymale Transition, kurz EndoMT oder EndMT, ist ein Prozess bei dem endotheliale Zellen typische endotheliale Marker verlieren und mesenchymale Merkmale neu exprimieren. Zu diesen neuen mesenchymalen Zelleigenschaften zählen dann beispielsweise $\alpha$-SMA oder S100A4, die unter Abschnitt 1.3.3 erläutert wurden. Der Prozess kann u. a. durch TGF- $\beta$ induziert werden (Jimenez 2013). Krankheitsprozesse, bei denen die EndoMT als pathologisch bedeutend beschrieben ist, sind z. B. die kardiale oder nephrogene Fibrose, die systemische Sklerose und Tumorprozesse (Jimenez 2013; Le Bleu et al. 2013; Zeisberg et al. 2007a; Zeisberg et al. 2007b). In dieser Arbeit wurden auf Fibronektin gezüchtete Kolonien auf $\alpha$-SMA und S100A4 hin untersucht. Hierbei zeigte sich im Vergleich zur Kontrollgruppe für bei Marker keine signifikante Aufregulation in den Krankheitsgruppen, so dass nicht von einer EndoMT der untersuchten Zellen ausgegangen wird.

Ein weiterer zu diskutierender Aspekt stellt in diesem Zusammenhang die Beobachtung der Einarbeitung von zirkulierenden hämatopoetischen Vorläuferzellen (HPCs) in den geschädigten Skelettmuskel dar. Dieser Prozess wurde neben dem Reparaturprozess durch Satellitenzellen als ein weiterer Regenerationsprozess von geschädigtem Skelettmuskel beschrieben (Hollemann et al. 2008; Le Bleu et al. 2013). Hollemann et al. untersuchten dafür die myoendotheliale Differenzierung von HPCs, indem sie die Expression von u. a. endothelialen Markern wie CD31 oder hämatopoetischen Markern wie CD34 und CD133 im Skelettmuskel von Patienten mit DM, PM und IBM bestimmten (Hollemann et al. 2008). Dabei konnten mononukleäre Zellen interstitiell in Entzündungsarealen nachgewiesen werden, die positiv für CD34- und CD31-Antigene waren. Die Ausprägung wurde als weniger intensiv als bei endothelialen Zellen beschrieben (Hollemann et al. 2008). Auch in der vorliegenden Arbeit wurden Aufregulationen von CD31 im Interstitium, perifibrillär, perimysial und sehr selten auch endomysial beobachtet, wie Abbildung 14 bei einem Patienten mit Polymyositis zeigt. Ob hier über das Gefäßsystem eingewanderte oder ortsständige EPCs vorliegen oder doch eine EndoMT zu vermuten ist, lässt sich nicht klären. Es sollte jedoch zukünftig mit betrachtet und evaluiert werden.

Ein weiterer Prozess, der zuletzt in der Literatur im Zusammenhang mit der EndoMT genannt wird, ist eine vaskuläre Mimikry durch funktionelle Veränderung von Makrophagen oder Tumorzellen ( $\mathrm{Z}$ Liu et al. 2012; Scavelli et al. 2007). Die Eigenschaft wurde zumindest in vitro durch angiogene Stimuli an Makrophagen von Patienten mit multiplem Myelom nachgewiesen (Scavelli et al. 2007). Es ist weiterhin bekannt, dass Makrophagen die Angiogenese fördern. Bei kardialer Ischämie konnte zudem gezeigt werden, dass sie zur alternativen Mikrozirkulation „Kanäle“ formen können, die nicht von 
Endothelzellen ausgekleidet werden (Barnett et al. 2016; Moldovan et al. 2000). Ob dieser Mechanismus vor dem Hintergrund von Makrophageninfiltrationen bei inflammatorischen Myositiden (Bassez et al. 2003) und der dargestellten endothelialen Dysfunktion mit Kapillarreduktion auch eine Rolle spielt, bleibt zu erforschen.

\subsection{Kapillarmikroskopie bei inflammatorischen Myopathien}

Unter Abschnitt 1.7 wurden typische Veränderungen der Kapillarmikroskopie bei Patienten mit Dermatomyositis beschrieben. Dazu gehören neben der Kapillarreduktion, Verzweigungen bis hin zur Büschelkapillare, Elongationen mit Ektasie des afferenten sowie efferenten Schenkels auch Megakapillaren und Einblutungen (Gerhold 2012; Manfredi et al. 2015; Mercer et al. 2010). Diese Veränderungen traten in der vorliegenden Arbeit auch bei einem Großteil der DM-Patienten auf. In der statistischen Auswertung zeigte sich zudem eine Tendenz zu niedrigen Koloniezahlen bei Patienten mit vorhandenen Megakapillaren. Bei $50 \%$ der untersuchten Patienten konnte äquivalent zur Muskelbiopsie eine Kapillarreduktion beobachtet werden.

Auch für die Polymyositis wurden diese Veränderungen beschrieben, allerdings zuletzt durch Manfredi et al. sowie Klein-Weigl et al. davon Abstand genommen (Manfredi et al. 2015). In dieser Arbeit konnten Verzweigungen und Einblutungen zu gleichen Anteilen wie in der DM-Gruppe beobachtet werden. Dabei sah man eine Tendenz zur verringerten Koloniezahlen bei Patienten mit PM wenn Einblutungen vorlagen. Die Ektasie des afferenten und efferenten Schenkels sowie Megakapillaren traten deutlich seltener auf.

Untersuchungen zu Patienten mit nekrotisierender Myopathie sind aktuell nicht in der Literatur beschrieben. In dieser Arbeit konnten bei geringer Fallzahl keine typischen Veränderungen wie Megakapillaren, Einblutungen oder Ektasien des afferenten und efferenten Schenkels beobachtet werden. Es traten lediglich Verzweigungen auf. Um aussagekräftige Ergebnisse zu erhalten, muss hier eine größere Kohorte mit nekrotisierender Myopathie kapillarmikroskopiert werden.

\subsection{Methodenkritik}

\subsubsection{Patientenauswahl und -zahl}

Insgesamt besteht bei den eingeschlossenen Patienten der Krankheitsgruppen aufgrund der geringen Inzidenz des Auftretens ein Ungleichgewicht der neu diagnostizierten Patienten zu den Patienten, die die Diagnose einer inflammatorischen Myopathie bereits in der Vergangenheit erhielten und im Rahmen einer Verlaufskontrolle eingeschlossen wurden. Es war daher nicht möglich, statistisch sinnvolle Untergruppen zu bilden. Da die Blutentnahmen auf EPCs damit überdurchschnittlich zum Befragungszeitpunkt und nicht Diagnosezeitpunkt erfolgten, liegen hier vorrangig Verlaufsergebnisse der EPCs vor. 
Insgesamt besteht auch aufgrund der Seltenheit der Krankheitsbilder pro Krankheits- und Muskelkontrollgruppen eine geringe Fallzahl, so dass hier zufällige Verteilungen im Fall von Tendenzen sichtbar wurden, die sich ggf. in einer größeren Kohorte relativieren.

\subsubsection{Antikörperwechsel}

Da die Firma abcam die Herstellung des Antikörpers CD133 im Verlauf der Datensammlung einstellte, musste bei einem Teil der gesunden Kontrollgruppe dieser Antikörper durch den CD133-Antikörper der Firma EMELCA ersetzt werden. Dies hatte statistisch eine auffällige Abnahme der CD133+ ${ }^{+} /$VEGFR-2 ${ }^{+}$- und CD133 ${ }^{+} / \mathrm{c}-\mathrm{KIT}^{+}$-Zellen zur Folge, so dass dieser Auswertungsabschnitt in seiner inhaltlichen Aussage vernachlässigt werden musste.

\subsubsection{Fluoreszenzauswertung}

Um einzelne Muskelfasern und Muskelgefäße für eine Auszählung zu kennzeichnen, wurden diese pro Biopsieschnitt in drei bis vier Abschnitte untergliedert und mittels Nummerierung ausgezählt. Hierbei war es notwendig, die Auswertung stets in möglichst abgedunkelten Verhältnissen vorzunehmen, um eine exakte und konstante Deutung des Farbprofils zu gewährleisten. Kleine wahrgenommene Farbdifferenzen können durch Umgebungsdifferenzen ggf. zu dezenten Auswertungsverschiebungen geführt haben.

\subsection{Assoziation der EPC-Abweichung zu vaskulärer Pathologie und veränderter Regeneration - ein Ausblick}

Vor dem Hintergrund der aufgeführten Ergebnisse liegt es nahe, dass Mechanismen der EPC-Regulation und -Reifung bei den drei Krankheitsgruppen eine Rolle im pathologischen Prozess von IIM spielen. In der Folge dieser Dysregulation konnte in den DM- und PM-Gruppen eine Kapillarreduktion beobachtet werden. Vor allem bei DMPatienten lagen, wie in der Literatur beschrieben, inflammatorische Infiltrate perivaskulär. Wie in Tabelle 35 aufgeführt, fand sich eine Gefäßabnahme zudem vor allem in Muskelfaserarealen, die MHC-I-aufreguliert waren. Im Vergleich zu den mit Nestin signifikant aufregulierten Muskelfasern der DM-, PM- und NM-Gruppen fiel der Regenerationsmarker im Bereich der Gefäßfärbung, wie Abbildung 27 zeigt, trotz Krankheitsprozess mit Kapillarreduktion den gesunden Probenden gegenüber äquivalent mit Tendenz zur Verminderung aus.

$\mathrm{Da}$ auch angiogene Mediatoren wie VEGF und Angiopoetin 1 nicht deutlich erhöht ausfielen, die Arbeitsgruppe um Ekholm eine ggf. Typ I-Interferon und Interleukin-18 bedingte reduzierte Zahl peripher zirkulierender EPCs beschreiben und CD133+ ${ }^{+} / \mathrm{c}_{\mathrm{KIT}}^{+}$hämangiopoetische Vorläuferzellen zumindest in der DM-Gruppe dieser Arbeit signifikant vermindert nachgewiesen wurden, lässt sich ein pathologischer vaskulärer Prozess mit 
Regenerationsstörung auf verschiedenen Ebenen vermuten. Darunter sind zu nennen: eine verminderte Mobilisierung aus dem Knochenmark, ein erhöhter Verbrauch, inflammatorische Einflüsse auf EPCs und eine dadurch ggf. bedingt veränderte Überlebenszeit von EPCs. Eine sich aus den Ergebnissen ableitende Hypothese ist pro Krankheitsentität in Abbildung 45, Abbildung 46 und Abbildung 47 dargestellt.

Die genaue Bedeutung von vaskulären Prozessen bei inflammatorischen Myositiden ist noch ungeklärt, jedoch gerade vor dem Hintergrund der EPC-Veränderungen, wie sie Ekholm et al. beschrieben, von wachsendem Interesse (Ekholm et al. 2016). Die sich in die bisherigen Befunde einreihenden Ergebnisse dieser Arbeit gilt es an weiteren Kohorten mit größerer Patientenzahl und Untergruppenbildung zu prüfen und zu evaluieren. Weiterhin offen sind zudem Prozesse der EndoMT sowie eine vaskuläre Mimikry durch funktionelle Veränderung von Makrophagen unter ischämischen Bedingungen und im vaskulären Regenerationsprozess.

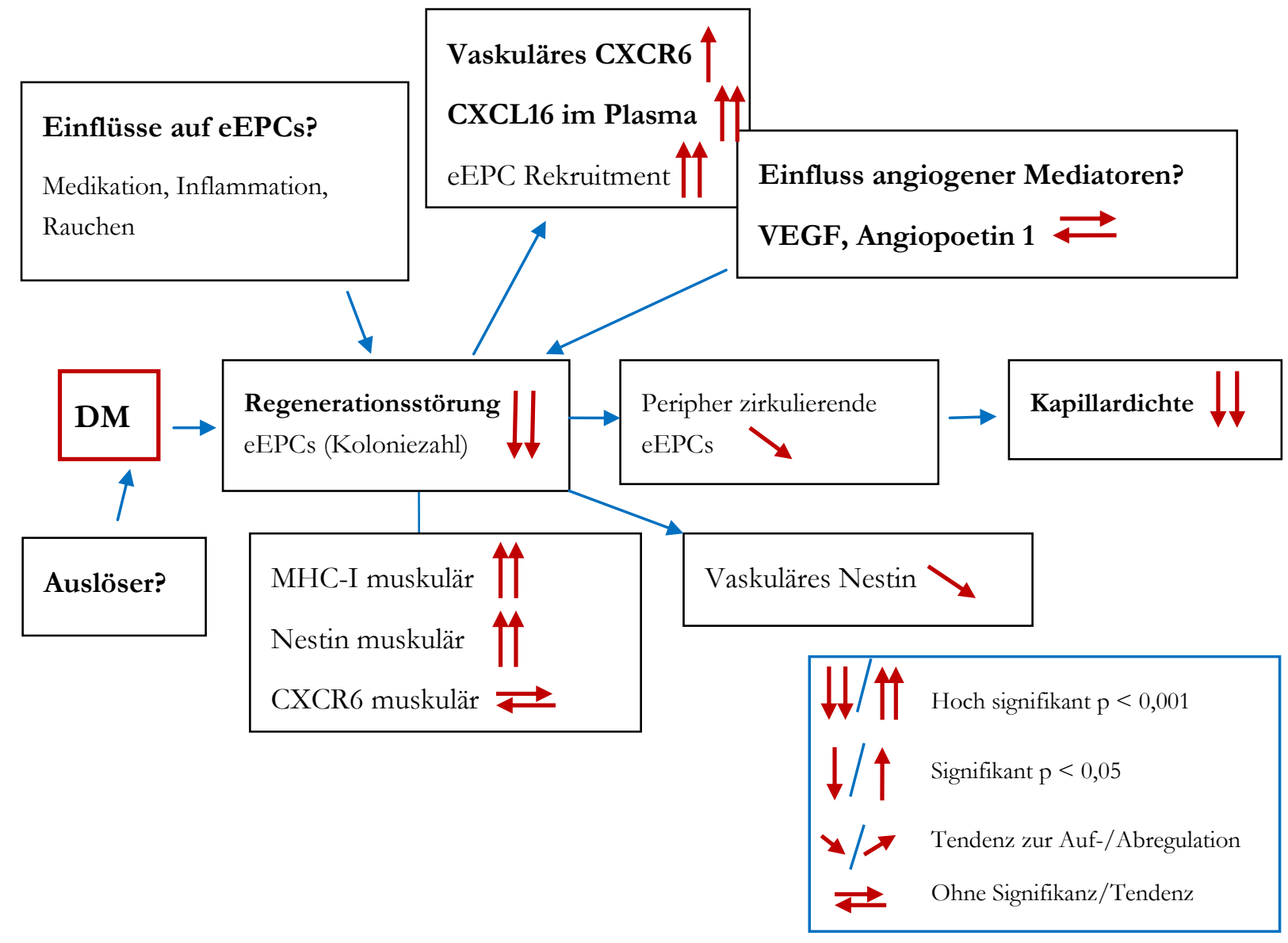

Abbildung 45: Hypothesenaufstellung zur Dermatomyositis (DM) anhand der vorliegenden Ergebnisse 


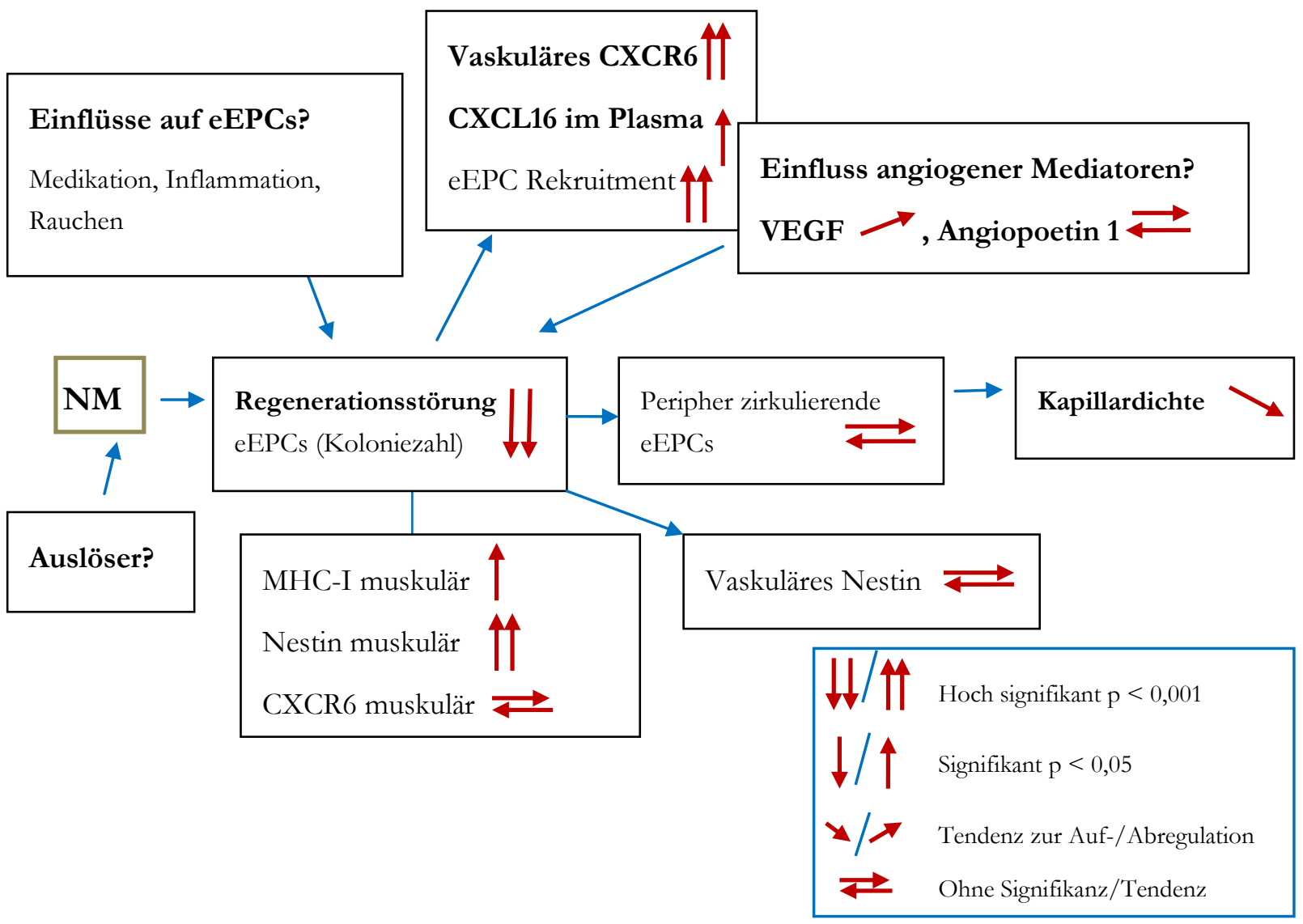

Abbildung 46: Hypothesenaufstellung zur nekrotisiernden Myopathie (NM) anhand der vorliegenden Ergebnisse 


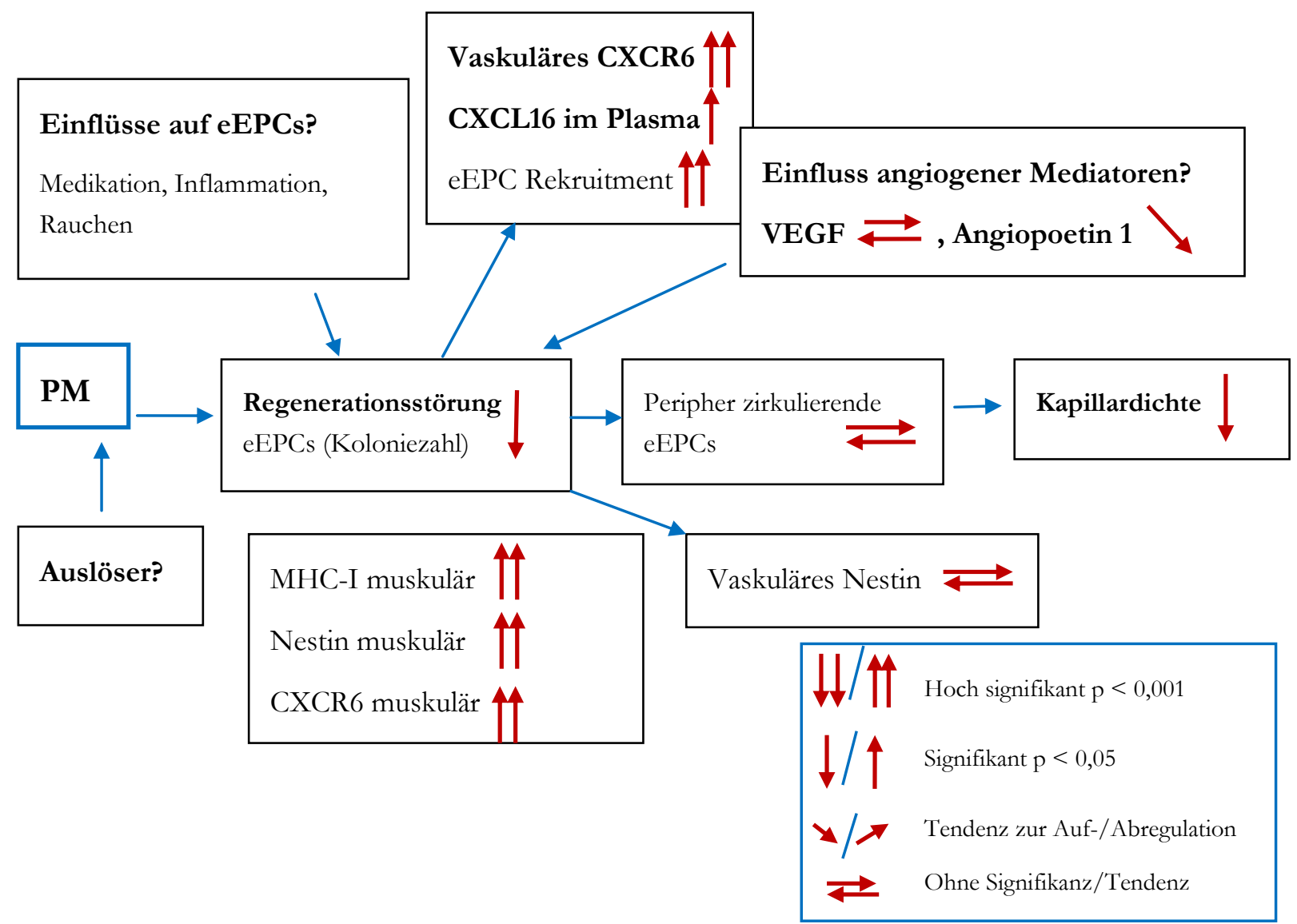

Abbildung 47: Hypothesenaufstellung zur Polymyositis (PM) anhand der vorliegenden Ergebnisse 


\section{$5 \quad$ Zusammenfassung}

Die Pathogenese der Dermatomyositis (DM) wird auf humorale Immunmechanismen zurückgeführt, die Polymyositis (PM) wird hingegen durch zytotoxische T-Zellen verursacht. Die nekrotisierende Myopathie (NM) ist histopathologisch charakterisiert durch Muskelfasernekrosen und im Vergleich zur PM durch Abwesenheit von Inflammation. Kapillargefäße stellen eine Voraussetzung für die Invasion von Immunzellen in Muskelfasern dar. Eine endotheliale Dysfunktion kann daher für die Pathogenese der verschiedenen Myositiden angenommen werden. Es ist bekannt, dass Gefäße bei der DM direkt beschädigt werden, was sich z. B. durch Kapillarreduktion widerspiegelt. Endotheliale Vorläuferzellen (EPCs) werden für Prozesse der Vaskulo- und Angiogenese im Rahmen ischämischer Schädigungen herangezogen und können auch bei Regenerationsprozessen im entzündeten Muskel von Bedeutung sein.

Ziel dieser Untersuchung ist es, das vaskuläre Regenerationspotential anhand von relevanten Markern von Gefäßen und Muskelfasern in Muskelbiopsien von Probanden mit DM, PM, NM im Vergleich zu Kontrollen zu analysieren. Weiterhin soll eine Charakterisierung des Regenerationspotentials und der Funktionalität von EPCs im Blut der Patienten erfolgen. Es soll dabei geklärt werden, ob es Hinweise für einen vaskulären Regenerationsschaden im Zusammenhang mit der Myositispathologie gibt.

In die Untersuchung wurden 35 Patienten (DM 17, PM 11, NM 7) sowie 40 nichtmyopathische Kontrollen eingeschlossen. Folgende EPC-Parameter wurden evaluiert: EPC-Kolonien via Culture Assay sowie peripher zirkulierende EPCs (CD133+-/VEGFR-2 ${ }^{+}$Zellen) und hämangiopoetische Vorläuferzellen $\left(\mathrm{CD}_{133^{+}} / \mathrm{c}-\mathrm{KIT}^{+}\right)$über eine zytometrische Analyse. Das Plasma der Patienten wurde auf angiogene Mediatoren via ELISA auf VEGF, Angiopoetin 1 und CXCL16 analysiert. Zudem wurden SMA und S100 an EPC-Kolonien über die iCys-Mikroskopie ermittelt. Muskelbiopsien standen von zehn Patienten mit DM, sechs mit PM und sechs mit NM zur Verfügung und wurden mit Markern für CD31 (Endothel), Nestin (Regeneration von Muskeln; Reifen von Endothel), MHC-I (Inflammation) und CXCR6 (EPC-Rekruitment) gefärbt und durch Immunfluoreszenz und manuelle Auswertung evaluiert.

EPC-Kolonien waren bei allen drei Myositisformen im Vergleich zu gesunden Probanden signifikant vermindert. Peripher zirkulierende EPCs zeigten auf Ebene der hämangiopoetischen (DM-Gruppe) und angiopoetischen (PM-Gruppe) Marker eine Tendenz zur Verminderung. Die ausgezählten Gefäße waren für Nestin-positiv, ohne dass signifikante Unterschiede belegt werden konnten. Dementgegen fielen Gefäßfärbungen auf CXCR6 signifikant positiv für alle drei Krankheitsentitäten aus. Die Auswertung der angiogenen Mediatoren zeigte dabei einen unterschiedlichen Trend, wobei CXCL16 
signifikant für alle drei Gruppen erhöht ausfiel, VEGF und Angiopoetin 1 hingegen gleich (DM-Gruppe), mit abfallender Tendenz (Angiopoetin 1 in der PM-Gruppe) oder mit steigender Tendenz (VEGF in der NM-Gruppe) nachgewiesen wurden. Eine Kapillarreduktion pro Muskelfaseranteil konnte für die DM- und PM-Gruppen ermittelt werden, in der NM-Gruppe zeigte sich lediglich eine abnehmende Tendenz. Diese Beobachtung kann im Zusammenhang mit der insgesamt kurzen Krankheitsdauer der NMProbanden und einer erhöhten angiogenen Aktivität von VEGF stehen. Eine tendenziell verminderte Koloniezahl konnte im Rahmen der Kapillarmikroskopie bei Megakapillaren in der DM-Gruppe und bei Einblutungen in der PM-Gruppe nachgewiesen werden. Im Muskel war der Anteil der Nestin-positiven Muskelfasern bei allen Myositisformen im Vergleich zur Kontrolle signifikant erhöht. MHC-I war, wie erwartet, nur bei DM- und PM-Patienten signifikant hochreguliert und zeigte bei NM-Patienten lediglich eine etwas erhöhte Expression in den Fasern. Der Anteil der CXCR6-positiven Fasern war nur bei der PM-Gruppe im Vergleich zur Kontrolle signifikant erhöht, wohingegen die Expression bei den anderen Myositiden lediglich einen Trend zur Hochregulation zeigte. In der Doppelfärbung auf CXCR6/CD4 und CXCR6/CD8 zum Ausschluss einer fälschlichen TZell-Darstellung wurden keine signifikant erhöhten doppelt positiven Fasern ermittelt. Möglicherweise spielt hier ein humoraler Faktor eine Rolle, der über die bisherigen Färbungen nicht erfasst wurde. Alternativ kommen ins Mesenchym abgewanderte Epithelzellen in Frage, die im Rahmen der EndoMT entstanden, oder der umgekehrte Mechanismus.

Die Daten legen nahe, dass Mechanismen des EPC-Systems bei allen Myositisformen von Bedeutung sind. Ferner tragen die Daten zu einer erweiterten Modellvorstellung und besserem Verständnis der Pathogenese von Myositiden bei. Dabei führt ein mikroangiopathischer Prozess infolge der EPC-Regenerationsstörung bei allen drei Entitäten, möglicherweise in Abhängigkeit von Krankheitsdauer/-aktivität und angiogenen Mediatoren, zu einer dauerhaften Kapillarschädigung, die sich eher in MHC-Iaufregulierten Regionen findet. Im Umkehrschluss konnte in Regionen mit vermindertem Kapillarschaden eine erhöhte muskuläre Nestin-Aufregulation - im Sinne der Regenration gezeigt werden. 


\section{$6 \quad$ Literaturverzeichnis}

Altmeyer P, Paech V: Enzyklopädie der Dermatologie, Venerologie, Allergologie und Umweltmedizin. Springer, Heidelberg 2011

Appleyard S, Dunn MZ, Dublitz M, Rose ML (1985): Increased expression of HLA-ABC class I antigens by muscle fibers in Duchenne muscular dystrophy, inflammatory myopathy and other neuromuscular disorders. Lancet $1,361-363$

Asahara T, Murohara T, Sullivan A, Silver M, van der Zee R, Li T, Witzenbichler B, Schatteman G, Isner JM (1997): Isolation of putative progenitor endothelial cells for angiogenesis. Science $\underline{275}, 964-967$

Asahara T, Takahashi T, Masuda H, Kalka C, Chen D, Iwaguro H, Inai Y, Silver M, Isner JM (1999): VEGF contributes to postnatal neovascularization by mobilizing bone marrowderived endothelial progenitor cells. EMBO J $\underline{18}, 3964-3972$

Assmus B, Schächinger V, Teupe C, Britten M, Lehmann R, Döbert N, Grünwald, Aicher, Urbich C, Martin H (2002): Transplantation of Progenitor Cells and Regeneration Enhancement in Acute Myocardial Infarction (TOPCARE-AMI). Circulation 106, 30093017

Assmus B, Fischer-Rasokat U, Honold J, Seeger FH, Fichtlscherer S, Tonn T, Seifried E, Schachinger V, Dimmeler S, Zeihe AM (2007): Transcoronary transplantation of functionally competent BMCs is associated with a decrease in natriuretic peptide serum levels and improved survival of patients with chronic postinfarction heart failure: results of the TOPCARE-CHD Registry. Circ Res 100, 1234-1241

Bahadir M, Parlar H, Spiteller M: Springer Umweltlexikon. Springer, Heidelberg 2000

Barnett FH, Rosenfeld M, Wood M, Kiosses WB, Usui Y, Marchetti V, Aguilar E, Friedlander M (2016): Macrophages form functional vascular mimicry channels in vivo. Sci Rep $\underline{6}, 36659$

Bassez G, Authier FJ, Lechapt-Zalcman E, Delfau-Larue MH, Plonquet A, Coquet M, Illa I, Gherardi RK (2003): Inflammatory myopathy with abundant macrophages (IMAM): a condition sharing similarities with cytophagic histiocytic panniculitis and distinct from macrophagic myofasciitis. J Neuropathol Exp Neurol 62, 464-474 
Benveniste O, Drouot L, Jouen F, Charuel J-L, Bloch-Queyrat C, Behin A, Amoura Z, Marie I, Guiguet M, Eymard B (2011): Correlation of anti-signal recognition particle autoantibody levels with creatine kinase activity in patients with necrotizing myopathy. Arthritis Rheum 63, 1961-1971

Benveniste O, Rider LG (2016): 213th ENMC International Workshop: Outcome measures and clinical trial readiness in idiopathic inflammatory myopathies, Heemskerk, The Netherlands, 18-20 September 2015. Neuromuscul Disord 26, 523-534

Betteridge Z, McHugh N (2016): Myositis-specific autoantibodies: an important tool to support diagnosis of myositis. J Intern Med $\underline{280}, 8-23$

Bock C, Rack B, Huober J, Andergassen U, Jeschke U, Doisneau-Sixou S (2014): Distinct expression of cytokeratin, N-cadherin and CD133 in circulating tumor cells of metastatic breast cancer patients. Future Oncol 10, 1751-1765

Bodoki L, Nagy-Vincze M, Griger Z, Dankó K (2015): Dermatomyositisspezifische Antikörper. Z Rheumatol 74, 363-369

Bohan A, Peter JB (1975): Polymyositis and dermatomyositis (first of two parts). N Engl J Med 292, 344-347

Boye K, Mælandsmo GM (2010): S100A4 and Metastasis : A Small Actor Playing Many Roles. Am J Pathol 176, 528-535

Breithaupt M, Schmidt J (2014): Zertifizierte Fortbildung: Inflammatorische Muskelerkrankungen - Diagnostik und Therapie von Myositiden. Neuro Transmitter 12, 46-55

Byrne AM, Bouchier-Hayes DJ, Harmey JH (2005): Angiogenic and cell survival functions of vascular endothelial growth factor (VEGF). J Cell Mol Med 2 , 777-794

Carstens PO, Schmidt J (2014): Diagnosis, pathogenesis and treatment of myositis: recent advances. Clin Exp Immunol 175, 349-358

Carter JG, Gammons MVR, Damodaran G, Churchill AJ, Harper SJ, Bates DO (2015): The carboxyl terminus of VEGF-A is a potential target for anti-angiogenic therapy. Angiogenesis 18, 23-30

Casciola-Rosen L, Mammen AL (2012): Myositis autoantibodies. Curr Opin Rheumatol 24, 602-608 
Ceribelli A, Fredi M, Taraborelli M, Cavazzana I, Franceschini F, Quinzanini M, Tincani A, Ross SJ, Chan JYF, Pauley BA (2012): Anti-MJ/NXP-2 autoantibody specificity in a cohort of adult Italian patients with polymyositis/dermatomyositis. Arthritis Res Ther 14, R97

Chen H, Xu C, Jin Q, Liu Z (2014): S100 protein family in human cancer. Am J Cancer Res 4, 89-115

Cheng CC, Chang SJ, Chueh YN, Huang TS, Huang PH, Cheng SM, Tsai TN, Chen JW, Wang HW (2013): Distinct angiogenesis roles and surface markers of early and late endothelial progenitor cells revealed by functional group analyses. BMC Genomics $\underline{14}, 182$

Cines DB, Pollak ES, Buck cA, Loscalzo J, Zimmermann GA, McEver RP, Pober JS, Wick TM, Konkle BA, Schwartz BS (1998): Endothelial Cells in Physiology and in the Pathophysiology of Vascular Disorders. Blood 11, 3527-3561

Cong L, Pu CQ, Shi Q, Wang Q, Lu XH (2014): Complement membrane attack complex is related with immune-mediated necrotizing myopathy. Int J Clin Exp Pathol 7, 4143-4149

Crum-Cianflone NF (2008): Bacterial, fungal, parasitic, and viral myositis. Clin Microbiol Rev 21, 473-494

Cutolo M, Sulli A, Secchi ME, Paolino S, Pizzorni C (2006): Nailfold capillaroscopy is useful for the diagnosis and follow-up of autoimmune rheumatic diseases. A future tool for the analysis of microvascular heart involvement? Rheumatology (Oxford) $\underline{45}$, iv43-46

Cutolo M, Smith V (2013): State of the art on nailfold capillaroscopy: a reliable diagnostic tool and putative biomarker in rheumatology? Rheumatology (Oxford) $\underline{52}$, 1933-1940

Dalakas MC, Hohlfeld R (2003): Polymyositis and dermatomyositis. Lancet $\underline{362}$, 971-982

Dalakas MC (2011): Review: An update on inflammatory and autoimmune myopathies. Neuropathol Appl Neurobiol 37, 226-242

Dalakas MC (2012): Pathogenesis and therapies of immune-mediated myopathies. Autoimmun Rev 11, 203-206

Dalakas MC (2015): Inflammatory Muscle Diseases. N Engl J Med 굴, 1734-1747

Dankó K, Ponyi A, Constantin T, Borgulya G, Szegedi G (2004): Long-Term Survival of Patients With Idiopathic Inflammatory Myopathies According to Clinical Features: A Longitudinal Study of 162 Cases. Medicine (Baltimore) $\underline{83}$, 35-42 
Davis S, Aldrich TH, Jones PF, Acheson A, Compton DL, Jain V, Ryan TE, Bruno J, Radziejewski C, Maisonpierre PC (1996): Isolation of angiopoietin-1, a ligand for the TIE2 receptor, by secretion-trap expression cloning. Cell $\underline{87}, 1161-1169$

Day K, Shefer G, Richardson JB, Enikolopov G, Yablonka-Reuveni Z (2007): Nestin-GFP reporter expression defines the quiescent state of skeletal muscle satellite cells. Dev Biol 304, 246-259

Deng L, Chen N, Li Y, Zheng H, Lei Q (2010): CXCR6/CXCL16 functions as a regulator in metastasis and progression of cancer. Biochim Biophys Acta 1806, $42-49$

Dentelli P, Rosso A, Balsamo A, Colmenares Benedetto S, Zeoli A, Pegoraro M, Camussi G, Pegoraro L, Brizzi MF (2007): C-KIT, by interacting with the membrane-bound ligand, recruits endothelial progenitor cells to inflamed endothelium. Blood $\underline{109}, 4264-4271$

Diller GP, Thum T, Wilkins MR, Wharton J (2010): Endothelial progenitor cells in pulmonary arterial hypertension. Trends Cardiovasc Med 20, 22-29

Dimmler S, Aicher A, Vasa M, Mildner-Rihm C, Adler K, Tiemann M, Rutten H, Fichtlscherer S, Martin H, Zeiher A (2001): HMG-CoA reductase inhibitors (statins) increase endothelial progenitor cells via the PI 3-kinase/Akt pathway. J Clin Invest 108 , 391-397

Dourmishev LA, Dourmishev AL, Plewig G: Dermatomyositis Advances in Recognition, Understanding and Management. Springer, Berlin 2009

Drake CJ (2003): Embryonic and adult vasculogenesis. Birth Defects Res C Embryo Today $\underline{69}, 73-82$

Ekholm L, Kahlenberg JM, Barbasso Helmers S, Tjarnlund A, Yalavarthi S, Zhao W, Seto N, Betteridge Z, Lundberg IE, Kaplan MJ (2016): Dysfunction of endothelial progenitor cells is associated with the type I IFN pathway in patients with polymyositis and dermatomyositis. Rheumatology (Oxford) $\underline{55}$, 1987-1992

Eloranta ML, Barbasso Helmers S, Ulfgren AK, Ronnblom L, Alm GV, Lundberg IE (2007): A possible mechanism for endogenous activation of the type I interferon system in myositis patients with anti-Jo-1 or anti-Ro 52/anti-Ro 60 autoantibodies. Arthritis Rheum $\underline{56}, 3112-3124$

Emslie-Smith AM, Arahata K, Engel AG (1989): Major histocompatibility complex class I antigen expression, immunolocalization of interferon subtypes, and $\mathrm{T}$ cell-mediated cytotoxicity in myopathies. Hum Pathol 20, 224-231 
Fadini GP, Losordo D, Dimmeler S (2012): Critical re-evaluation of endothelial progenitor cell phenotypes for therapeutic and diagnostic use. Circ Res $\underline{110}$, 624-637

Fagiani E, Christofori G (2013): Angiopoietins in angiogenesis. Cancer Lett $\underline{328}$, 18-26

Fan Y, Shen F, Frenzel T, Zhu W, Ye J, Liu J, Chen Y, Su H, Young WL, Yang GY (2010): Endothelial progenitor cell transplantation improves long-term stroke outcome in mice. Ann Neurol 67, 488-497

Fernandez C, Bardin N, De Paula AM, Salort-Campana E, Benyamine A, Franques J, Schleinitz N, Weiller PJ, Pouget J, Pellissier JF (2013): Correlation of clinicoserologic and pathologic classifications of inflammatory myopathies: study of 178 cases and guidelines for diagnosis. Medicine (Baltimore) 2, 15-24

Fishman AP (1982): Endothelium: A Distributed Organ of Diverse Capabilities. Ann N Y Acad Sci 401, 1-8

Flindt R: Biologie in Zahlen. Eine Datensammlung in Tabellen mit über 10000 Einzelwerten. Gustav Fischer Verlag, Stuttgart 1995

Florczyk U, Jazwa A, Maleszewska M, Mendel M, Szade K, Kozakowska M, GrochotPrzeczek A, Viscardi M, Czauderna S, Bukowska-Strakova K (2014): Nrf2 Regulates Angiogenesis: Effect on Endothelial Cells, Bone Marrow-Derived Proangiogenic Cells and Hind Limb Ischemia. Antioxid Redox Signal 20, 1693-1708

Fujimoto M (2013): [Myositis-specific autoantibodies]. Brain Nerve 65, 449-460

Gabbiani G, Schmid E, Winter S, Chaponnier C, de Ckhastonay C, Vandekerckhove J, Weber K, Franke WW (1981): Vascular smooth muscle cells differ from other smooth muscle cells: predominance of vimentin filaments and a specific alpha-type actin. Proc Natl Acad Sci U S A $\underline{78}, 298-302$

Ganczarczyk ML, Lee P, Armstrong SK (1988): Nailfold capillary microscopy in polymyositis and dermatomyositis. Arthritis Rheum $\underline{31}$, 116-119

Gerhold K (2012): Möglichkeiten und Grenzen der Kapillarmikroskopie in der Kinderrheumatologie. arthritis + rheuma $\underline{32}$, 323-329

Ghirardello A, Bassi N, Palma L, Borella E, Domeneghetti M, Punzi L, Doria A (2013): Autoantibodies in Polymyositis and Dermatomyositis. Curr Rheumatol Rep 15, 335 
Ghirardello A, Borella E, Beggio M, Franceschini F, Fredi M, Doria A (2014): Myositis autoantibodies and clinical phenotypes. Auto Immun Highlights $\underline{5}$, 69-75

Gitiaux C, Kostallari E, Lafuste P, Authier FJ, Christov C, Gherardi RK (2013): Whole microvascular unit deletions in dermatomyositis. Ann Rheum Dis $\underline{72}, 445-452$

Goligorsky MS (2014): Endothelial Progenitor Cells: From Senescence to Rejuvenation. Semin Nephrol $\underline{34}, 365-373$

González-González JB, Meisel C, Unterwalder N (2015): Autoantikörper bei juveniler idiopathischer inflammatorischer Myopathie. arthritis + rheuma $\underline{35}$, 176-182

Greenberg SA (2010): Dermatomyositis and Type 1 Interferons. Curr Rheumatol Rep $\underline{12}$, 198-203

Grisar J, Aletaha D, Steiner CW, Kapral T, Steiner S, Saemann M, Schwarzinger I, Buranyi B, Steiner G, Smolen JS (2007): Endothelial progenitor cells in active rheumatoid arthritis: effects of tumour necrosis factor and glucocorticoid therapy. Ann Rheum Dis $\underline{66}, 1284-$ 1288

Grundtman C, Tham E, Ulfgren AK, Lundberg IE (2008): Vascular endothelial growth factor is highly expressed in muscle tissue of patients with polymyositis and patients with dermatomyositis. Arthritis Rheum 58, 3224-3238

Hall JC, Casciola-Rosen L, Samedy LA, Werner J, Owoyemi K, Danoff SK, Christopher-

Stine L (2013): Anti-melanoma differentiation-associated protein 5-associated dermatomyositis: expanding the clinical spectrum. Arthritis Care Res (Hoboken) $\underline{65}$, 13071315

Hattermann K, Ludwig A, Gieselmann V, Held-Deindt J, Mentlein R (2008): The chemokine CXCL16 induces migration and invastion of glial precursor cells via its receptor CXCR6. Mol Cell Neurosci $\underline{39}$, 133-141

Hausmann G, Herrero C, Cid MC, Casademont J, Lecha M, Mascaro JM (1991): Immunopathologic study of skin lesions in dermatomyositis. J Am Acad Dermatol 25, 225230

He T, Smith LA, Harrington S, Nath KA, Caplice NM, Noel M, Katusic, Zvonimir S (2004): Transplantation of Circulating Endothelial Progenitor Cells Restores Endothelial Function of Denuded Rabbit Carotid Arteries. Stroke 35, 2378-2384 
Heeschen C, Aicher A, Lehmann R, Fichtlscherer S, Vasa M, Urbich C, Mildner-Rihm C, Martin H, Zeiher AM, Dimmeler S (2003): Erythropoietin is a potent physiologic stimulus for endothelial progenitor cell mobilization. Blood 102, 1340-1346

Herbert MK, Stammen-Vogelzangs J, Verbeek MM, Rietveld A, Lundberg IE, Chinoy H, Lamb JA, Cooper RG, Roberts M, Badrising UA (2016): Disease specificity of autoantibodies to cytosolic 5 '-nucleotidase $1 \mathrm{~A}$ in sporadic inclusion body myositis versus known autoimmune diseases. Ann Rheum Dis $\underline{75}$, 696-701

Hermann A, Donato R, Weiger TM, Chazin WJ (2012): S100 Calcium Binding Proteins and Ion Channels. Front Pharmacol $\underline{3}, 67$

Heydtmann M, Lalor PF, Eksteen JA, Hübscher SG, Briskin M, Adams DH (2005): CXC Chemikone Ligand 16 promotes integrin-mediated adhesion of liver-infiltrating lymphocytes to cholangiocytes and hepatocytes within the inflamed human liver. J Immunol $\underline{174}, 1055-1062$

Hilbe W, Dirnhofer S, Oberwasserlechner F, Schmid T, Gunsilius E, Hilbe G, Wöll E (2004): CD133 positive endothelial progenitor cells contribute to tumor vasculature in nonsmall cell lung cancer. J Clin Pathol 푸, 965-969

Hill CL, Zhang Y, Sigurgeirsson B, Pukkala E, Mellemkjaer L, Airio A, Evans SR, Felson DT (2001): Frequency of specific cancer types in dermatomyositis and polymyositis: a population-based study. Lancet $\underline{357}$, 96-100

Hoeben A, Landuyt B, Highley MS, Wildiers H, Van Oosterom AT, De Bruijn EA (2004): Vascular endothelial growth factor and angiogenesis. Pharmacol Rev $\underline{56}, 549-580$

Hofmann E: Medizinische Biochemie systematisch. UNI-MED, Bremen 2006

Hollemann D, Budka H, Löscher WN, Yanagida G, Fischer MB, Wanschitz JV (2008): Endothelial and Myogenic Differentiation of Hematopoietic Progenitor Cells in Inflammatory Myopathies. J Neuropathol Exp Neurol $\underline{67}$, 711-719

Hoogendijk JE, Amato AA, Lecky BR, Choy EH, Lundberg IE, Rose MR, Vencovsky J, de Visser M, Hughes RA (2004): 119th ENMC international workshop: Trial design in adult idiopathic inflammatory myopathies, with the exception of inclusion body myositis, 10-12 October 2003, Naarden, The Netherlands. Neuromuscul Disord 14, 337-345

Hristov M, Erl W, Weber PC (2003): Brief Review Endothelial Progenitor Cells Mobilization, Differentiation and Homing. Arterioscler Thromb Vasc Biol 23, 1185-1189 
Hunting CB, Noort WA, Zwaginga JJ (2005): Circulating endothelial (progenitor) cells reflect the state of the endothelium: vascular injury, repair and neovascularization. Vox Sang $\underline{88}, 1-9$

Hur J, Yoon C-H, Kim H-S, Choi J-H, Kang H-J, Hwang K-K, Oh B-H, Lee M-M, Park Y-B (2004): Characterization of Two Types of Endothelial Progenitor Cells and Their Different Contributions to Neovasculogenesis. Arterioscler Thromb Vasc Biol 24, 288-293

Ioannou Y, Sultan S, Isenberg DA (1999): Myositis overlap syndromes. Curr Opin Rheumatol 11, 468-474

Isozaki T, Arbab AS, Haas CS, Amin MA, Arendt MD, Koch AE, Ruth JH (2013): Evidence for CXCL16 as a potent angiogenic mediator and endothelial progenitor cell chemotactic factor. Arthritis Rheum $\underline{65}$, 1736-1746

Iuchi T, Akaike M, Mitsui T, Ohshima Y, Shintani Y, Azuma H, Matsumoto T (2003): Glucocorticoid Excess Induces Superoxide Production in Vascular Endothelial Cells and Elicits Vascular Endothelial Dysfunction. Circ Res 22, 81-87

Jaffe EA, Nachman RL, Becker CG, Minick CR (1973): Culture of Human Endothelial Cells Derived from Umbilical Veins. IDENTIFICATION BY MORPHOLOGIC AND

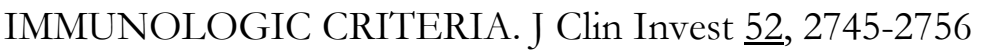

Janda V: Muscle Function Testing. Butterworths, London 1983

Jimenez SA (2013): Role of Endothelial to Mesenchymal Transition in the Pathogenesis of the Vascular Alterations in Systemic Sclerosis. ISRN Rheumatol 2013, 835948

Jovanovic I, Zivkovic M, Djuric T, Popovic M, Alavantic D, Stankovic A (2015): CXCL16 in vascular pathology research: from macro effects to microRNAs. J Atheroscler Thromb $\underline{22}, 1012-1024$

Kadoya M, Hida A, Hashimoto Maeda M, Taira K, Ikenaga C, Uchio N, Kubota A, Kaida K, Miwa Y, Kurasawa K (2016): Cancer association as a risk factor for anti-HMGCR antibody-positive myopathy. Neurol Neuroimmunol Neuroinflamm $\underline{3}$, e290

Kahlenberg JM, Kaplan MJ (2014): The inflammasome and lupus: another innate immune mechanism contributing to disease pathogenesis? Curr Opin Rheumatol 26, 475-481

Kassardjian CD, Lennon VA, Alfugham NB, Mahler M, Milone M (2015): Clinical features and treatment outcomes of necrotizing autoimmune myopathy. JAMA Neurol $\underline{72}$, 9961003 
Kim MH, Cho HJ, Kim SW, Liu B, Choi YJ, Lee JY, Sohn YD, Lee MY, Houge MA, Yoon Y (2010): CD31(+) cells represent highly angiogenic and vasculogenic cells in bone marrow: novel role of non-endothelial $\mathrm{CD} 31(+)$ cells in neovascularization and their therapeutic effects on ischemic vascular disease. Circ Res 107, 602-614

Kim MH, Guo L, Kim H-S-, Kim S-W (2014): Characteristics of circulating CD31+ cells from patients with coronary artery disease. J Cell Mol Med 18, 2321-2330

Klein-Weigel PF, Sunderkotter C, Sander O (2016): Nailfold capillaroscopy microscopy an interdisciplinary appraisal. Vasa $\underline{45}, 353-364$

Krupkova OJ, Loja T, Zambo I, Veselska R (2010): Nestin expression in human tumors and tumor cell lines. Neoplasma $\underline{57}, 291-298$

Latta M, Mohan K, Issekutz TB (2007): CXCR6 is expressed on T cells in both T helper type 1 (Th1) inflammation and allergen-induced Th2 lung inflammation but is only a weak mediator of chemotaxis. Immunology $\underline{121}, 555-564$

Le Bleu VS, Taduri G, O'Connell J, Teng Y, Cooke VG, Woda C, Sugimoto H, Kalluri R (2013): Origin and function of myofibroblasts in kidney fibrosis. Nat Med $\underline{19}, 1047-1053$

Lennartsson J, Ronnstrand L (2012): Stem cell factor receptor/c-Kit: from basic science to clinical implications. Physiol Rev 22, 1619-1649

Liang C, Needham M (2011): Necrotizing autoimmune myopathy. Curr Opin Rheumatol $\underline{23}, 612-619$

Lin G, Finger E, Gutierrez-Ramos JC (1995): Expression of CD34 in endothelial cells, hematopoietic progenitors and nervous cells in fetal and adult mouse tissues. Eur J Immunol 25, 1508-1516

Lin Y, Weisdorf DJ, Solovey A, Hebbel RP (2000): Origins of circulating endothelial cells and endothelial outgrowth from blood. J Clin Invest 105, 71-77

Liu L, Shi G-P (2012): CD31: beyond a marker for endothelial cells. Cardiovasc Res $\underline{94}$, 3-5

Liu Z, Sun B, Qi L, Li H, Gao J, Leng X (2012): Zinc finger E-box binding homeobox 1 promotes vasculogenic mimicry in colorectal cancer through induction of epithelial-tomesenchymal transition. Cancer Sci 103, 813-820 
Lu X, Dunn J, Dickinson AM, Gillespie JI, Baudouin SV (2004): Smooth muscle alphaactin expression in endothelial cells derived from CD34+ human cord blood cells. Stem Cells Dev 13, 521-527

Lundberg IE, Forbess CJ (2008): Mortality in idiopathic inflammatory myopathies. Clin Exp Rheumatol 26, 109-114

Luo YB, Mastaglia FL (2015): Dermatomyositis, polymyositis and immune-mediated necrotising myopathies. Biochim Biophys Acta 1852, 622-632

Magro CM, Dyrsen M, Kerns MJ (2008): Cutaneous lesions of dermatomyositis with supervening fibrosis. J Cutan Pathol 35, 31-39

Malik A, Hayat G, Kalia JS, Guzman MA (2016): Idiopathic Inflammatory Myopathies: Clinical Approach and Management. Front Neurol 7, 64

Mammen AL (2014): Necrotizing myopathies: beyond statins. Curr Opin Rheumatol 26, 679-683

Manfredi A, Sebastiani M, Cassone G, Pipitone N, Guggioli D, Colaci M, Salvarani C, Ferri C (2015): Nailfold capillaroscopic changes in dermatomyositis and polymyositis. Clin Rheumatol $\underline{34}, 279-284$

Marenholz I, Heizmann CW, Fritz G (2004): S100 proteins in mouse and man: from evolution to function and pathology (including an update of the nomenclature). Biochem Biophys Res Commun $\underline{322}$, 1111-1122

Marie I, Josse S, Decaux O, Dominique S, Diot E, Landron C, Roblot P, Jouneau S, Hatron PY, Tiev KP (2012): Comparison of long-term outcome between anti-Jo1- and anti-PL7/PL12 positive patients with antisynthetase syndrome. Autoimmun Rev 11, 739745

Meisel C, González J-B (2015): Inflammatorische Myopathien Neue Autoantikörper in der Myositis Diagnostik. Labor Berlin Diagnostik Bulletin (Charité Vivantes $\mathrm{GmbH}$ ) http://www.laborberlin.com/fileadmin/user upload/aktuelles/diagnostik bulletins/15 0 $7 \quad 17$ DB final.pdf, Zugriff am 22.11.2016] 17, 2

Mercer LK, Moore TL, Chinoy L, Murray AK, Vail A, Cooper RG, Herrick AL (2010): Quantitative nailfold video capillaroscopy in patients with idiopathic inflammatory myopathy. Rheumatology (Oxford) $\underline{49}$, 1699-1705

Michalczyk K, Ziman M (2005): Nestin structure and predicted function in cellular cytoskeletal organisation. Histol Histopathol 20, 665-671 
Miettinen M, Rikala MS, Rysz J, Lasota J, Wang ZF (2012): Vascular Endothelial Growth Factor Receptor 2 (VEGFR2) as a Marker For Malignant Vascular Tumors and Mesothelioma - Immunhistochemical Study of 262 Vascular Endothelial and 1640 Nonvascular Tumors. Am J Surg Pathol $\underline{36}$, 629-639

Mohassel P, Mammen AL (2013): Statin-associated autoimmune myopathy and antiHMGCR autoantibodies. Muscle Nerve $\underline{48}, 477-483$

Mokrý J, Cizková D, Filip S, Ehrmann J, Osterreicher J, Kolár Z, English D (2004): Nestin Expression by Newly Formed Human Blood Vessels. Stem Cells Dev 13, 658-664

Moldovan NI, Goldschmidt-Clermont PJ, Parker-Thornburg J, Shapiro SD, Kolattukudy PE (2000): Contribution of monocytes/macrophages to compensatory neovascularization: the drilling of metalloelastase-positive tunnels in ischemic myocardium. Circ Res $\underline{87}, 378$ 384

Moore MAS, Hattori K, Heissig B, Shieh JH, Dias S, Crystal RG, Rafii S (2001): Mobilization of Endothelial and Hematopoietic Stem and Progenitor Cells by Adenovector-Mediated Elevation of Serum Levels of SDF-1, VEGF, and Angiopoietin-1. Ann N Y Acad Sci 938, 36-47

Mukai N, Akahori T, Komaki M, Li Q, Kanayasu-Toyoda T, Ishii-Watabe A, Kobayashi A, Yamaguchi T, Abe M, Amagasa T (2008): A comparison of the tube forming potentials of early and late endothelial progenitor cells. Exp Cell Res $\underline{314}$, 430-440

Needham M, Fabian V, Knezevic W, Panegyres P, Zilko P, Mastaglia FL (2007): Progressive myopathy with up-regulation of MHC-I associated with statin therapy. Neuromuscul Disord 17, 194-200

Oikawa H, Hayashi K, Maesawa C, Masuda T, Sobue K (2010): Expression profiles of nestin in vascular smooth muscle cells in vivo and in vitro. Exp Cell Res $\underline{316}$, 940-950

Osterreicher CH, Penz-Osterreicher M, Grivennikov SI, Guma M, Koltsova EK, Datz C, Sasik R, Hardiman G, Karin M, Brenner DA (2011): Fibroblast-specific protein 1 identifies an inflammatory subpopulation of macrophages in the liver. Proc Natl Acad Sci U S A $\underline{108}$, 308-313

Papadakis MA, McPhee SJ, Rabow MW: Current Medical Diagnosis \& Treatment 2014. Lange, New York 2014

Pappu R, Seetharaman M, Diamond HS (2015): Polymyositis. Medscape [http://emedicine.medscape.com/article/335925-overview\#a6, Zugriff am 19.11.2016] 
Patenaude A, Parker J, Karsan A (2010): Involvement of endothelial progenitor cells in tumor vascularization. Microvasc Res $\underline{79}$, 217-223

Patschan D, Krupincza K, Patschan S, Zhang Z, Hamby C, Goligorsky MS (2006): Dynamics of mobilization and homing of endothelial progenitor cells after acute renal ischemia: modulation by ischemic preconditioning. Am J Physiol Renal Physiol 291, F176F185

Patschan D, Kribben A, Müller GA (2016): Postischemic microvasculopathy and endothelial progenitor cell-based therapy in ischemic AKI: update and perspectives. Am J Physiol Renal Physiol 311, F382-394

Patschan S, Patschan D, Henze E, Blaschke S, Wessels JT, Müller GA (2012): Impairment and differential expression of PR3 and MPO on peripheral myelomonocytic cells with endothelial properties in granulomatosis with polyangitis. Int J Nephrol 2012, 715049

Patschan S, Patschan D, Potulski M, Henze E, Scholze J, Muller GA (2013): Endothelial progenitor cells in systemic lupus erythematosus. J Nephrol 26, $1065-1072$

Patschan S, Tampe D, Müller C, Seitz C, Herink C, Müller GA, Zeisberg E, Zeisberg M, Henze E, Patschan D (2016): Early Endothelial Progenitor Cells (eEPCs) in systemic sclerosis (SSc) - dynamics of cellular regeneration and mesenchymal transdifferentiation. BMC Musculoskelet Disord 17, 339

Prabowo AS, Iyer AM, Anink JJ, Sliet WG, Rijen PC, Aronica E (2013): Differential expression of major histocompatibility complex class I in developmental glioneuronal lesions. J Neuroinflammation $\underline{10}, 12$

Rahimi N (2006): VEGFR-1 and VEGFR-2: two non-identical twins with a unique physiognomy. Front Biosci 11, 818-829

Richardson MR, Yoder MC (2011): Endothelial progenitor cells: quo vadis? J Mol Cell Cardiol 50, 266-272

Rider LG, Miller FW (2011): Deciphering the clinical presentations, pathogenesis, and treatment of the idiopathic inflammatory myopathies. JAMA $\underline{305}, 183-190$

Rojana-Udomsart A, Mitrpant C, Bundell C, Price L, Luo Y-B, Fabian V, Wilton SD, Hollingsworth P, Mastaglia FL (2013): Complement-mediated muscle cell lysis: A possible mechanism of myonecrosis in anti-SRP associated necrotizing myopathy (ASANM). J Neuroimmunol 264, 65-70 
Rosler KM, Scheidegger O (2015): [Myositides: What is the current situation?]. Z Rheumatol 74, 496-506

Rusak M, Radzikowska U, Glowinska-Olszewska B, Dobrenko E, Piotrowska-Jastrzebska J, Dabrowska M, Bodzenta-Lukaszyk A, Bossowski A, Moniuszko M (2015): Endothelial progenitor cell levels in juvenile idiopathic arthritis patients: effects of anti-inflammatory therapies. Pediatr Rheumatol Online J $\underline{13}, 6$

Sallum AM, Kiss MH, Silva CA, Wakamatsu A, Sachetti S, Lotufo S, Matsumura N, Marie SK (2009): MHC class I and II expression in juvenile dermatomyositis skeletal muscle. Clin Exp Rheumatol 27, 519-526

Sander O, Sunderkötter C, Kötter I, Wagner I, Becker M, Herrgott I, Schwarting A, Ostendorf B, Ilking-Konert C, Genth E (2010): Kapillarmikroskopie - Durchführung und Nomenklatur. Z Rheumatol $\underline{69}, 253$

Scavelli C, Nico B, Cirulli T, Ria R, Di Pietro G, Mangieri D, Bacigalupo A, Mangialardi G, Coluccia AML, Caravita T (2007): Vasculogenic mimicry by bone marrow macrophages in patients with multiple myeloma. Oncogene 27, 663-674

Schmidt J, Vorgerd M (2011): Standard treatment for myositis and muscular dystrophies. Nervenarzt $\underline{82}, 723-732$

Schoser B (2009): Inflammatorische Myopathien. Z Rheumatol 68, 665-677

Schroder NW, Goebel HH, Brandis A, Ladhoff AM, Heppner FL, Stenzel W (2013): Pipestem capillaries in necrotizing myopathy revisited. Neuromuscul Disord $\underline{23}$, 66-74

Schuleri KH, Amado LC, Boyle AJ, Centola M, Saliaris AP, Gutman MR, Hatzistergos KE, Oskouei BN, Zimmet JM, Young RG (2008): Early improvement in cardiac tissue perfusion due to mesenchymal stem cells. Am J Physiol Heart Circ Physiol 294, H20022011

Sejersen T, Lendahl U (1993): Transient expression of the intermediate filament nestin during skeletal muscle development. J Cell Sci 106, 1291-1300

Shinjo SK, Sallum AME, Silva CA, Marie SKN (2012): Skeletal muscle major histocompatibility complex class I and II expression differences in adult and juvenile dermatomyositis. Clinics (Sao Paulo) $\underline{67}, 885-890$

Shintani S, Murohara T, Ikeda H, Ueno T, Honma T, Katoh A, Sasaki K-I, Shimada T, Oike Y, Imaizumi T (2001): Mobilization of Endothelial Progenitor Cells in Patients With Acute Myocardial Infarction. Circulation 103, 2776-2779 
Siemerink MJ, Klaassen I, Vogels IMC, Griffioen AW, Van Noorden CJF, Schlingemann RO (2012): CD34 marks angiogenic tip cells in human vascular endothelial cell cultures. Angiogenesis 15, 151-163

Sieveking DP, Buckle A, Celermajer DS, Ng MKC (2008): Strikingly Different Angiogenic Properties of Endothelial Progenitor Cell Subpopulations: Insights From a Novel Human Angiogenesis Assay. J Am Coll Cardiol 1ㅜ, 660-668

Singh R, Kapur N, Mir H, Singh N, Lillard JW, Jr., Singh S (2016): CXCR6-CXCL16 axis promotes prostate cancer by mediating cytoskeleton rearrangement via Ezrin activation and alpha $_{\mathrm{v}}$ beta $_{3}$ integrin clustering. Oncotarget $\underline{7}, 7343-7353$

Small GR, Hadoke PW, Sharif I, Dover AR, Armour D, Kenyon CJ, Gray GA, Walker BR (2005): Preventing local regeneration of glucocorticoids by 11 beta-hydroxysteroid dehydrogenase type 1 enhances angiogenesis. Proc Natl Acad Sci U S A $\underline{102}$, 12165-12170

Souza EJR, Kayser C (2015): Nailfold capillaroscopy: relevance to the practice of rheumatology. Rev Bras Rheumatol 55, 264-271

Stenzel W, Goebel HH, Aronica E (2012): Review: Immune-mediated necrotizing myopathies - a heterogeneous group of diseases with specific myopathological features. Neuropathol Appl Neurobiol $\underline{38}$, 632-646

Surette AP, Madureira PA, Phipps KD, Miller VA, Svenningsson P, Waisman DM (2011): Regulation of fibrinolysis by S100A10 in vivo. Blood $118,3172-3181$

Suzuki S, Namiki J, Shibata S, Mastuzaki Y, Okano H (2010): The neural stem/progenitor cell marker nestin is expressed in proliferative endothelial cells, but not in mature vasculature. J Histochem Cytochem $\underline{58}, 721-730$

Szmitko PE, Wang C-H, Weisel RD, de Almeida JR, Anderson TJ, Verma S (2003): New Markers of Inflammation and Endothelial Cell Activation: Part I. Circulation 108, 19171923

Tanimoto K, Nakano K, Kano S, Mori S, Ueki H, Nishitani H, Sato T, Kiuchi T, Ohashi Y (1995): Classification criteria for polymyositis and dermatomyositis. J Rheumatol 22, 668674

Tansley S, Gunawardena H (2014): The Evolving Spectrum of Polymyositis and Dermatomyositis-Moving Towards Clinicoserological Syndromes: A Critical Review. Clin Rev Allergy Immunol 47, 264-273 
Tiwari A, Bansal V, Chugh A, Mookhtiar K (2006): Statins and myotoxicity: a therapeutic limitation. Expert Opin Drug Saf $\underline{5}, 651-666$

Toshner M, Morrell NW (2010): Endothelial progenitor cells in pulmonary hypertension dawn of cell-based therapy? Int J Clin Pract Suppl 64, 7-12

Urbich C, Dimmeler S (2004): Endothelial progenitor cells: characterization and role in vascular biology. Circ Res $\underline{95}$, 343-353

Vaittinen S, Lukka R, Sahlgren C, Hurme T, Rantanen J, Lendahl U, Eriksson JE, Kalimo $\mathrm{H}$ (2001): The expression of intermediate filament protein nestin as related to vimentin and desmin in regenerating skeletal muscle. J Neuropathol Exp Neurol $\underline{60}$, 588-597

van der Meulen MF, Bronner IM, Hoogendijk JE, Burger H, van Venrooij WJ, Voskuyl AE, Dinant HJ, Linssen WH, Wokke JH, de Visser M (2003): Polymyositis: an overdiagnosed entity. Neurology 61, 316-321

Vasa M, Fichtlscherer S, Adler K, Aicher A, Martin H, Zeiher AM, Dimmeler S (2001): Increase in Circulating Endothelial Progenitor Cells by Statin Therapy in Patients With Stable Coronary Artery Disease. Circulation 103, 2885-2890

Verma S, Wang CH, Li SH, Dumont AS, Fedak PW, Badiwala MV, Dhillon B, Weisel RD, Li RK, Mickle DA (2002): A self-fulfilling prophecy: C-reactive protein attenuates nitric oxide production and inhibits angiogenesis. Circulation 106, 913-919

Webster JD, Yuzbasiyan-Gurkan V, Kaneene JB, Reasau JH, Kiupel M (2006): The Role of c-KIT in TUmorgenesis: Evaluation in Canine Cutaneous Mast Cell Tumors. Neoplasia $\underline{8}$, 104-111

Werner JL, Christopher-Stine L, Ghazarian SR, Pak KS, Kus JE, Daya NR, Lloyd TE, Mammen AL (2012): Antibody levels correlate with creatine kinase levels and strength in anti-3-hydroxy-3-methylglutaryl-coenzyme A reductase-associated autoimmune myopathy. Arthritis Rheum 64, 4087-4093

Wilbanks A, Zondlo SC, Murphy K, Mak S, Soler D, Langdon P, Andrew DP, Wu L, Briskin M (2001): Expression cloning of the STRL33/BONZO/TYMSTRligand reveals elements of CC, CXC, and CX3C chemokines. J Immunol 166, 5145-5154

Xiao L, Kim DJ, Davis CL, McCann JV, Dunleavey JM, Vanderlinden A, Xu N, Pattenden SG, Frye SV, Xu X (2015): Tumor endothelial cells with distinct patterns of TGF $\beta$-driven endothelial-to-mesenchymal transition. Cancer Res $\underline{75}$, 1244-1254 
Xie L, Zeng X, Hu J, Chen Q (2015): Characerization of Nestin, a selective marker for bone marrow derived mesenchymal stem cells. Stem Cells Int 2015, 762098

Xu JM, Weng MZ, Song FB, Chen JY, Zhang JY, Wu JY, Qin J, Jin T, Wang XL (2014): Blockade of the CXCR6 signaling inhibits growth and invasion of hepatocellular carcinoma cells through inhibition of the VEGF expression. Int J Immunopathol Pharmacol 27, 553561

Yoon C-H, Hur J, Park K-W, Kim J-H, Lee C-S, Oh I-Y, Kim T-Y, Cho H-J, Kang H-J, Chae I-H (2005): Synergistic Neovascularization by Mixed Transplantation of Early Endothelial Progenitor Cells and Late Outgrowth Endothelial Cells: The Role of Angiogenic Cytokines and Matrix Metalloproteinases. Circulation 112, 1618-1627

Yuan SM (2015): alpha-Smooth Muscle Actin and ACTA2 Gene Expressions in Vasculopathies. Braz J Cardiovasc Surg 30, 644-649

Zeisberg EM, Potenta S, Xie L, Zeisberg M, Kalluri R (2007a): Discovery of endothelial to mesenchymal transition as a source for carcinoma-associated fibroblasts. Cancer Res $\underline{67}$, 10123-10128

Zeisberg EM, Tarnavski O, Zeisberg M, Dorfman AL, McMullen JR, Gustafsson E, Chandraker A, Yuan X, Pu WT, Roberts AB (2007b): Endothelial-to-mesenchymal transition contributes to cardiac fibrosis. Nat Med $\underline{13}$, 952-961

Zierz S, Deschauer M, Eger K, Jordan B, Kornhuber M, Kraya T, Müller TJ: Muskelerkrankungen. Thieme, Stuttgart 2014 